Silvia Mazzali-Verst

\title{
Monitoração neurofisiológica intraoperatória em tumores de ângulo pontocerebelar: papel de parâmetros distintos na predição do resultado funcional do nervo facial
}

Tese apresentada à Faculdade de Medicina da Universidade de São Paulo para obtenção do título de doutor em Ciências

Programa de Neurologia

Orientador: Prof. Dr. Paulo Henrique Pires de Aguiar

São Paulo 
Dados Internacionais de Catalogação na Publicação (CIP)

Preparada pela Biblioteca da

Faculdade de Medicina da Universidade de São Paulo

\section{Creprodução autorizada pelo autor}

Verst, Silvia Mazzali

Monitoração neurofisiológica intraoperatória em tumores de ângulo pontocerebelar : papel de parâmetros distintos na predição do resultado funcional do nervo facial / Silvia Mazzali Verst. -- São Paulo, 2011.

Tese(doutorado)--Faculdade de Medicina da Universidade de São Paulo.

Programa de Neurologia.

Orientador: Paulo Henrique Pires de Aguiar.

Descritores: 1.Potencial evocado motor 2.Neoplasias infratentoriais 3.Neuroma acústico 4.Monitoração neurofisiológica intraoperatória 5.Nervo facial

USP/FM/DBD-136/11 
Dedico este trabaJho a meu pai, que pauta sua vida pelo respeito à ética e apreço ao confiecimento, e a meu marido e fifhos, que tornaram possivel a dedicação do meu tempo a este doutorado क्षेंminta mãe in memoriam 
Especial agradecimento ao Prof. Dr. Telson Mizumoto, pela amizade, tempo o orientação nos úftimos seís anos 
Esta tese está de acordo com as seguintes normas, em vigor no

momento desta publicação:

Referências: adaptado de International Committee of Medical Journals Editors

(Vancouver)

Universidade de São Paulo. Faculdade de Medicina. Serviço de Biblioteca e Documentação. Guia de apresentação de dissertações, teses e monografias.

Elaborado por Anneliese Carneiro da Cunha, Maria Julia de A. L. Freddi, Maria F. Crestana, Marinalva de Souza Aragão, Suely Campos Cardoso, Valéria Vilhena. 2a ed.

São Paulo: Serviço de Biblioteca e Documentação; 2005. Abreviaturas dos títulos dos periódicos de acordo com List of Journals Indexed in Index Medicus. 


\section{Sumário:}

Lista de Abreviaturas e Siglas

Lista de Tabelas

Lista de Gráficos

Lista de Figuras

Resumo

Summary

1. INTRODUÇÃO

1.1. OS MENINGIOMAS E NEURINOMAS E O ÂNGULO PONTOCEREBELAR

1.2. MONITORAÇÃO NEUROFISIOLÓGICA INTRAOPERATÓRIA

3. MÉTODOS 22

4. RESULTADOS 26

5. DISCUSSÃO 39

6. CONSIDERAÇÕES FINAIS 53

7. CONCLUSÃO 54

8. ANEXOS 55

8.1. FIGURAS

8.2. GRÁFICOS 63

8.3. APRESENTAÇÃO DE CASOS ILUSTRATIVOS 64

8.4. TABELAS 68

9. REFERÊNCIA

10..Apêndice 


\section{Lista de Abreviaturas e Siglas:}

Al: $\quad$ atividade irritativa ou neurotônica do tipo $A$

AMPL: $\quad$ Amplitude

APC: $\quad$ ângulo pontocerebelar

BERA: potencial evocado auditivo

Conjunto sequência de potenciais trifásicos originados

de pulsos: espontaneamente do tecido nervoso ou sequência de pulsos elétricos com duração e intervalo entre eles estabelecidos pelo estimulador elétrico transcraniano. Do termo americano "train"

EEG: eletroencefalograma

EETc: estimulação elétrica transcraniana

EETcCN: potencial motor captado em músculos inervados pelos nervos cranianos após estimulação elétrica transcraniana

EETcMM: potencial motor captado em músculos das extremidades superior e inferior após estimulação elétrica transcraniana

EMG: eletromiografia

HB: $\quad$ índice de House-Brackmann

$\mathrm{Hz}: \quad$ Hertz

INTENS: intensidade

$\mathrm{mA}: \quad$ miliampere

MAI: $\quad$ meato acústico interno

MNIO: $\quad$ monitoração neurofisiológica intraoperatória

ms: milissegundo

$\mathrm{mV}: \quad$ Milivolt

$\mu \mathrm{V}: \quad$ Microvolt

PAC: $\quad$ Paciente

PMM: $\quad$ potencial evocado motor muscular obtido com a estimulação elétrica transcraniana

PESS: $\quad$ potencial evocado somatossensitivo 
PMAC: $\quad$ potencial muscular de ação composta

p.o.: $\quad$ pós-operatório

TcoE: $\quad$ tracto corticoespinhal

TcoB: $\quad$ tracto corticobulbar 


\section{Lista de Tabelas:}

Tabela 1: Índice de House-Brackmann de gradação funcional do nervo facial

Tabela 2: agulhamento muscular para estudo via EETc 68

Tabela 3: Dados clínicos, informações sobre o tumor e resultado funcional

Tabela 4: Integra dos dados neurofisiológicos relativos à EETcCN

Tabela 5: Relação da variação da amplitude final do MEP do $7^{\circ}$ nervo com o índice de HB no p.o. imediato e no último acompanhamento

Tabela 6: Variação na intensidade da EETc necessária para obtenção do PMM do $7^{\circ}$ nervo e correlação com o índice de $\mathrm{HB}$

Tabela 7: Número de repetições e duração dos episódios da atividade irritativa e o índice de HB no p.o. imediato e no último acompanhamento

Tabela 8: Classificação dos pacientes de acordo com a 74 apresentação neurofisiológica do $7^{0}$ nervo

Tabela 9: Apresentação neurofisiológica por paciente e 75 correlação com o índice de HB

Tabela 10: Análise estatística do grupo I

Tabela 11: Análise estatística do grupo lla 34

Tabela 12: Análise estatística do grupo llb 35

Tabela 13: Análise estatística do grupo Illa 35

Tabela 14: Análise Estatística do grupo Illbb 36

Tabela 15: Análise Estatística do grupo IV 36

Tabela 16: Revisão da literatura em relação à montagem da EETc 76 e sua eficácia e apresentação dos resultados de sensibilidade e especificidade para diferentes critérios de avaliação do PMM 


\section{Lista de Gráficos:}

Gráfico 1: Registro do PMM 7ำ nervo após EETc 27

Gráfico 2: Evolução clínica imediata dos grupos estudados 31

Gráfico 3: Variação do índice de HB em relação à queda de 32 amplitude $\mathrm{PMM} 7^{\circ}$ nervo nos pacientes com queda Maior ou igual a $50 \%$ da amplitude inicial

Gráfico 4: Duração ininterrupta do episódio mais longo de Al por paciente

Gráfico 5: Apresentação dos resultados de sensibilidade, especificidade, prevalência, valores preditivos positivo e negativo entre os grupos estatisticamente significativos

Gráfico 6: Comparação do resultado estatístico entre Prell et al. e este estudo 


\section{Lista de Figuras:}

Figura 1: Anatomia de APC normal e modificada pelo tumor 55

Figura 2: Sistema 10-20 de EEG simplificado 56

Figura 3: Sistema Internacional de EEG 10-10 57

Figura 4: Pontos motores clássicos para EETc: geração de estímulo 58 único e em trem e suas respectivas respostas

Figura 5: Representação da via de estimulação motora descendente 59 do TCoE com a EETc

Figura 6: Intensidade do estímulo da EETc e via motora ativada 60

Figura 7: Indicação dos pontos utilizados para EETcCN sobre o 61 homúnculo de Penfield

Figura 8: Latência do PMM do 7ํㅡㄴ nervo 62 


\section{Lista de Apresentação de Casos:}

Caso 1: Al e queda de amplitude PMM do $7^{\circ}$ nervo 64

Caso 2: Posicionamento de eletrodos da paciente 15

Caso 3: Colocação de eletrodos- nervos cranianos III-VI 66

Caso 4: Al e queda da amplitude PMM do $7^{\circ}$ nervo 67 
Verst SM. Monitoração neurofisiológica intraoperatória em tumores de ângulo pontocerebelar: papel de parâmetros distintos na predição do resultado funcional do nervo facial [ tese ]. São Paulo: Faculdade de Medicina, Universidade de São Paulo; 2011.

\section{Resumo:}

Nas cirurgias de ressecção de tumores do ângulo pontocerebelar, a preservação do nervo facial está entre os seus principais objetivos. Diversas técnicas neurofisiológicas vêm sendo empregadas com o objetivo de predizer déficit imediato do nervo facial no pós-operatório, como a eletromiografia contínua para registro de atividade neurotônica tipo $A$, a estimulação direta do nervo facial no sítio tumoral e a estimulação elétrica transcraniana com captação em músculos de face. Analisamos 23 pacientes de forma prospectiva, submetidos à cranectomia retrossigmoide para ressecção de tumores em fossa posterior no período de janeiro de 2008 a março de 2010. Os pacientes foram avaliados clinicamente de acordo com a gradação de House-Brackmann para a função do nervo facial. Foram observadas a ocorrência de atividade neurotônica do tipo $A$, também chamada de atividade irritativa, a queda da amplitude do potencial motor do nervo facial obtido com a estimulação elétrica transcraniana e o aumento na intensidade do estímulo elétrico da estimulação elétrica transcraniana para a obtenção desse potencial. Esses dados foram relacionados à condição clínica do nervo facial no pós-operatório imediato e na última data de acompanhamento. Observamos que a queda da amplitude do nervo facial acima de $60 \%$ do seu valor inicial basal foi a variável mais sensível (89\%) e com maior valor preditivo positivo (92\%) para a piora clínica do nervo facial. A ocorrência de atividade irritativa isolada foi a variável menos sensível (7\%) e com valor preditivo positivo de apenas $25 \%$. O aumento na intensidade da estimulação elétrica transcraniana não mostrou significância estatística ( $p=$ $0,287)$. Concluímos que das variáveis estudadas, a queda na amplitude do potencial evocado motor do $7^{\circ}$ nervo craniano acima de $60 \%$ foi a melhor na predição de piora clínica imediata do nervo facial. 
Descritores: potencial evocado motor, neoplasias infratentoriais, neuroma acústico, monitoração neurofisiológica intraoperatória, nervo facial 
Verst, S.M., Intraoperative neurophysiology monitoring for cerebellopontine angle tumors: role of distinctive parameters in predicting the facial nerve functional outcome [ thesis ]. Faculty of Medicine, University of Sao Paulo, SP (Brazil); 2011.

\section{Summary:}

The preservation of facial nerve function is one of the most important goals of the cerebellopontine angle tumor resection surgeries. Valuable neurophysiologic techniques have been used to predict the facial nerve outcome, such as continuous electromyography to identify neurotonic activity type $A$, direct facial nerve stimulation in the vicinity of the tumor and transcranial motor evoked potential recording in face muscles. We analyzed 23 patients undergoing retrossigmoidectomy approaches for posterior fossa tumor resection between January 2008 and March 2010. Their facial nerve function was evaluated using the House-Brackmann score. We correlated the occurrence of type A neurotonic activity, facial nerve motor evoked potential amplitude obtained with transcranial electrical stimulation and increase in the electric stimulus threshold to the immediate and last follow-up facial nerve outcome. In this series, the increase in electric stimulus threshold showed no statistical significance $(p=0,287)$. The drop of the facial nerve motor evoked potential amplitude equal or above $60 \%$ was the most sensitive (89\%) and with the highest positive predictive value (92\%) in identifying poor facial nerve outcome. The occurrence of neurotonic activity type A showed to be the least sensitive $(7 \%)$ and with the poorest positive predictive value $(25 \%)$ of them. We conclude that among the used parameters, the drop of the final $7^{\circ}$ nerve motor evoked potential amplitude equal or above $60 \%$ of basal recording was the best one in predicting poor facial nerve outcome.

Descriptors: motor evoked potentials, infratentorial neoplasms, accoustic neuroma,, intraoperative neurophysiology monitoring, facial nerve 


\section{INTRODUÇÃO}

\subsubsection{S MENINGIOMAS E NEURINOMAS E $O$ ÂNGULO PONTOCEREBELAR}

Tumores de APC correspondem a $8 \%$ a $10 \%$ de todos os tumores intracranianos ${ }^{1}$ e, destes, $80 \%$ a $90 \%$ são neurinomas do acústico ${ }^{1}$ e 14 a $16,6 \%{ }^{2}$ correspondem a meningiomas. Os neurinomas acometem igualmente homens e mulheres por volta dos 50 anos $^{3}$, e os meningiomas acometem, na maioria dos casos, mulheres $(2,4: 1)^{4}$ na faixa dos $45-60$ anos $^{2}$, podendo ocorrer durante a gestação.

Os neurinomas do acústico originam-se, comumente, da bainha de Schwann dos nervos sensitivos, principalmente no ramo vestibular do $7^{\circ}$. nervo, dentro do meato acústico interno (MAl), e crescem na direção do tronco cerebral. Seu crescimento lento leva à compressão, deformação e até separação fascicular do nervo facial nesse trajeto. Apesar do neurinoma se originar fora da aracnoide e estar envolvido por ela, o que o mantém separado de estruturas neurovasculares, em raras ocasiões ele pode invadir os nervos adjacentes ${ }^{5}$.

A ressecção tumoral total de um neurinoma do acústico de grande volume é talvez uma das neurocirurgias mais difíceis ${ }^{6}$. A craniectomia na posição semissentada é um dos acessos possíveis, embora seja muito delicado do ponto de vista anestésico. O paciente é colocado numa posição semissentada com a cabeça fletida e rotacionada $30^{\circ}$ na direção do tumor. 
Após a craniectomia subocciptal e abertura da dura-máter, é realizada a drenagem da cisterna magna e a retração leve do cerebelo. Desta forma, após o esvaziamento tumoral parcial, obtém-se uma visão desde o MAI até o tronco cerebral. Após a remoção da dura-máter da porção posterior do MAl, é realizada a brocagem do canal auditivo para a visualização do tumor intrameatal, que é, então, ressecado. A porção extrameatal é novamente manipulada, com o objetivo de promover a separação segura entre o tumor e o nervo facial. Especial atenção deve ser dada à homeostasia final, para que o uso excessivo do coagulador bipolar não promova vasoespasmo da vasa nervorum do nervo facial. A interface mais estreita entre o tumor e o nervo facial e sua vascularização é encontrada próxima à sua entrada no MAl e deve ser cuidadosamente manipulada para evitar uma distensão excessiva do nervo ${ }^{7}$.

Os meningiomas têm origem na aracnoide e localizam-se quase sempre na região supratentorial (90\% dos casos). Apenas em $3,6 \%^{2}$ dos casos situamse na fossa posterior, onde em $50 \%$ dos casos ocupam o ângulo pontocerebelar (APC). São os tumores mais comuns da região petroclival, onde podem infiltrar as estruturas ósseas da base do crânio, vasos e nervos cranianos $^{8}$. Devido ao seu crescimento lento, os tumores são identificados usualmente apenas quando bastante volumosos e em consequência do comprometimento dos nervos cranianos. A ressecção radical é de alta morbidade e mortalidade ${ }^{8}$, e a preservação das estruturas vasculares e nervosas envolvidas constitui um grande desafio para o neurocirurgião. $O$ planejamento cirúrgico da ressecção dos meningiomas prevê a prévia 
identificação de seu ponto de aderência na aracnoide, ressecção da sua base de implantação após coagulação, esvaziamento da porção intracapsular, separação das estruturas adjacentes infiltradas pelo tumor, dissecção da sua cápsula superficial e brocagem da exostose óssea ${ }^{6}$.

$\mathrm{Na}$ cirurgia de tumores de fossa posterior, após colocação de drenagem lombar do líquido cefalorraquidiano, desde que não haja hidrocefalia obstrutiva, quando usa-se drenagem ventricular externa, e o paciente é colocado na posição supina, com o tórax elevado em 10-15\%. O ombro ipsilateral é elevado com uma almofada de gel-silicone, e a cabeça é rotacionada para o lado contralateral, de forma a deixar a sutura sagital paralela ao chão. Após craniectomia subtemporal padrão, o osso temporal é brocado até que haja exposição do assoalho da fossa média. A dura-máter temporal é elevada para expor o triângulo de Kawase, o que permite a localização e secção do grande nervo petroso superficial. Segue-se a brocagem do osso petroso, o que permitirá a exposição da dura-máter da fossa posterior. A cóclea é preservada para evitar surdez e vertigens. A abertura da dura-máter temporal e da fossa posterior e a elevação do lobo temporal permitem a visualização dos nervos cranianos IV, V, VI e VII. Após a remoção tumoral, podem ser identificados a artéria basilar e a cerebelar anteroinferior.

O APC é como um espaço triangular com a base voltada para cima e o ápice para baixo. É limitado superiormente pelo tentorium, inferiormente pelo espaço lateral da medula oblongata, forâmen jugular e nervos IX e X que aí penetram, medialmente pela ponte e lateralmente pela pirâmide petrosa. 
Dentro desse espaço transitam os nervos cranianos $\mathrm{V}, \mathrm{VI}, \mathrm{VII}$ e VIII, as artérias cerebelosa e cerebelar posteroinferior (responsáveis pela irrigação da porção lateral do bulbo), a cerebelosa anteroinferior (que vai originar a artéria auditiva interna) e a veia petrosa superior $^{6}$. Logo abaixo desse triângulo, visualizam-se os nervos bulbares, que não fazem parte desse triângulo, mas que podem estar deslocados e retorcidos nos tumores de grande volume (anexo, figura 1).

O nervo facial transita no sentido medial lateral dentro do espaço do APC, entre a zona de entrada no tronco cerebral (abaixo do plexo coroide próximo ao IX nervo) e o meato acústico interno. Transita juntamente com o nervo acústico, o vestibular e o intermédio.

Sintomas e sinais de tumores localizados no APC incluem perda auditiva, zumbido e vertigens (mais comuns nos neurinomas), cefaleia, paresia e disestesia facial em território de nervos $\mathrm{V}$ e VII, disfunção cerebelar, síndrome do neurônio motor superior - por envolvimento do tracto corticoespinhal (TcoE) descendente - e sinais de hidrocefalia. $O$ envolvimento de nervos cranianos mais baixos é mais comum no meningioma e depende do grande volume tumoral.

A diferenciação entre meningiomas e neurinomas antes da cirurgia é importante, para efeito de planejamento da cirurgia e avaliação prognóstica. Os neurinomas apresentam geralmente uma extensão para dentro do canal auditivo interno, enquanto os meningiomas apresentam uma cauda meníngea, vista por impregnação de gadolínio na ressonância magnética. 
Fatores que influenciam o resultado funcional da ressecção do tumor de fossa posterior são o tamanho do tumor ${ }^{9}$, sua consistência e sua aderência aos nervos cranianos ${ }^{10,11,12,13,14}$. A presença pré-operatória de déficit de nervo facial ${ }^{15}$ e ataxia são fatores predisponentes para a piora imediata do índice de House-Brackmann $(\mathrm{HB})^{16}$.

Nos últimos vinte anos, os avanços nas técnicas de microdissecção e no conhecimento de anatomia cirúrgica, o desenvolvimento de novas brocas diamantadas, microscópios mais potentes, exames de imagem com melhor resolução e novas drogas anestésicas tornaram possíveis procedimentos cirúrgicos na profundidade da cabeça, em espaços anatômicos complexos e diminutos, onde impera a presença de estruturas anatômicas importantes. Essas cirurgias de alta complexidade são comuns em grandes hospitais devido ao acúmulo de conhecimento dos cirurgiões seniores e aos programas de treinamento dos cirurgiões mais jovens. A apuração da técnica cirúrgica é inquestionável, e o objetivo atual a ser alcançado é a baixa morbidade e a preservação funcional motora dos pacientes.

Nas cirurgias de APC, o grau de preservação anatômica do nervo facial é de $73 \%$ a $96 \%$, embora isso não assegure que o nervo esteja funcionado adequadamente $^{17}$. Brackmann cita que numa série de 500 casos, o índice de preservação anatômica foi de $96,6 \%$, mas que, questionados, $10 \%$ dos pacientes com tumores de médio porte e $20 \%$ dos pacientes com tumores grandes relataram paralisia facial total no pós-operatório (p.o. $)^{17}$. De um total de 414 dos pacientes que responderam ao questionário, 14\% apresentavam déficit do nervo facial. Para os nervos bulbares $I X$ e $X$ o risco de déficit é 
ainda maior, sendo de $76 \%$ em grandes tumores da base do crânio e de $84,5 \%$ quando o acesso cirúrgico for lateral ${ }^{18}$.

A identificação intraoperatória da secção do nervo facial leva à sua imediata anastomose terminoterminal. No caso de haver preservação anatômica, mas o paciente evoluir com déficit funcional permanente, está indicada a anastomose hipoglossofacial.

A plegia de nervo facial tem efeito devastador na qualidade de vida do paciente, acarretando alterações funcionais como o não fechamento do olho, o escorrer de líquidos pelo canto da boca, a perda do sorriso simétrico e a atrofia da hemiface acometida, conferindo uma aparência grotesca ao rosto do paciente, que não pode ser disfarçada. Disto advêm as alterações psicológicas, como a perda de autoestima e a depressão e, por fim, a reclusão social. Por isso, nas cirurgias para ressecção de tumores de APC devem ser utilizadas todas as metodologias comprovadas para a preservação funcional do nervo facial. 


\subsection{MONITORAÇÃO NEUROFISIOLÓGICA INTRAOPERATÓRIA}

A monitoração neurofisiológica intraoperatória (MNIO) tem contribuído de forma importante nas cirurgias na base de crânio e nos neurinomas do acústico, levando a uma redução na incidência de paresia facial p.o. do nervo anatomicamente preservado ${ }^{10,13,14,19,20}$. Permite uma ressecção tumoral mais extensa e com menos sequelas, o que é determinante no tempo de progressão tumoral, na qualidade funcional e na sobrevida do paciente ${ }^{21,22,23,24}$. A MNIO não substitui conhecimentos avançados em neuroanatomia nem o julgamento clínico de situações complicadas durante a cirurgia, mas oferece dados funcionais que auxiliam a melhorar os resultados ${ }^{25}$.

O uso da MNIO tem se mostrado útil ao auxiliar nas cirurgias neurológicas e ortopédicas, que trazem risco ao tecido nervoso envolvido ou adjacente à patologia ${ }^{11,12,19,26}$, porque monitora a função, enquanto o microscópio e a neuronavegação auxiliam no aspecto anatômico. Propicia a correlação entre a manipulação cirúrgica e as alterações neurofisiológicas, identificando situações de risco iminente, permitindo ao cirurgião reprogramar a estratégia cirúrgica a tempo de evitar a instalação de um déficit motor duradouro.

O conhecimento das alterações dos padrões neurofisiológicos que se correlacionam com déficits imediatos no p.o. é essencial para conferir segurança e confiabilidade ao método. Para cirurgias de ressecção de tumores intramedulares ${ }^{25,26,27}$ e cirurgias supratentoriais ${ }^{28,29,30}$ esses parâmetros já foram extensamente documentados. A identificação dos 
mecanismos fisiopatológicos responsáveis por essas alterações permite sua prevenção segura e consciente.

Wilder Penfield ${ }^{1}$ (1937), citado por Deletis $^{12}$, foi pioneiro na estimulação elétrica intraoperatória do córtex motor, e seu sistemático trabalho de mapeamento da organização somatotópica criou os fundamentos do que viria a ser a monitoração intraoperatória.

Após 50 anos do trabalho de Penfield, nas décadas de 50 e 60, a neurofisiologia clínica se subdividiu em três campos: eletroencefalografia (EEG), eletromiografia (EMG) e potenciais evocados (PE). A partir daí, o desenvolvimento de cada área levaria ao acúmulo de conhecimento que viria a permitir o emprego dessas técnicas na sala operatória. Apesar da MNIO ser uma metodologia que agrega diferentes testes neurofisiológicos para uso simultâneo ou alternado num mesmo paciente durante o procedimento cirúrgico, o grande avanço e reconhecimento do método aconteceu na década de 90, quando foi capaz de responder de forma rápida, confiável e reprodutível ao grande questionamento do cirurgião e do paciente: Haverá paralisia motora pós-operatória?

A história da MNIO começa obrigatoriamente com a descrição dos testes que foram utilizados primeiramente.

Desde a década de 80 , nas cirurgias para ressecção de tumores de APC tem sido empregado o potencial evocado auditivo (BERA) $)^{32,33,34,35}$, a eletromiografia $(E M G)^{10,36}$ e a estimulação direta do nervo facial ${ }^{10,35,37}$.

${ }^{1}$ Penfield, W. and Boldrey, E. ${ }^{31}$ Somatic motor and sensory representation in the cerebral cortex of man as studied by electrical stimulation. Brain 60: 389-443 
O BERA é um teste pouco invasivo, que permite a obtenção de ondas que traduzem o trânsito do estímulo sonoro sobre a via auditiva aferente. No ambiente cirúrgico, a principal onda a ser identificada e evoluída é a onda $\mathrm{V}$, que se forma a nível do colículo inferior do tronco cerebral, com uma latência por volta de 6,0 ms. O retardo de $1 \mathrm{~ms}$ nesta latência ou a queda acima de $50 \%$ na amplitude desse potencial se correlaciona com perda auditiva no pós-operatório ${ }^{32,33,38}$. Em tumores de grande volume (maiores que $3 \mathrm{~cm}$ ), geralmente já há déficit auditivo pré-operatório importante e maior aderência entre lesão e nervo acústico ${ }^{33}$, tornando improvável a preservação da acuidade auditiva.

A EMG pode registrar atividade irritativa ou neurotônica do tipo $A(A l)$, que são potenciais de alta frequência e aparência homogênea, ocorrendo em forma sequencial, caracterizando um conjunto de pulsos com amplitude de 100 a $200 \mu \mathrm{V}$ (não mais do que $500 \mu \mathrm{V}$ ), durando de milissegundos a vários segundos ${ }^{10,36}$. Exemplos de Al podem ser vistos nos registros do caso 1. Gjuric et al. $(2008)^{16}$ relatam que com o uso da EMG contínua o índice de preservação do nervo facial é de $95 \%$ a $100 \%$ para tumores menores que 1 $\mathrm{cm}, 80 \%$ a $92 \%$ em tumores de 1 a $2 \mathrm{~cm}$ e $50 \%$ a $76 \%$ em tumores maiores que $2 \mathrm{~cm}$. Outros relatos correlacionam a ocorrência de Al com paresia p.o. imediata $^{14,20,36,39,40}$, mas não há consenso ${ }^{10}$.

A EMG realizada de forma contínua e com uso de alto-falantes permite ao cirurgião ouvir a ocorrência de Al, orientando-o sobre o risco de lesão de fibras do nervo facial. É um procedimento simples, relativamente barato, usado desde o início da cirurgia e durante toda a fase de ressecção tumoral, 
que dispensa a presença de um médico neurofisiologista para interpretar os sinais. O próprio cirurgião coloca os eletrodos nos músculos inervados pelos ramos do nervo facial e os conecta a aparelhos simples de dois canais. Pode haver uma tela que permita a visualização do traçado da Al.

A estimulação direta do nervo facial auxilia na sua identificação e de seus fascículos distorcidos e deslocados pelo tumor ${ }^{13}$, exceto nos casos de tumores de grande volume, em que até que haja ressecção de uma porção considerável do tumor, o nervo facial não será visto, pois se encontra deslocado anterior e medialmente à capsula tumoral ${ }^{13,41,42}$. A dissecção de seus fascículos pelo crescimento tumoral lento pode resultar numa banda nervosa transitando no bordo ventral do neurinoma do acústico e outra paralela ao tronco cerebral ${ }^{42}$. Em nível do meato acústico interno, o nervo facial pode estar distendido, distorcido, comprimido ou extremamente aderido ao tumor ${ }^{43}$.

A variação na intensidade da estimulação direta do nervo facial, próximo ao tronco cerebral antes e após a ressecção tumoral, e a razão da diferença nas amplitudes do potencial de nervo facial, ao ser estimulado proximal e distalmente ao tumor, são parâmetros relacionados com déficit p.o. imediato 10,37,44,45. Entretanto, esses testes não poderão ser realizados antes do início da ressecção dos tumores de grande volume, não havendo dados para serem comparados com os obtidos após a ressecção tumoral.

Em 1998, Cuevas ${ }^{46}$ desenvolveu um eletrodo que permite a captação de um potencial diretamente sobre o nervo acústico após a estimulação auditiva com "clicks", que ele chamou de potencial do nervo auditivo. A queda da 
amplitude desse potencial tem boa correlação com a perda auditiva no p.o. ${ }^{35,46}$. Esse eletrodo tem seu uso limitado nas cirurgias para tumores de grande volume, nas quais a identificação e o acesso imediato ao nervo acústico não são possíveis.

O potencial evocado somatossensitivo (PESS) corresponde ao estudo dos potenciais obtidos ao longo do nervo periférico, funículo posterior da medula espinhal, tálamo e córtex sensorial a partir da estimulação de um nervo sensorial periférico. Para sua obtenção é necessária que haja somação de dezenas ou centenas de respostas, com o objetivo de eliminar por filtragem analógica variações decorrentes de interferências externas. Seu uso clínico está extensamente reconhecido ${ }^{47}$.

Na década de 70, o PESS passou a ser cada vez mais utilizado nas cirurgias de escoliose ${ }^{40}$, com o objetivo de avaliar a medula espinhal. Tentativas de correlacionar os achados com o aparecimento de déficits motores no p.o. mostraram-se infrutíferas ${ }^{18}$, visto que os potenciais obtidos correspondiam ao trânsito no funículo posterior da medula espinhal e que a mielotomia dorsal necessária para a cirurgia de tumor intramedular levava à perda imediata dos potenciais sensitivos. A medula espinhal tem uma vascularização muito particular, com a artéria espinhal posterior vascularizando o terço posterior da medula e a artéria espinhal anterior os dois terços anteriores, o que justifica o insucesso em utilizar um potencial que transita na via posterior para estimar dano às vias lateral e anterior. A baixa correlação da técnica de PESS com déficits motores forçou a busca por metodologia confiável, com pesquisas que ocorreram de forma 
simultânea no Japão e nos Estados Unidos, na década de 80. As primeiras tentativas para avaliação da via motora descendente compreendiam o emprego de técnicas de estimulação e captação sobre a medula espinhal e técnicas de estimulação da medula espinhal e captação nos nervos periféricos e músculos.

A técnica de estimulação direta sobre a medula leva à propagação ascendente e descendente do estímulo simultaneamente, estimulando de forma não seletivas os tractos motores descendentes e sensoriais ascendentes. O potencial resultante corresponde à somatória de todos os tractos estimulados e dependerá do local de captação em relação à estimulação. Estudos críticos não puderam confirmar a validade dessa técnica para uso em ressecção de tumores medulares ${ }^{19}$.

A técnica de estimulação medular e captação periférica sobre 0 nervo/músculo pressupõe que haverá estimulação do tracto corticoespinhal (TCoE) e consequente ativação do motoneurônio alfa e também que o potencial periférico captado será puramente motor. Entretanto, a estimulação medular leva à ativação de vários tractos descendentes e ascendentes, levando à ativação de arcos reflexos medulares segmentares complexos. 0 estímulo ao transitar nos tractos sensoriais se faz nos dois sentidos: ortodrômico (ascendente) e antidrômico (descendente). Por causa disso, a resposta captada sobre o nervo periférico é uma somatória da estimulação das fibras sensoriais e motoras que transitam dentro dele. Os potenciais obtidos com essa técnica correspondem à somatória da ativação de diferentes vias e é, portanto, inespecífico. 
Merton e Morton ${ }^{2}$ (1982), citado por Deletis ${ }^{12}$, criaram em 1980 a metodologia para obtenção do potencial evocado motor por estimulação elétrica transcraniana (EETc) do paciente acordado. Baseada nessa metodologia, duas novas foram criadas, utilizando pulso único ou múltiplos pulsos elétricos.

A metodologia do pulso único aplicado sobre a calota craniana ou sobre o córtex motor exposto leva à captação de um potencial medular sobre a via motora descendente - a onda direta (onda D) ${ }^{13,28,49}$.

A metodologia de múltiplos pulsos aplicados na forma de um conjunto de 3 a 7 pulsos, na frequência de até $2 \mathrm{~Hz}$, resulta na ativação de um potencial motor muscular (PMM). Essa técnica difere da técnica de Penfield, que aplica uma estimulação contínua, com frequência de $50 \mathrm{~Hz}$ a $60 \mathrm{~Hz}$ por vários segundos sobre o córtex motor exposto, o que pode desencadear crises convulsivas ${ }^{19}$.

Na década de 90, o desenvolvimento de estimuladores que geram conjunto de pulsos elétricos e o emprego de novas drogas anestésicas, com menor capacidade de inibição sináptica, tornaram factível o emprego do potencial evocado motor por EETc com registro de PMM no ambiente cirúrgico. A avaliação intraoperatória das vias motoras se tornou amplamente difundida e suas alterações passaram a ser correlacionadas com déficit motor p.o. ${ }^{13,25,50,51,52}$. Nos primeiros anos, o papel da EETc se limitou a predizer danos motores, mas não auxiliou na identificação de situações de risco e na prevenção da lesão.

\footnotetext{
${ }^{2}$ Merton, P.A., Hill D.K, Marsden, C.D. and Morton, H.B. Scope of a technique for
} electrical stimulation of human brain, spinal cord and muscle. Lancet, ii, 597-598 48 
Somente na década seguinte o acúmulo de conhecimento e experiência por parte do cirurgião e do neurofisiologista permitiu a correlação dos achados intraoperatórios com os eventos na cirurgia, e assim a MNIO passou a ser utilizada como uma ferramenta para prevenir a lesão e não apenas identificá-la ainda no centro cirúrgico. Essa mudança na forma de trabalhar a informação neurofisiológica nas situações de risco contribuiu significativamente para a popularização da MNIO entre os neurocirurgiões.

O princípio básico da EETc é o conjunto de pulsos aplicado sobre a calota craniana, sobre pontos representativos da área motora do Sistema Internacional 10-20 para colocação de eletrodos para EEG ${ }^{53}$ (anexo, figuras 2 e 3). Este conjunto de pulsos estimula sequencialmente o primeiro neurônio de forma eficiente para provocar múltiplas ondas descendentes com potência suficiente para atingir o limiar de despolarização dos neurônios motores secundários, que se despolarizam e levam à contração de fibras musculares - o potencial motor muscular (anexo, figuras 4 e 5). Não há na literatura padronização dos parâmetros de estimulação por tipo de cirurgia 54,55,56, ou seja, a quantidade de pulsos no conjunto de pulsos (variação de 3 a 7), duração do pulso (0,3 ms a 0,5 ms), intervalo entre eles (2 ms a $5 \mathrm{~ms}$ ) e frequência de repetição do conjunto de pulsos $(\mathrm{em} \mathrm{Hz})$. A estimulação com o anodo (+) situado sobre o córtex motor que se quer ativar $r^{55}$ desencadeia condução descendente sincronizada, que ativa de forma eficaz os segundos neurônios motores na medula espinhal. Ocorre, então, a despolarização da unidade motora e a contração das fibras musculares que dela fazem parte, resultando num potencial polifásico motor de máxima amplitude e latência 
constante, o PMM. Como a cada estímulo neurônios diferentes podem ser ativados por causa do período refratário, pode haver uma alteração pequena na morfologia dos PMM registrados, pois unidades motoras diferentes se despolarizam.

O registro pode ser feito em qualquer músculo estriado, incluindo músculos extraorbiculares, faciais, mastigatórios, de laringe ${ }^{55}$ e língua, o que permite monitorar os nervos cranianos ${ }^{13,24,28}$.

Relatos consistentes de utilização de potencial evocado motor com EETc do tracto corticobulbar (TCoB) são recentes. O objetivo do emprego dessa técnica é a preservação da integridade de toda a via motora, desde o córtex motor até os músculos inervados pelos nervos cranianos, passando pelo $\mathrm{TCoB}^{29,57,58}$ e $\mathrm{TCoE}^{59,60}$. A EETc gera um PMM resultante da ativação conjunta e sincronizada de vários neurônios motores secundários nos núcleos dos nervos cranianos ${ }^{27,28,58}$. Fatores que interferem com esse recrutamento são fisiológicos, farmacológicos e patológicos. Excluídos os fisiológicos e farmacológicos, a queda de amplitude do potencial é atribuída à perda axonal por lesão intraoperatória. As lesões podem ser decorrentes de isquemia, alterações metabólicas do tecido nervoso, trauma mecânico ou compressão ${ }^{28}$.

A queda da amplitude do PMM final do nervo facial em relação à amplitude inicial maior que $50 \%{ }^{19}$ ou acima de $65 \%{ }^{29}$ está relacionada à piora do índice de HB.

O aumento da intensidade do estímulo da EETc para a obtenção do PMM pode significar lesão axonal irreversível e pode preceder em minutos ou 
horas a perda completa da resposta motora ou ocorrer isoladamente ${ }^{61}$. Esse parâmetro tem sido analisado recentemente na EETc em relação aos PMM obtidos nas extremidades em cirurgias de medula espinhal e ainda está para ser determinado qual é o seu papel nas cirurgias supratentoriais que envolvam o tracto corticobulbar.

O emprego da EETc pode ser realizado de forma praticamente contínua, com intervalos curtos entre as estimulações e possibilita registrar queda na amplitude dos potenciais, enquanto ainda podem ser revertidas por atos do cirurgião, como irrigação com soro morno, liberação da tração ou da compressão sobre o nervo e manipulação tumoral por outro ângulo.

Não há contraindicações absolutas para a realização do EETc. Contraindicações relativas são pacientes com histórico de epilepsia e crises convulsivas e de estimuladores implantados - marca-passo ou estimuladores profundos muito próximos do campo de estimulação, que devem ter a EETc suspensa imediatamente se apresentarem problema.

Como complicações, podem ocorrer mordedura de língua pela contração da musculatura mastigatória durante a EETc, que é evitada colocando-se um rolo de gaze entre as arcadas dentárias superior e inferior, hematoma no ponto de inserção muscular do eletrodo de agulha e crise convulsiva (apenas para estimulação direta do córtex a $50 \mathrm{~Hz}$ a $60 \mathrm{~Hz}$ ).

O potencial evocado motor por estimulação magnética transcraniana no ambiente cirúrgico não se difundiu porque a técnica é muito sensível ao regime anestésico, sua via de ativação é multissináptica e as bobinas existentes superaquecem e se deslocam facilmente durante a cirurgia. 
Até 1985 , não havia critérios claros para a avaliação funcional do nervo facial. A partir desse ano, o índice de $\mathrm{HB}^{62}$ foi adotado pela Sociedade Americana de Otorrinolaringologia e Cirurgia de Cabeça e Pescoço para tornar uniforme a avaliação funcional do nervo facial, fornecendo critérios claros e objetivos, tornando a comparação entre trabalhos mais homogênea. Compõe-se de seis graus de classificação funcional do nervo facial, sendo I o nervo normal, II paresia leve, evoluindo com piora progressiva da função do nervo facial até o grau VI que corresponde a plegia completa ${ }^{62}$ (anexo, tabela 1). Há uma correlação direta entre os graus I a III do índice de HB no p.o. imediato e uma boa função do nervo facial na evolução tardia ${ }^{45}$.

A piora do índice de HB do nervo anatomicamente intacto após o final da cirurgia pode ser resultado de aracnoidite, hemorragia aracnoídea, edema do tecido nervoso, geralmente no meato acústico interno, levando a isquemia, vaso espasmo da vasa nervorum do nervo facial ou obstrução do fluxo venoso ${ }^{63}$.

Os objetivos básicos da neuroanestesia são impedir flutuações agudas no volume e pressão intracraniana e permitir que o paciente acorde ao final da cirurgia para possibilitar uma avaliação neurológica simples ${ }^{64}$. Os agentes anestésicos controlam basicamente o volume sanguíneo cerebral, dessa forma interferindo diretamente na pressão intracraniana. Numa situação em que já há hidrocefalia, qualquer mínimo aumento no volume cerebral pode acarretar aumento dramático na pressão intracraniana. Hipercapnia, hipóxia e hipertensão arterial são pouco tolerados nessa situação, por levarem a vasodilatação cerebral. 
A escolha do regime anestésico pode viabilizar ou impedir a realização da MNIO. A infusão endovenosa contínua de propofol e opoides especialmente o remyfentanyl - é considerado o padrão ouro para a realização de MNIO 12,29,61,64,65. A administração súbita de uma dose maior dessas drogas, o chamado "bolus", deve ser comunicada ao neurofisiologista, pois leva a perda imediata das respostas motoras, mas de origem farmacológica.

Todas as drogas anestésicas agem como depressoras da atividade do sistema nervoso, com intensidade e em local de ação diferentes ${ }^{66}$. Os agentes inalatórios halogenados promovem um aumento na latência e queda na amplitude dos potenciais motores registrados, por inibição sináptica subcortical e na medula espinhal. Devem ser evitados sempre que houver necessidade de $E E T c^{67}$, pois resultam na inibição completa do PMM ou no seu aparecimento inconstante e aleatório. O nitróxido tem um efeito depressor mais leve sobre os potenciais neurofisiológicos e pode ser tolerado até a concentração de 50\%. A ketamina e o etomidato podem facilitar a ativação cortical na EETc, gerando potenciais motores de maior amplitude. Droperidol não afeta os potenciais, mas o tiopental e os benzodiazepínicos podem aboli-los, exceção para o midazolam, que é bem tolerado $^{65}$. Os bloqueadores de junção mioneural devem ser empregados apenas para facilitar a entubação e suspensos em seguida. O teste que avalia o grau de bloqueio da junção mioneural, o chamado trem de 4 respostas, considera que a presença de 2 respostas após 4 estímulos traduz um bloqueio apenas parcial, não impedindo a realização do potencial 
evocado motor. Temos de considerar que o paciente está sob efeito de outras drogas depressoras do sistema nervoso, que o bloqueio da junção mioneural não é uniforme, e que se já houver déficit motor pré-operatório, a resposta motora já estará muito diminuída. A somatória de todos estes fatores complica a correta avaliação da variação da amplitude dos PMM registrados, portanto os bloqueados de junção mioneural devem ser evitados.

O médico que realiza a MNIO deve ter amplos conhecimentos das etapas da cirurgia, de neuroanatomia e de neuroanestesia ${ }^{26,68}$ para poder antecipar as situações potencialmente danosas e analisar criticamente os dados neurofisiológicos. As drogas anestésicas deprimem as respostas visuais, motoras e sensitivas, tornando essencial o acompanhamento bem próximo do regime administrado ao paciente. Alterações de pressão arterial média, hipotermia, queda de hematócrito e hipóxia podem alterar amplitude e latência dos potenciais registrados. O neurocirurgião e o anestesista devem estar familiarizados com a avaliação neurofisiológica utilizada, o primeiro para analisar as alterações informadas face ao momento cirúrgico e o segundo para tornar possível o registro. É fundamental a interação entre todos ${ }^{65}$.

Uma questão que se coloca é a ausência de evidência nível 1 para o uso da MNIO. Diversos tratamentos em neurocirurgia, como trauma medular agudo, trauma cranioencefálico, aneurismas, e mesmo as análises mais criteriosas, como as revisões Cochrane, falham em fornecer nível 1 de evidência ${ }^{43}$. Há situações em MNIO nas quais os benefícios do seu uso já estão tão 
extensamente comprovados, que seria inaceitável formar um grupo controle, como no caso das cirurgias para ressecção dos tumores medulares ${ }^{18}$. Neuloh et al. ${ }^{29}$ usaram como grupo controle 5 pacientes nos quais não foi mais possível a obtenção do PMM com EETc após a craniotomia, num estudo sobre o uso da MNIO durante ressecção de tumores intra e extraaxiais de tronco encefálico. $25 \%$ do grupo não monito rado desenvolveu déficit motor, o que ocorreu com apenas $1,4 \%$ dos pacientes do grupo monitorado 29 .

O uso da MNIO está numa fase atual de produtividade, em que as pesquisas se multiplicam em instituições acadêmicas e hospitais terciários, de acordo com alto padrão de qualidade no atendimento dos pacientes e de qualificação profissional. As futuras fronteiras que serão conquistadas em neurofisiologia intraoperatória dizem respeito ao tracto corticobulbar, às cirurgias para ressecção de tumores na área da insula e da fala e à análise dos reflexos medulares complexos.

Para os tumores de APC, a determinação da significância de cada teste neurofisiológico intraoperatório no resultado funcional p.o. dos nervos cranianos ainda está para ser determinada. 


\section{OBJETIVO}

Os objetivos deste trabalho foram:

- Utilizar diferentes técnicas de MNIO e determinar qual delas teve o melhor valor preditivo de déficit p.o. imediato no nervo facial em cirurgias de ressecção de tumores extra-axiais de fossa posterior.

D Determinar se o uso dos pontos C5/C6 - Cz na EETc é eficaz para a obtenção do PMM do VII nervo. 


\section{MÉTODOS}

Foi realizado um estudo piloto inicial com 36 pacientes entre janeiro de 2006 e dezembro de 2007. Os achados sugeriam que a avaliação da amplitude do PMM de nervo facial após a estimulação elétrica transcraniana tinha uma boa correlação com o resultado funcional do nervo facial. Foram, então, estudados de forma prospectiva 33 pacientes operados no Hospital Santa Paula e Hospital Israelita Albert Einstein, atendidos entre janeiro de 2008 e março de 2010. O projeto foi aprovado pela Comissão de Ética em Pesquisa do Hospital Santa Paula, cuja documentação foi encaminhada para aprovação pelo Comitê de Ética para Análise de Projetos de Pesquisa da Diretoria Clínica do Hospital da Clínicas e da Faculdade de Medicina da Universidade de São Paulo, sendo aprovado com o número 0800/07 (apêndice 10.1) e aprovado na Comissão de Ética em Pesquisa do Hospital Israelita Albert Einstein com o número 1255-10 (apêndice 10.2). Todos os pacientes foram devidamente informados sobre a MNIO e os que foram atendidos no Hospital Santa Paula assinaram o termo de consentimento para a utilização dos dados coletados (apêndice 10.3).

Foram utilizados como critérios de exclusão: tumores intra-axiais, pacientes com história de neurofibromatose do tipo II, epilepsia e crises convulsivas, estimuladores implantados - marca-passo ou estimuladores profundos muito próximos do campo de estimulação e clipes vasculares cerebrais. 
Os pacientes foram avaliados clinicamente de acordo com a graduação clínica de HB (anexo, tabela 3 ) antes da cirurgia e em todas as consultas de seguimento, sempre realizadas pelo cirurgião responsável.

Todas as monitorações foram realizadas pela mesma neurofisiologista. Os pacientes foram operados por 4 equipes distintas de neurocirurgiões, e todos tinham mais de dez anos de experiência em neurocirurgia.

Para a indução anestésica foi utilizado um bloqueador de junção mioneural de ação curta, o cloreto de suxametônio (Quelicin ${ }^{\mathrm{R}}$ ), com duração de ação de 4 a 6 minutos. A anestesia foi mantida com infusão contínua de propofole remyfentanyl em todos os casos. A MNIO multimodal foi realizada com um aparelho Endevor CR, Vyasis Healthcare Inc. Utilizamos agulhas subcutâneas do tipo saca-rolhas para EETc e eletrodos de agulha monopolar não teflonados de $13 \mathrm{~mm}$ para agulhamento duplo de cada músculo estudado (anexo, tabela 2 /casos ilustrativos 2 e 3 ). O trabalho foi desenvolvido sem suporte econômico.

Os pacientes foram submetidos a craniectomia retrossigmoide em decúbito dorsal com a cabeça rotacionada para o lado oposto ou em posição semissentada (anexo, apresentação de caso 1).

Foi utilizado o BERA para aferição de via auditiva, o potencial evocado motor com EETc com captação de PMM nos 4 membros (EETcMM) e PESS dos 4 membros, com o objetivo de monitoração de tronco cerebral. EETc com captação em músculos inervados pelos nervos cranianos (EETcCN) sob risco (anexo, tabela 3), escolhidos após consenso com o cirurgião 
responsável, EMG contínua desses mesmos músculos e estimulação direta dos nervos cranianos para sua identificação.

Para EETcMM, foram testados a combinação de pontos C3 (+)-C4 (-) e C4 (+)-C3(-), do sistema internacional 10-20 de EEG e estimulados os pontos que resultavam na obtenção simultânea do PMM nas 4 extremidades.

A EETcCN foi realizada com a estimulação dos pontos C5(+)-Cz(-) ou C6(+)$\mathrm{Cz}(-)$, com o anodo sempre posicionado sobre o córtex contralateral aos nervos cranianos estudados. Foi utilizado um conjunto de 3 pulsos, com duração de $0,5 \mathrm{~ms}$ e intervalo entre eles de $2 \mathrm{~ms}$, numa frequência de 1,1 $\mathrm{Hz}$, com estimulador de voltagem constante (voltagem máxima de $400 \mathrm{~V}$ ). Para evitar grandes artefatos de estímulo, os filtros utilizados foram de 150 $\mathrm{Hz}$ a $1 \mathrm{KHz}$. A amplitude do PMM foi definida como a diferença entre os picos máximos positivo e negativo da onda polifásica, de latência igual ou superior a $10 \mathrm{~ms}$.

Com a estimulação supramáxima foi obtido o PMM basal após o posicionamento e antes da incisão da pele, com o qual os demais potenciais foram comparados constantemente durante a cirurgia. A intensidade foi então mantida nesse nível durante toda a cirurgia - e denominada intensidade inicial. Os PMM foram registrados nos momentos mais marcantes da cirurgia: pós-posicionamento, pós-craniectomia, pósdurotomia, afastamento do cerebelo, abertura da cisterna magna, ressecção tumoral, brocagem do canal auditivo interno, homeostasia final, duroplastia e cranioplastia. Os dados finais de amplitude e intensidade foram obtidos após a cranioplastia. 
A queda na amplitude dos PMM requisitava a aferição da pressão arterial, temperatura corporal e da administração de alguma droga em "bolus" por parte do anestesista, pois a queda simultânea da amplitude de vários PMM estava relacionada invariavelmente a fatores fisiológicos ou medicamentosos. Afastadas essas causas, aumentou-se a intensidade lentamente para obtenção da correção da amplitude. Tendo esta sido recuperada ou não, informou-se o cirurgião do aumento da intensidade de estímulo ou da queda da amplitude do PMM. Todo esse processo levava de 3 a 4 minutos. O cirurgião promoveu irrigação com soro morno, mudou o ângulo de abordagem do tumor, ignorou a informação ou, no caso de estar fazendo a separação da cápsula do tumor aderida ao nervo, abandonou a ressecção. Se a queda da amplitude ocorria ainda durante a ressecção tumoral ou brocagem do meato acústico, a cirurgia recomeçava em seguida, tendo o PMM se recuperado ou não.

Durante a ressecção tumoral, a estimulação foi sempre repetida com a maior frequência possível, ou seja, todas as vezes em que o cirurgião interrompia a microdissecção tumoral, após descargas neurotônicas ou por solicitação do cirurgião. O procedimento era acompanhado pelo monitor na sala, permitindo a visualização do campo cirúrgico,

Foi utilizado o programa SPSS ("Statistical Package for Social Sciences"), em sua versão 17.0, para a obtenção dos resultados e aplicação da Análise de Correlação de Spearman, com o intuito de verificar o grau de relacionamento entre as variáveis de interesse - variação na intensidade da 
EETc, na amplitude do PMM do 7º. nervo e número de episódios e duração da Al.

\section{RESULTADOS}

Foram excluídos 4 pacientes que apresentavam componente intra-axial importante e 6 pacientes com quadro de neurofibromatose tipo 2, restando 23 pacientes que foram efetivamente avaliados.

A idade média dos pacientes foi 41,6 anos, variando de 3 a 81 anos, entre os quais 8 homens e 15 mulheres (anexo,tabela 3 ).

O exame anatomopatológico revelou meningeoma (10 casos) e neurinoma do acústico (13 casos). A ressecção foi total em 15 e subtotal em 8 pacientes (anexo, tabela 3).

Os tumores localizavam-se na fossa posterior, com tamanhos variando de 3 a $6 \mathrm{~cm}$, localizados no APC e 3 apresentavam extensão petroclival. $O$ tamanho foi determinado pelo maior diâmetro na ressonância pré-operatória, excluindo-se a porção intracanalicular do tumor.

Dados neurofisiológicos completos da EETcCN são apresentados na tabela 4.

Os músculos utilizados para EETcCN estão na tabela 2. Registro de EETc nos músculos de $7^{\circ}$ nervo foi possível em todos os 23 pacientes com a metodologia utilizada, sendo que em 18 pôde ser simultâneo nos seus 2 ramos zigomático e mandibular (78,2\%). Em 14 destes pacientes $(77,7 \%)$ as alterações neurofisiológicas se manifestaram nos 2 ramos simultaneamente e em $4(22,2 \%)$ em apenas um dos ramos (gráfico 1). Nos 5 pacientes 
restantes, o registro só foi possível num dos ramos do facial, por motivos variados, a saber: quando a monitoração envolveu outros nervos cranianos, implicando na colocação de grande quantidade de eletrodos (paciente 7); o paciente já apresentava déficit de $7^{0}$ nervo e não obtivemos $P M M$ em músculo orbicular do olho (OO) (pacientes 2 e 6) e houve deslocamento do eletrodo muscular após a colocação dos campos, impedindo o registro nos 2 canais (pacientes 10 e 13) .

\section{Gráfico 1: Registro do PMM do 7º nervo após EETc}

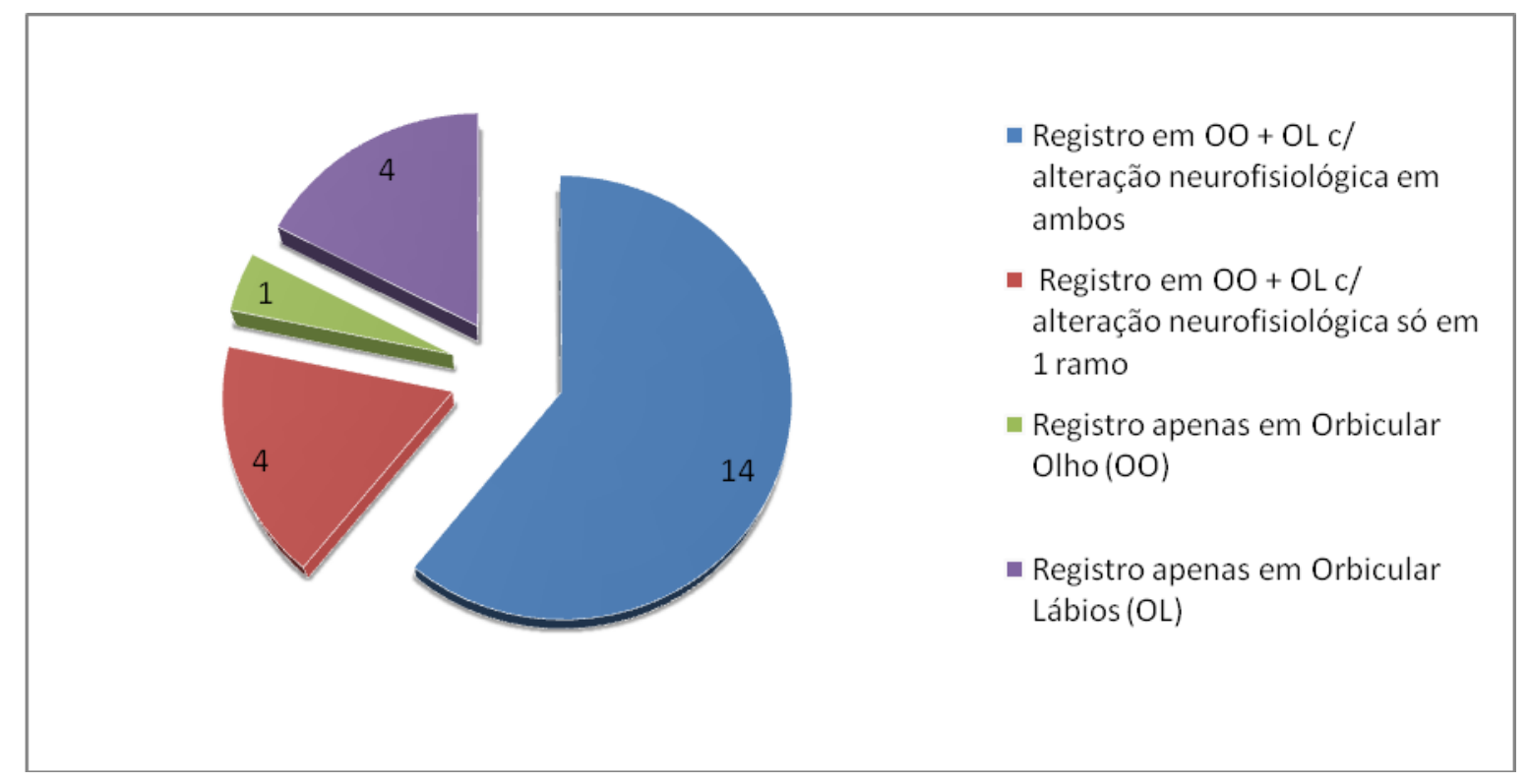

NOTA: OO = orbicular olho (inervação pelos ramos temporal e zigomático); $\mathrm{OL}=$ orbicular lábios (inervação pelo ramo mandibular); O PMM do $7^{0}$ nervo foi obtido em $100 \%$ dos pacientes com a metodologia empregada. Pacientes do grupo $B=$ pacientes $1,8,12,17$, todos com déficit p.o. 
Estudo do relacionamento entre variáveis de interesse:

Tabela 5: Relação da variação da amplitude final do PMM do $7^{\circ}$ nervo com o índice de HB no p.o. imediato e no último acompanhamento

\begin{tabular}{|c|c|c|c|c|}
\hline Amplitude & Estatística & $\begin{array}{c}\mathrm{HB} \\
\text { inicial }\end{array}$ & $\begin{array}{l}\text { HB no p.o. } \\
\text { imediato }\end{array}$ & $\begin{array}{c}\text { HB último } \\
\text { acompanhamento }\end{array}$ \\
\hline \multirow[t]{4}{*}{ INICIAL } & Coeficiente de & $-0,013$ & 0,132 & 0,095 \\
\hline & Correlação (r) & & & \\
\hline & Significância (p) & 0,881 & 0,119 & 0,263 \\
\hline & $\mathrm{N}$ & 135 & 141 & 141 \\
\hline \multirow[t]{4}{*}{ FINAL } & Coeficiente de & $-0,028$ & $-0,170$ & $-0,128$ \\
\hline & Correlação (r) & & & \\
\hline & Significância (p) & 0,741 & 0,042 & 0,129 \\
\hline & $N$ & 137 & 143 & 143 \\
\hline \multicolumn{5}{|c|}{$\begin{array}{l}\text { NOTA: Observamos coeficiente de correlação negativo e } p=0,042 \text {, } \\
\text { representando um resultado estatisticamente significante. Quanto maior foi o } \\
\text { valor numérico da amplitude final, tanto menor o valor numérico de HB no } \\
\text { p.o. imediato, e quanto menor o valor numérico da amplitude final, tanto } \\
\text { maior o valor numérico de HB no p.o. imediato. }\end{array}$} \\
\hline
\end{tabular}

Tabela 6: Variação na intensidade da EETc necessária para obtenção do PMM do $7^{\circ}$ nervo e correlação com o índice de HB

\begin{tabular}{cccc}
\hline Intensidade & Estatística & $\begin{array}{c}\text { HB no p.o. } \\
\text { imediato }\end{array}$ & $\begin{array}{c}\text { HB no último } \\
\text { acompanhamento }\end{array}$ \\
\hline INICIAL & Coeficiente de & $-0,260$ & $-0,212$ \\
& Correlação $(r)$ & & 0,331 \\
& Significância $(p)$ & 0,231 & 23 \\
FINAL & $n$ & 23 & $-0,122$ \\
& Coeficiente de & $-0,232$ & \\
& Correlação $(r)$ & & 0,579 \\
& Significância $(p)$ & 0,287 & 23 \\
& $n$ & 23 &
\end{tabular}


NOTA: O resultado não foi estatisticamente significante. O aumento do limiar de estímulo não foi determinante para a piora do índice de HB.

Tabela 7: Número de repetições e duração dos episódios da atividade irritativa e o índice de HB no p.o. imediato e último acompanhamento

\begin{tabular}{|c|c|c|c|}
\hline $\mathrm{Al}$ & Estatística & HB no p.o. imediato & $\begin{array}{c}\text { HB no último } \\
\text { acompanhame } \\
\text { nto }\end{array}$ \\
\hline Número de & Coeficiente de Correlação (r) & $-0,001$ & 0,097 \\
\hline \multirow[t]{2}{*}{ repetições } & Significância (p) & 0,995 & 0,543 \\
\hline & $\mathrm{N}$ & 43 & 42 \\
\hline $\mathrm{Al}$ & Coeficiente de Correlação (r) & $-0,252$ & $-0,176$ \\
\hline \multicolumn{4}{|l|}{ EPISÓDIO 1} \\
\hline & Significância (p) & 0,103 & 0,265 \\
\hline & $\mathrm{N}$ & 43 & 42 \\
\hline Al & Coeficiente de Correlação (r) & $-0,041$ & 0,183 \\
\hline \multicolumn{4}{|l|}{ EPISÓDIO 2} \\
\hline & Significância (p) & 0,861 & 0,428 \\
\hline & $\mathrm{N}$ & 21 & 21 \\
\hline Al & Coeficiente de Correlação (r) & 0,949 & 0,738 \\
\hline \multicolumn{4}{|l|}{ EPISÓDIO 3} \\
\hline & Significância (p) & 0,051 & 0,262 \\
\hline & $\mathrm{N}$ & 4 & 4 \\
\hline Al & Coeficiente de Correlação (r) & $+1,000$ & $+1,000$ \\
\hline \multicolumn{4}{|l|}{ EPISÓDIO 4} \\
\hline & Significância (p) & $<0,001$ & $<0,001$ \\
\hline & $\mathrm{N}$ & 2 & 2 \\
\hline
\end{tabular}

NOTA: Os dados são apresentados considerando-se a duração de cada episódio de atividade irritativa (Al), e houve registro de até 4 episódios de $\mathrm{Al}$ no $7^{0}$ nervo na mesma cirurgia. A duração de cada ocorrência é relatada como um episódio. Interpretação revela sinal do coeficiente de correlação positivo e $p<0,001$. Quanto maior a duração do episódio da $\mathrm{Al}$, maior o valor do índice de $\mathrm{HB}$, e quanto menor a duração do episódio de Al, menor o valor do índice de HB. 
Alterações que foram consideradas significativas para a piora do índice de HB foram, então, a queda da amplitude final do $\mathrm{PMM} 7^{\circ}$ nervo em relação à amplitude inicial e a duração dos episódios de Al.

Os pacientes foram divididos em 6 grupos de acordo com as alterações neurofisiológicas estatisticamente significativas observadas (tabela 8).

Dos 23 pacientes estudados, 20 apresentaram essas alterações neurofisiológicas. 10 pacientes apresentaram queda da amplitude final do PMM associada a Al; 6 pacientes, só queda da amplitude; 4 só Al. Desses 20 pacientes, 14 tiveram piora do índice de HB inicial. Não foi registrada alteração neurofisiológica intraoperatória de qualquer espécie em 3 pacientes, que evoluíram sem déficit novo (gráfico 2).

Dos 14 pacientes que evoluíram com piora do índice de HB, 13 apresentaram queda de amplitude do PMM do $7^{0}$ nervo, e em 8 deles com Al associada (anexos, gráfico 2 e tabela 9 ).

Ao avaliarmos o grau de déficit desenvolvido pelos pacientes dos grupos lla e llb em relação aos dos grupos Illa e Illb, observamos que os pacientes do grupo II evoluíram com uma piora leve (1 em 4 pacientes) ou sem piora clínica (2 em 4 pacientes), a exceção foi o paciente 6. Em contrapartida, o déficit desenvolvido pelos pacientes do grupo III foi importante na maioria dos pacientes (9 em 12 pacientes).

Dos 9 pacientes que evoluíram sem novos déficits, 6 apresentaram alteração na MNIO, sendo 3 no grupo 1 (pacientes 4, 9 e 11), 1 no grupo lla (paciente 10) e 1 no grupo llb (paciente 18). Nestes casos, a queda da amplitude do 
PMM do $7^{\circ}$ nervo foi inferior a $60 \% .1$ paciente era do grupo Illb (paciente 13).

Gráfico 2: Evolução clínica imediata dos grupos estudados

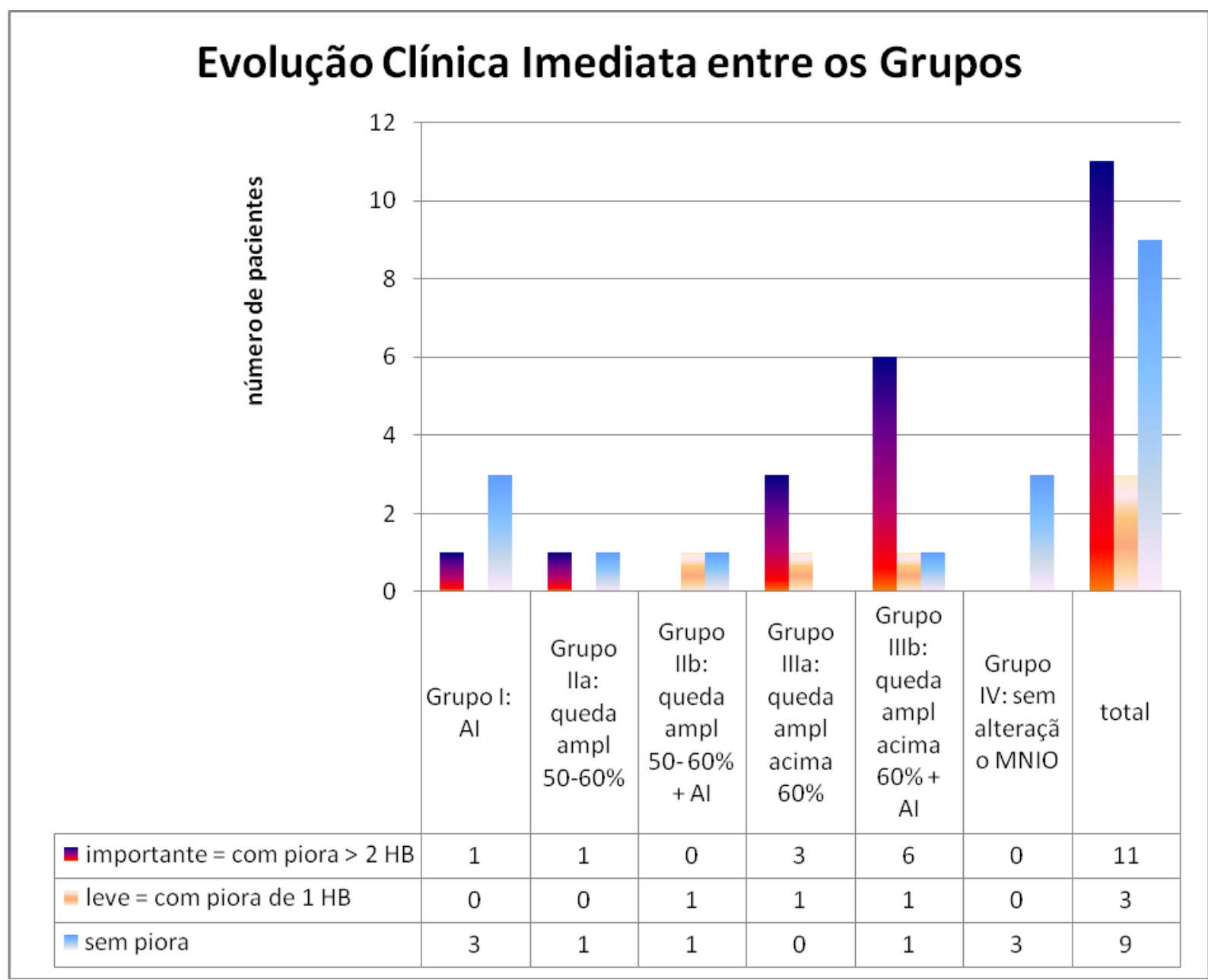

NOTA: Alteração no índice de HB em 1 grau (1 HB) ou superior a 2 graus (2 $\mathrm{HB}) . \quad A I=$ atividade irritativa; $a m p l=$ amplitude; $M N I O=$ monitoração neurofisiológica intraoperatória.

Dos 11 pacientes que aumentaram o índice de HB em 2 graus ou mais, 10 apresentaram queda da amplitude $\mathrm{PMM}$ do $7^{\circ}$ nervo proporcional à piora (gráfico 3). E 1 deles apresentou apenas Al com duração de 2 minutos (paciente 14/ gráfico 4) 
Gráfico 3: Variação índice de HB em relação à queda de amplitude PMM do $7^{\circ}$ nervo nos pacientes com queda $\geq 50 \%$ da amplitude inicial.

Ramo zigomático do $7^{\circ}$ nervo:

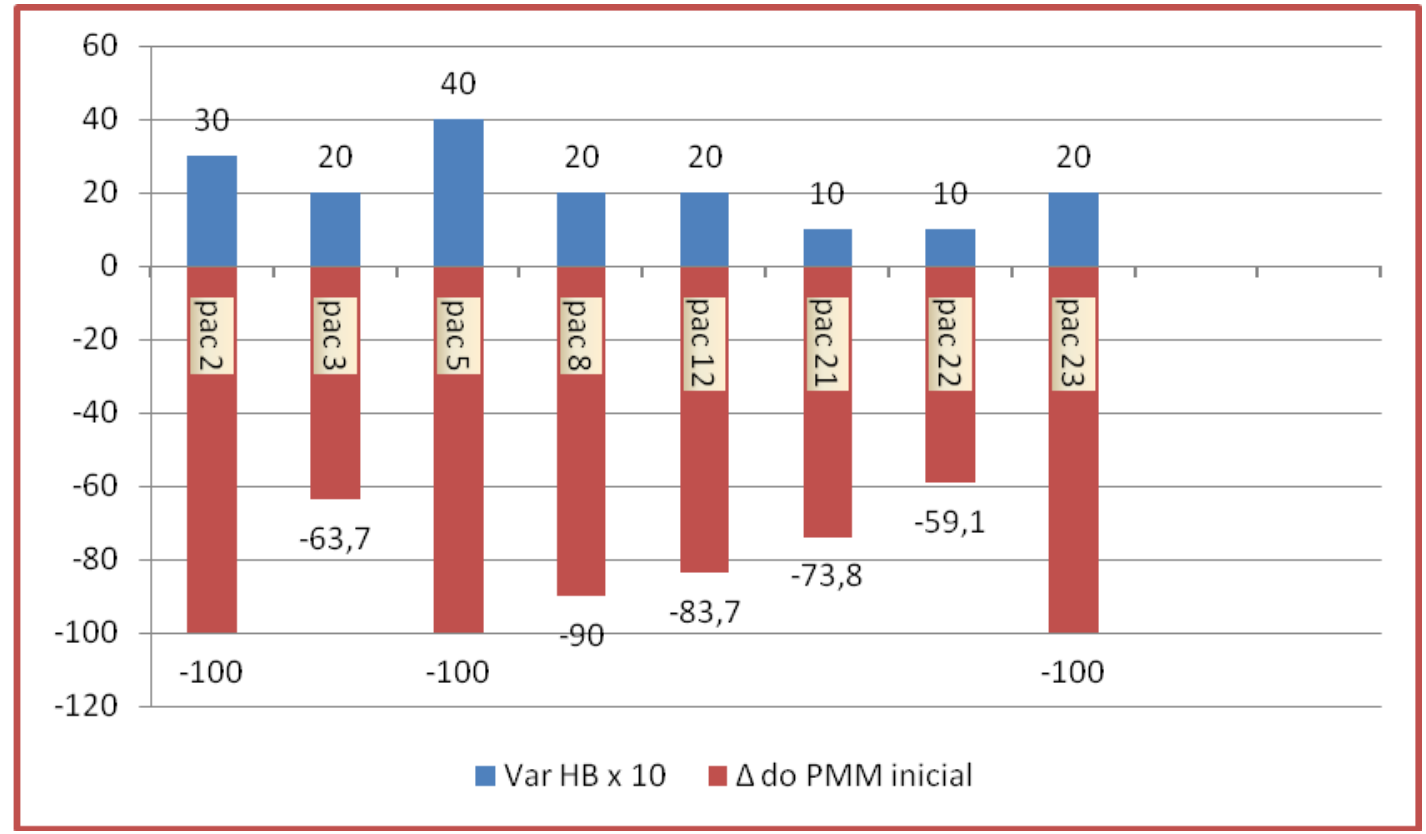

\section{Ramo mandibular do $7^{\circ}$ nervo:}

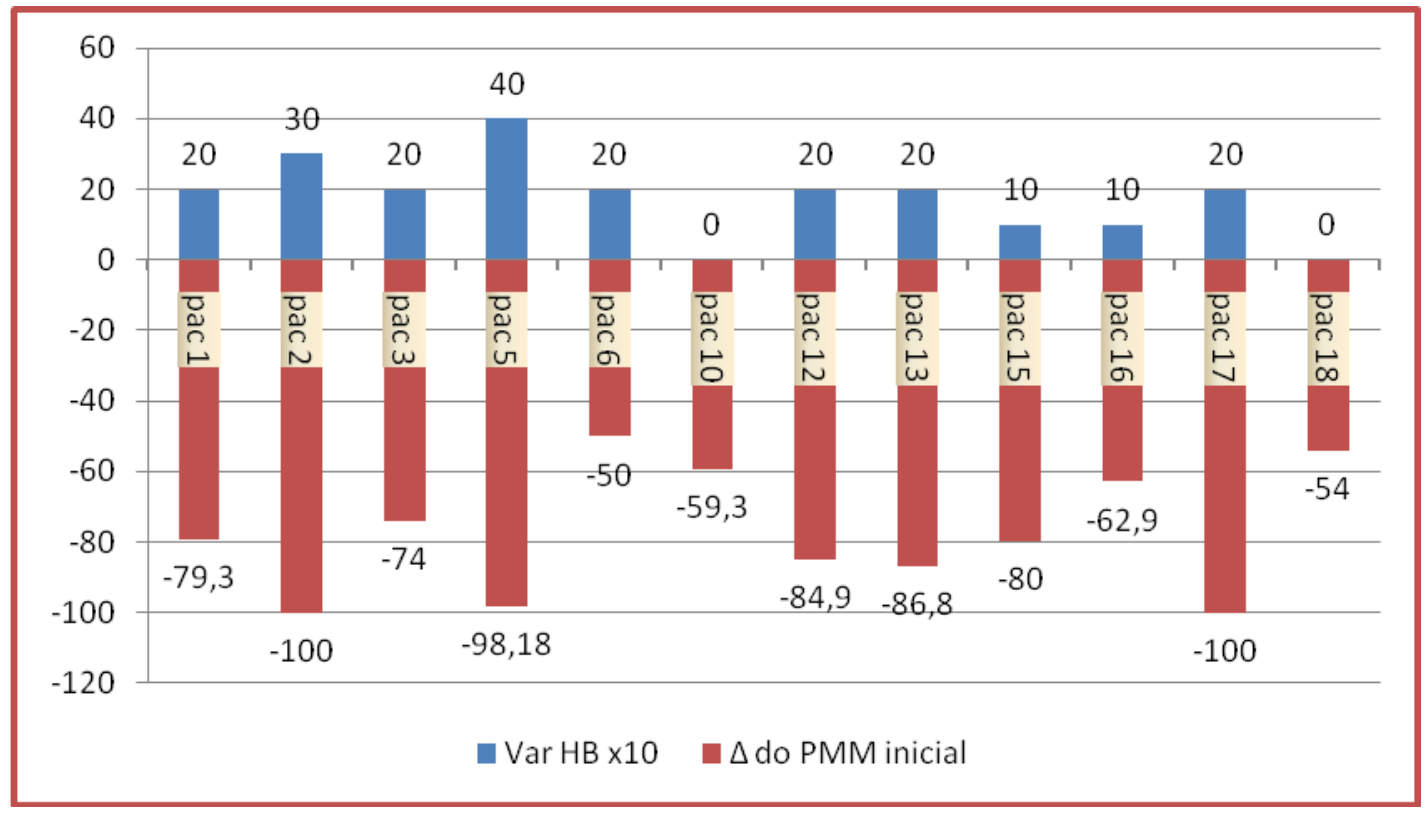

NOTA: Houve uma tendência de quanto maior a queda da amplitude do PMM do nervo facial, maior a variação em graus no índice de HB. Os 
pacientes 10 e 18 tiveram uma queda de $60 \%$ na amplitude, mas não variaram o $\mathrm{HB}$.

Gráfico 4: Duração ininterrupta do episódio mais longo de Al por paciente

\section{Duração do episódio mais longo da Al por paciente}

a pacsem piora HB $\quad$ pacc/ piora $\mathrm{HB}$

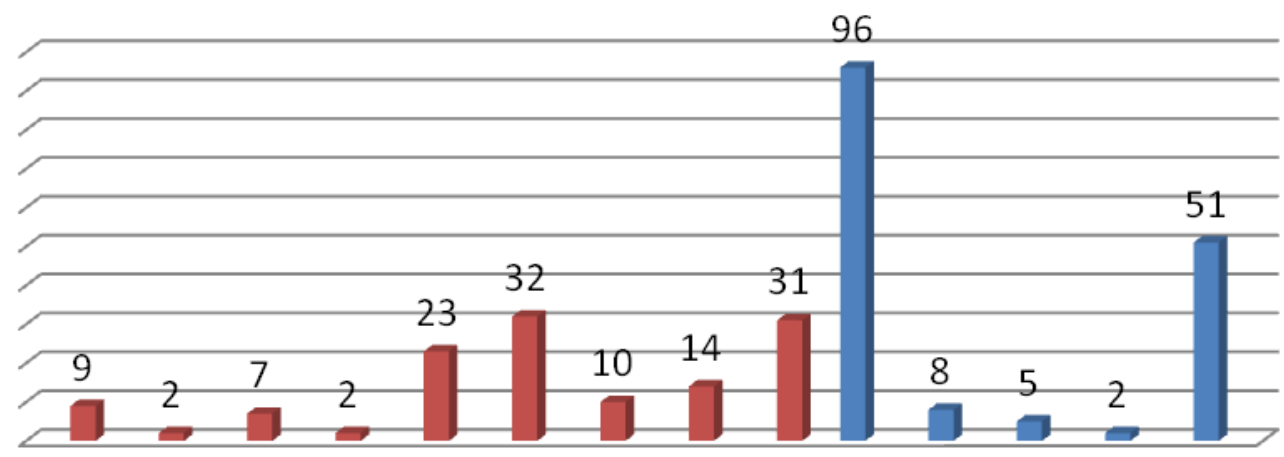

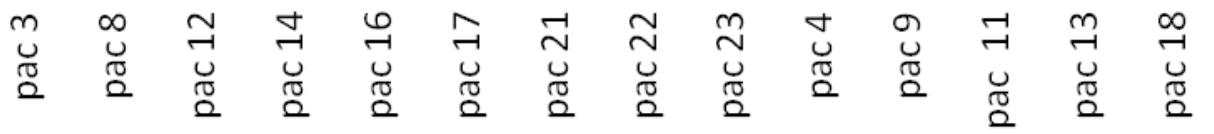

NOTA: O tempo de duração variou de 1 a 96 minutos ininterruptos. Grupo I: pacientes 4, 9, 11 e 14. Notar que o paciente 4 apresentou 96 minutos de Al ininterrupta e evoluiu sem piora do HB. Já o paciente 14 com apenas 2 minutos de Alapresentou piora do HB. 


\section{Análise Estatística de Cada Grupo}

\section{Tabela 10 - Análise Estatística do grupo I}

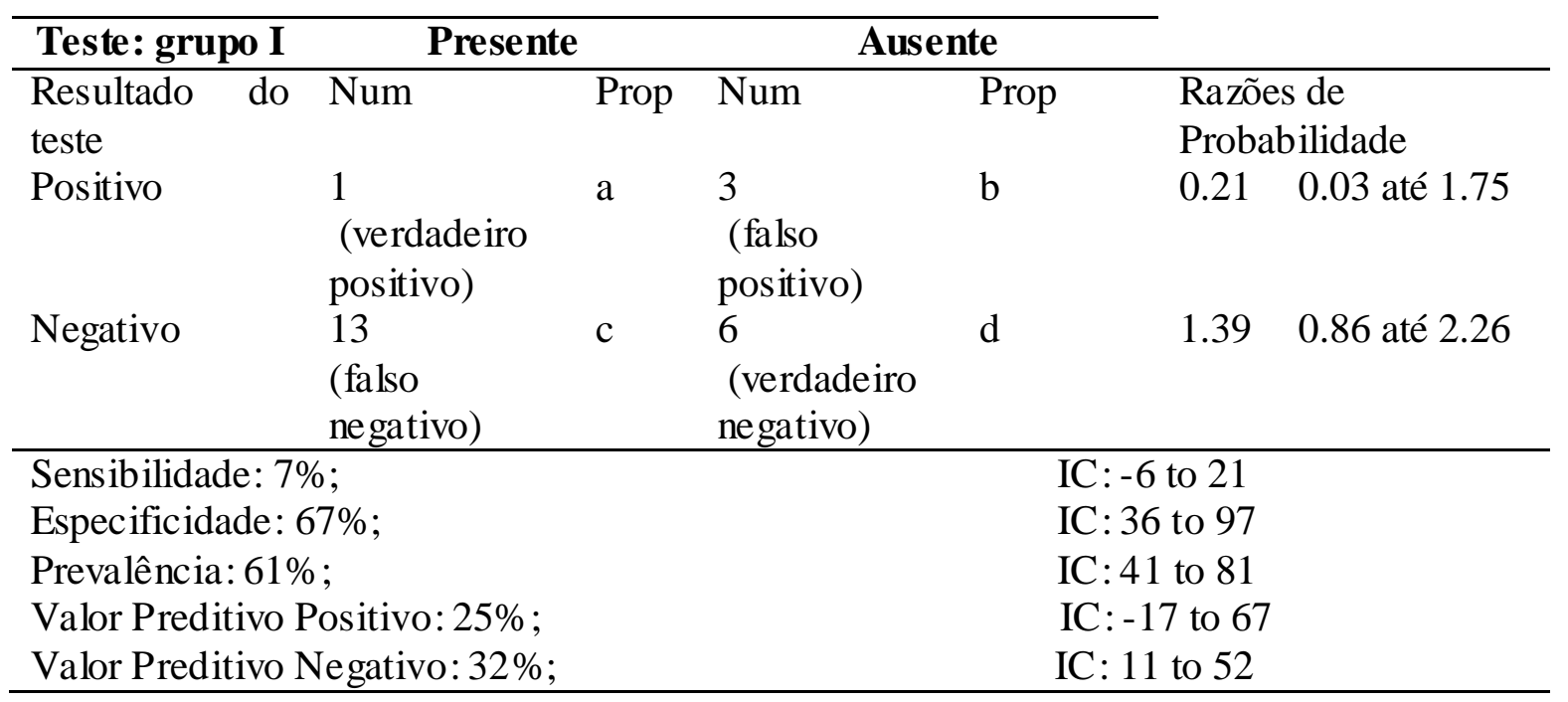

Tabela 11 -Análise Estatística do grupo lla

\begin{tabular}{|c|c|c|c|c|c|c|}
\hline Teste: grupo IIa & \multicolumn{2}{|c|}{ Presente } & \multicolumn{2}{|c|}{ Ausente } & \multirow{2}{*}{\multicolumn{2}{|c|}{$\begin{array}{l}\text { Razões de } \\
\text { Probabilidade }\end{array}$}} \\
\hline Resultado do teste & Num & Prop & Num & Prop & & \\
\hline Positivo & $\begin{array}{l}2 \\
\text { (verdadeir } \\
\text { o } \\
\text { positivo) }\end{array}$ & $\mathrm{a}$ & $\begin{array}{l}2 \\
\text { (falso } \\
\text { positivo) }\end{array}$ & $\mathrm{b}$ & 0.64 & 0.11 até 3.78 \\
\hline Negativo & $\begin{array}{l}12 \\
\text { (falso } \\
\text { negativo) }\end{array}$ & $\mathrm{c}$ & $\begin{array}{l}7 \\
\text { (verdadeiro } \\
\text { negativo) }\end{array}$ & d & 1.10 & 0.73 até 1.66 \\
\hline $\begin{array}{l}\text { Sensibilidade: } 14 \% \\
\text { Especificidade: } 78 \\
\text { Prevalência: } 61 \% \text {; } \\
\text { Valor Preditivo Po } \\
\text { Valor Preditivo Ne }\end{array}$ & $\begin{array}{l}\text { vo: } 50 \% \\
\text { ivo: } 37 \%\end{array}$ & & & & $\begin{array}{l}-4 \text { to } \\
51 \text { to } \\
41 \text { to } \\
1 \text { to } 9 \\
15 \text { to }\end{array}$ & \\
\hline
\end{tabular}


Tabela 12 - Análise Estatística do grupo Ilb

\begin{tabular}{|c|c|c|c|c|c|}
\hline \multirow{2}{*}{$\begin{array}{l}\text { Teste: grupo } \\
\text { IIb }\end{array}$} & \multicolumn{2}{|c|}{ Presente } & \multicolumn{2}{|c|}{ Ausente } & \multirow[b]{2}{*}{$\begin{array}{l}\text { Razões de } \\
\text { Probabilidade }\end{array}$} \\
\hline & Num & Prop & Num & Prop & \\
\hline Positivo & $\begin{array}{l}1 \\
\text { (verdadeiro } \\
\text { positivo) }\end{array}$ & $\mathrm{a}$ & $\begin{array}{l}1 \\
\text { (falso } \\
\text { positivo) }\end{array}$ & $\mathrm{b}$ & 0.640 .05 até 9.03 \\
\hline Negativo & $\begin{array}{l}13 \\
\text { (falso } \\
\text { negativo) }\end{array}$ & $\mathrm{c}$ & $\begin{array}{l}8 \\
\text { (verdadeiro } \\
\text { negativo) }\end{array}$ & $\mathrm{d}$ & $1.04 \quad 0.80$ até 1.37 \\
\hline \multicolumn{3}{|c|}{ Sensibilidade: $7 \%$; } & \multicolumn{3}{|c|}{ IC: -6 to 21} \\
\hline \multicolumn{3}{|c|}{ Especificidade: $89 \%$} & \multicolumn{3}{|c|}{ IC: 68 to 100} \\
\hline \multicolumn{3}{|c|}{ Prevalência: $61 \%$; } & \multicolumn{3}{|c|}{$\mathrm{IC}: 41$ to 81} \\
\hline \multicolumn{3}{|c|}{ Valor Preditivo Positivo: $50 \%$; } & \multicolumn{3}{|c|}{ IC: -19 to 100} \\
\hline \multicolumn{3}{|c|}{ Valor Preditivo Negativo: $38 \%$; } & \multicolumn{3}{|c|}{ IC: 17 to 59} \\
\hline
\end{tabular}

Tabela 13 - Análise Estatística do grupo Illa

\begin{tabular}{|c|c|c|c|c|c|c|}
\hline $\begin{array}{c}\text { Teste: grupo } \\
\text { IIIa } \\
\end{array}$ & \multicolumn{2}{|c|}{ Presente } & \multicolumn{2}{|c|}{ Ausente } & & \\
\hline $\begin{array}{ll}\begin{array}{l}\text { Resultado do } \\
\text { teste }\end{array} & \text { do }\end{array}$ & Num & Prop & Num & Prop & $\begin{array}{l}\text { Razõ } \\
\text { Proba }\end{array}$ & ilidade \\
\hline Positivo & $\begin{array}{l}11 \\
\text { (verdadeiro } \\
\text { positivo) }\end{array}$ & $\mathrm{a}$ & $\begin{array}{l}1 \\
\text { (falso } \\
\text { positivo) }\end{array}$ & $\mathrm{b}$ & 7.07 & 1.09 até 45.79 \\
\hline Negativo & $\begin{array}{l}3 \text { (falso } \\
\text { negativo) }\end{array}$ & $\mathrm{c}$ & $\begin{array}{l}8 \\
\text { (verdadeiro } \\
\text { negativo) }\end{array}$ & d & 0.24 & 0.09 até 0.67 \\
\hline $\begin{array}{l}\text { Sensibilidade: } 79 \\
\text { Especificidade: } 8 \\
\text { Prevalência: } 61 \% \\
\text { Valor Preditivo P } \\
\text { Valor Preditivo }\end{array}$ & $\begin{array}{l}\text { sitivo: } 92 \% \\
\text { gativo: } 73 \%\end{array}$ & & & & $\begin{array}{l}\text { to } 100 \\
\text { to } 100 \\
\text { to } 81 \\
\text { to } 100 \\
\text { to } 99\end{array}$ & \\
\hline
\end{tabular}


Tabela 14 - Análise Estatística do grupo Illb

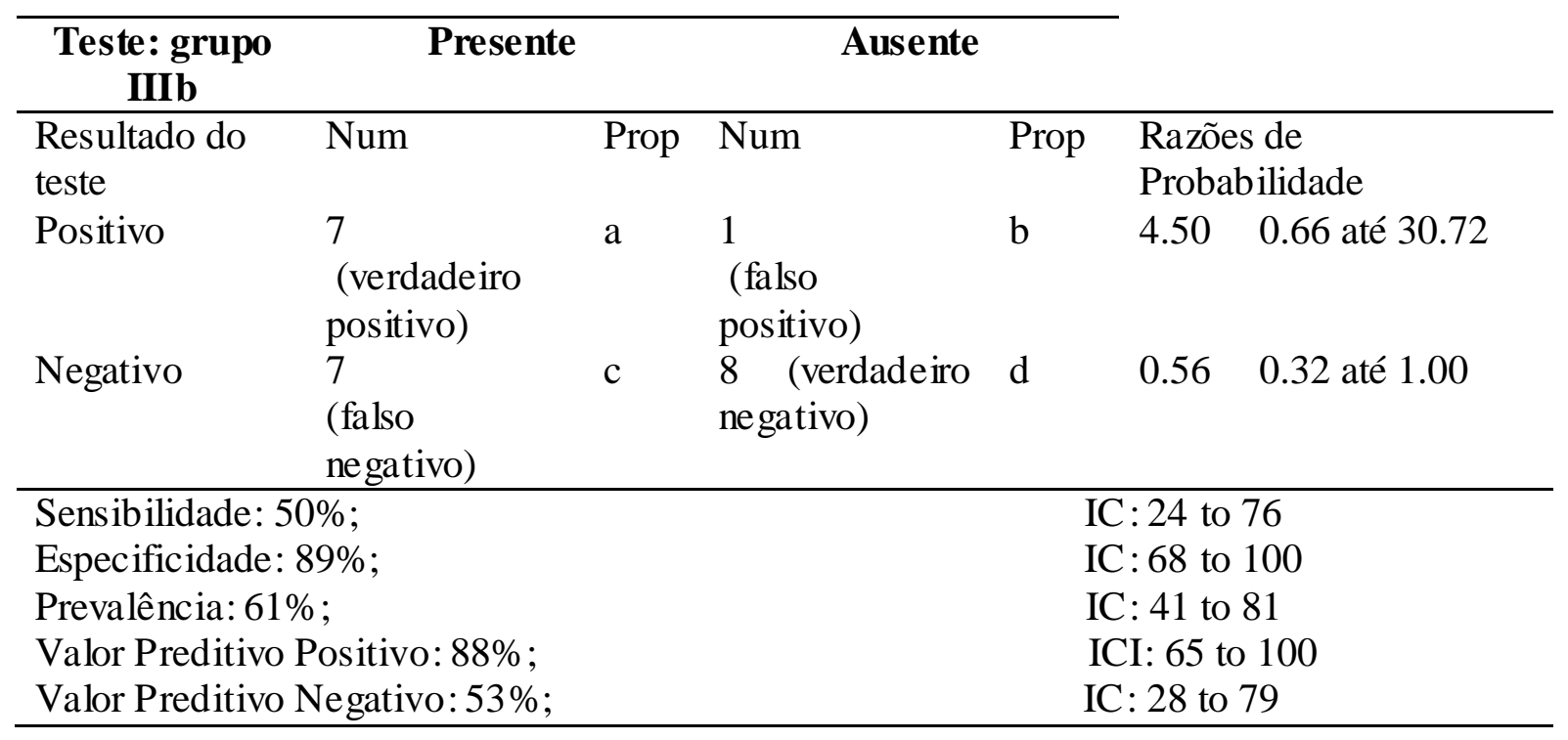

Tabela 15 - Análise Estatística do grupo IV

\begin{tabular}{|c|c|c|c|c|c|}
\hline \multirow{2}{*}{$\begin{array}{c}\text { Teste: grupo IV } \\
\text { Resultado do teste }\end{array}$} & \multicolumn{2}{|l|}{ Presente } & \multicolumn{2}{|c|}{ Ausente } & \multirow[b]{2}{*}{$\begin{array}{l}\text { Razões de } \\
\text { Probabilidade }\end{array}$} \\
\hline & Num & Prop & Num & Prop & \\
\hline Positivo & $\begin{array}{l}14 \\
\text { (verdadeiro } \\
\text { positivo) }\end{array}$ & a & $\begin{array}{l}6 \\
\text { (falso } \\
\text { positivo) }\end{array}$ & $\mathrm{b}$ & $\begin{array}{ll}1.50 & 0.95 \text { até } 2.38\end{array}$ \\
\hline Negativo & $\begin{array}{l}0 \\
\text { (falso negativo) }\end{array}$ & $\mathrm{c}$ & $\begin{array}{l}3 \\
\text { (verdadeiro } \\
\text { ne gativo) }\end{array}$ & $d$ & 0.32 até 1.00 \\
\hline \multicolumn{5}{|c|}{ Sensibilidade: $100 \%$} & IC: 100 to 100 \\
\hline \multicolumn{5}{|c|}{ Especificidade: $33 \%$} & IC: 3 to 64 \\
\hline \multicolumn{5}{|l|}{ Prevalência: $61 \%$; } & IC $: 41$ to 81 \\
\hline \multicolumn{5}{|c|}{ Valor Preditivo Positivo: 70\%; } & IC: 50 to 90 \\
\hline \multicolumn{5}{|c|}{ Valor Preditivo Negativo: $100 \%$; } & IC: 100 to 100 \\
\hline
\end{tabular}

IC = intervalo de confiança

Fonte: Catmaker <http://www.openclinical.org/dld catmaker.html>

acessada em 17/01/2011 
Gráfico 5: Apresentação dos resultados de sensibilidade, especificidade, prevalência, valores preditivos positivo e negativo entre os grupos estatisticamente significativos

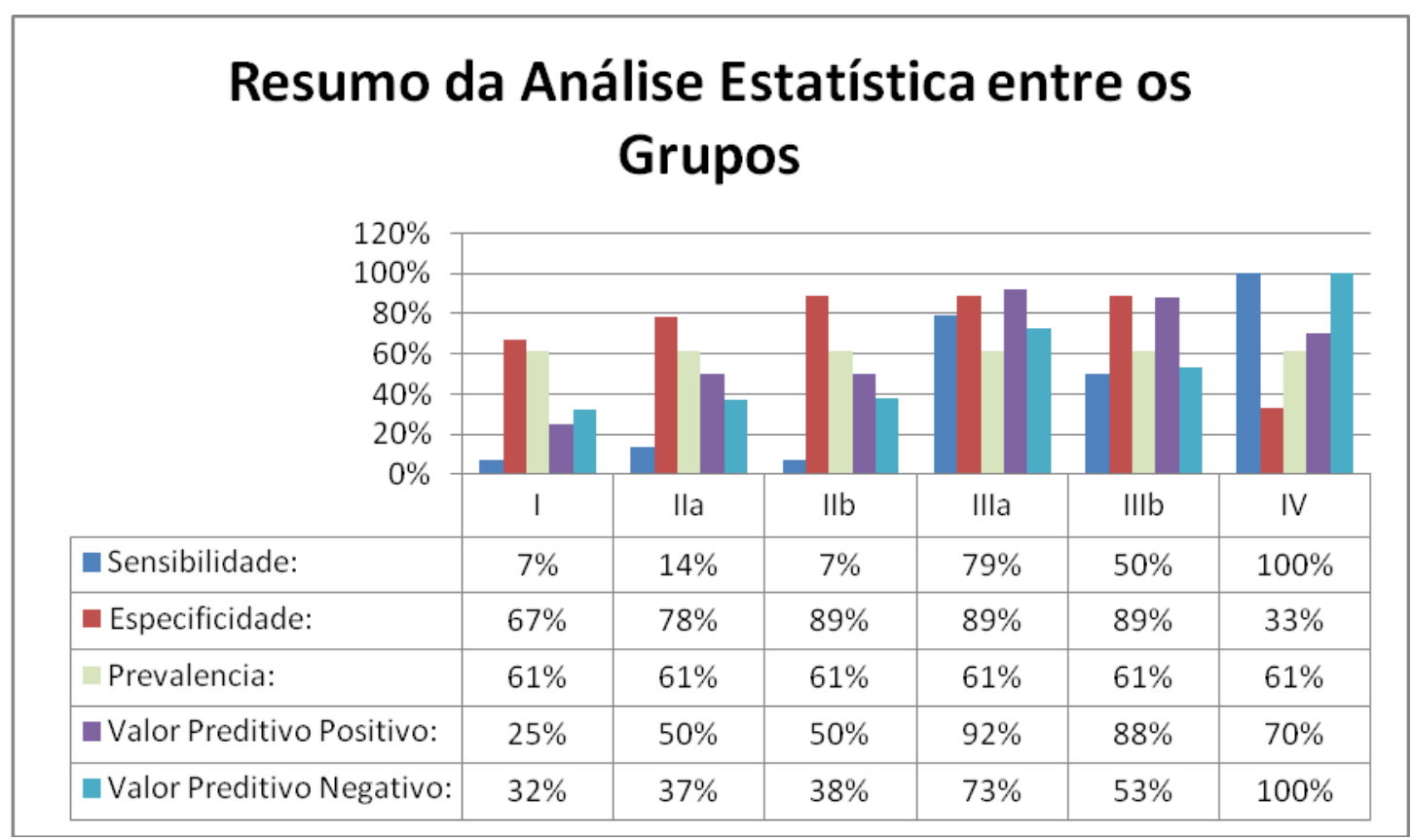

A análise dos resultados mostra que a MNIO é um método de alta sensibilidade (100\%) para o desenvolvimento de novo déficit do nervo facial, porém com uma especificidade baixa (33\%). A Al mostrou ser o parâmetro menos sensível (7\%), com especificidade de 67\%. Apenas 1 paciente em 4 desse grupo evoluiu com déficit p.o. imediato. O grupo II mostrou uma sensibilidade de $7 \%$ a $14 \%$ e especificidade de $78 \%$ a $89 \%$. Apenas 2 em 4 pacientes deste grupo evoluíram com déficit. O grupo III mostrou sensibilidade de $50 \%$ a $79 \%$ e especificidade de $89 \%$. Do grupo Illa todos os pacientes e do Illb 7 em 8 pacientes evoluíram com déficit (gráfico 2).

$70 \%$ dos pacientes que apresentaram alguma alteração neurofisiológica evoluíram com déficit e nenhum paciente que não apresentou alteração evoluiu com déficit - valor preditivo negativo de 100\% para o grupo IV. 
O valor preditivo positivo, ou seja, a chance do paciente desenvolver a patologia ao apresentar a alteração, é de $25 \%$ para o grupo I, 50\% para pacientes do grupo lla e salta para $92 \%$ para pacientes do grupo Illa. Encontramos a mesma correspondência ao considerarmos o valor preditivo negativo, ou seja, a chance do paciente não apresentar a patologia se não tiver a alteração, sendo de $37 \%$ para o grupo lla e de $73 \%$ para o grupo Illa. Não houve relato de complicações associadas ao uso da EETc nesta casuística. 


\section{DISCUSSÃO}

O manejo cirúrgico dos tumores de APC é de alta complexidade, pois o acesso anatômico é estreito e a área física dentro do crânio, na qual o cirurgião vai operar, é pequena e cheia de estruturas nervosas e vasculares, que não podem ser sacrificadas sem deixar sequelas graves aos pacientes. Graças ao avanço no conhecimento de neuroanatomia, desenvolvimento da neuroanestesia e da avaliação fisiológica, patologias que não eram ressecáveis há dez anos, o são agora.

Os métodos de avaliação neurofisiológica devem propiciar informação de qualidade, em tempo real, podendo ser correlacionadas imediatamente com o momento cirúrgico, permitindo ações imediatas de prevenção da lesão. Esse papel preventivo da MNIO é muito importante e é baseado no conhecimento de quais alterações dos potenciais se correlacionam com o déficit p.o..

Entre os métodos fisiológicos utilizados nas cirurgias de fossa posterior, enumeramos o BERA, a estimulação direta do nervo facial, a EMG contínua e o potencial evocado motor com EETc.

A discussão sobre BERA não cabe neste trabalho, pois a maioria dos casos é de tumor de grande volume (maior do que $3 \mathrm{~cm}$ ), no qual já há perda auditiva antes da cirurgia, levando à ausência de potencial registrável desde o início dos testes neurofisiológicos. Nesta casuística, 13 pacientes se queixavam de hipoacusia ou acusia no pré-operatório (anexo, tabela 3). Mesmo nos casos em que não há sintomatologia clínica, a condução 
fisiológica do nervo acústico pode estar comprometida, com bloqueio de condução provocada pela compressão de longo tempo sobre o nervo, não sendo possível a sincronização da resposta $V$. O estudo de todos os potenciais evocados se baseia na somação das respostas ao estímulo provocado centenas de vezes, de forma que a filtragem analógica limpe as ondas que não caem sempre no mesmo ponto. As ondas que caem centenas de vezes no mesmo ponto são os potenciais gerados sobre estruturas neurológicas próximas ou distantes, apresentando latência validada para o método utilizado de estimulação. A somação de ondas geradas em nervos desmielinizados resulta nula, pois as ondas geradas nas fibras desmielinizadas apresentam latências muito variáveis ou estão ausentes, resultando em ondas consecutivas se cancelando umas às outras. Isso explica a ausência de onda $\mathrm{V}$, mesmo nos casos em que há audição residual.

Nos tumores de APC de grande volume, a estimulação direta dos nervos cranianos e suas fibras é importante para seu mapeamento. No caso do nervo facial, não é possível sua visualização proximal ao tronco cerebral e no meato acústico interno até que um volume considerável do tumor seja retirado. Somente a partir desse momento é possível sua visualização e estimulação direta, realizada de forma intermitente e implicando na interrupção da ressecção tumoral. No início dos registros neurofisiológicos não será possível estabelecer a resposta basal - aquela anterior à manipulação tumoral - com a qual os demais registros seriam continuamente comparados, para avaliação de amplitude do potencial e da 
intensidade necessária para obtê-lo. Respostas obtidas a posteriori podem já representar uma alteração, mas não há resposta basal com a qual comparálas. A estimulação do nervo facial não identifica a queda progressiva da amplitude do potencial, não sinaliza a instalação de uma lesão, pois registra uma queda de amplitude de potencial depois que ela já se instalou. A estimulação direta do nervo facial não auxilia na prevenção à lesão nervosa, apenas identifica um déficit já instalado.

Na EMG, a ocorrência de Al pode estar associada à piora do índice de HB no p.o.. Episódios transitórios superiores a 10 segundos são relacionados à piora de 2 graus no índice de HB em $80 \%$ dos pacientes estudados por Prell et al. $^{36} \mathrm{Al}$ duradoura, que se inicia e perdura até o fim dos registros neurofisiológicos, está associada a déficits permanentes ${ }^{40}$. Al em outros nervos cranianos está associada a déficit p.o. imediato ${ }^{13,20,24,50}$. No caso dos bulbares, seria um sinal de alerta para uma eventual paresia, o que resultaria num risco aumentado de aspiração, devendo ser tomados cuidados extras com a extubação. Sua ocorrência deve ser comunicada à unidade de terapia intensiva, pois se recomenda um retardamento da extubação ${ }^{24}$. O déficit, nesse caso, é apenas presumido, pois não pode ser comprovado durante a cirurgia.

Na série de pacientes desta tese, a duração dos episódios de Al se mostrou estatisticamente significante para a piora do índice de HB. Entretando, AI como alteração isolada ocorreu apenas em 4 pacientes, e apenas 1 deles evoluiu com déficit p.o., traduzindo um valor preditivo positivo de apenas $25 \%$, sensibilidade de $7 \%$ e especificidade de $67 \%$. Esses dados 
contradizem o exposto por Prell ${ }^{36}$ em seu trabalho, que avaliou o valor da ocorrência de $\mathrm{Al}$ na predição de déficit do $7^{0}$ nervo (anexo, gráfico 6), relatando uma sensibilidade de $81 \%$ e especificidade de $100 \%$.

Nos três casos (pacientes 4, 9 e 11) que não evoluíram com novo déficit, pode ter sido decorrente da reação imediata do cirurgião, ao ser alertado, impedindo que a lesão do nervo se tornasse irreversível. Mas existem outras explicações possíveis. Al pode ser consequente da compressão, isquemia, tração, irrigação com soro frio, alteração eletroquímica do leito de ressecção tumoral ou secção parcial ou total do nervo ${ }^{13,20,69}$. No caso de secção completa, o coto distal do nervo, se manipulado, pode desencadear atividade neurotônica ${ }^{28}$, o que pode dar a falsa impressão de integridade axonal do nervo.

Devemos analisar a questão da ocorrência de Al pelo seu lado inverso: o dos casos falso-negativos, em que não há Al durante a cirurgia, mas há déficit p.o. imediato. Uma possível explicação para isso seria falha em registrar eventos que ocorrem em fibras musculares ou fascículos do nervo distantes dos eletrodos de captação utilizados ${ }^{30}$. Nesta casuística, 5 pacientes se encaixam nessa categoria e todos apresentaram queda da amplitude do PMM do $7^{\circ}$ nervo, e em 8 deles ocorreu queda de amplitude associada à ocorrência de $\mathrm{Al}$, o que resultou num valor preditivo positivo de $50 \%$ (grupo llb) e $88 \%$ (grupo lllb). Isso levanta a questão de ser insuficiente o uso isolado da EMG, sem a associação com outros testes de avaliação neurofisiológica. 
A ocorrência de Al teria o papel de identificar situações potencialmente danosas durante a cirurgia, mas sua correlação com a predição de novos déficits neste estudo foi insatisfatória.

O aumento da intensidade de estímulo elétrico na EETcMM representa um sinal precoce e anterior à perda do PMM nas cirurgias medulares e supratentoriais ${ }^{70}$, por sinalizar perda axonal no trajeto estimulado. Esse aumento não compensa a queda da amplitude do PMM ocasionada por uma perda axonal nesse trajeto ${ }^{54}$. $\mathrm{O}$ aumento na intensidade de estímulo igual ou superior a $100 \mathrm{~V}$ que persistir por mais de uma hora pode preceder em minutos a horas a queda da amplitude do PMM e culminar com déficit p.o. nas cirurgias medulares ${ }^{61}$. Ao investigar essa hipótese para as cirurgias de APC, nos deparamos com 9 pacientes nos quais aumentamos a intensidade do estímulo entre $15 \%$ e $400 \%$ da intensidade inicial (anexo, tabela 4). Esse parâmetro não apresentou significância estatística em relação ao desenvolvimento de déficit no p.o. imediato $(p=0,287)$. A necessidade de aumentar a intensidade pode ter sido ocasionada por acúmulo muscular das drogas anestésicas, levando a uma fadiga do potencial evocado ${ }^{54}$.

A queda de $50 \%$ a $75 \%$ na amplitude dos PMM após EETc correlaciona-se com déficit p.o. da via do $\operatorname{TCo}^{59,60,71}$, como nas cirurgias de coluna e de insula $^{30,72,73}$. Para as cirurgias medulares o critério de "tudo ou nada", que considera a perda do PMM como critério de avaliação, identifica o déficit motor instalado, mas não auxilia na sua prevenção $0^{28,54,61}$. Para essas cirurgias, o PMM é avaliado conjuntamente com a onda D; sua preservação ao final da cirurgia com amplitude maior ou igual a $50 \%$ da amplitude inicial 
garante um bom resultado motor funcional ${ }^{13,19,43,55,61}$. Para o nervo facial, a queda igual ou superior a $50 \%$ da amplitude inicial levaria a uma piora do índice de $\mathrm{HB}^{54,57,75,76,77}$. Já Neuloh et al. ${ }^{29}$ acreditam que a queda da amplitude superior a $65 \%$ do PMM do $7^{\circ}$ nervo leva a déficits p.o.. O mesmo parece ocorrer para os nervos $I X, X$ e $X I^{60}$. São poucas e recentes as publicações que versam sobre esse tema (anexo, tabela 16). Neste trabalho, usamos como critério de avaliação $50 \%$ na queda da amplitude do PMM do $7^{0}$ nervo. Todos os pacientes que evoluíram com piora do índice de HB tiveram queda de pelo menos $50 \%$ na amplitude do PMM do $7^{0}$ nervo (resultados, gráfico 3), mas com uma sensibilidade de apenas 14\%. Ao elevarmos o critério de avaliação para igual ou superior a $60 \%$, observamos aumento na sensibilidade para $79 \%$. A evolução p.o. também difere muito de acordo com o critério empregado, e a maioria dos pacientes do grupo Illa evoluiu com piora clínica importante do índice de HB (3 de 4 pacientes). Entre os pacientes do grupo lla, 1 evoluiu sem déficit (apresentação de caso 4) e 1, com déficit importante. Observamos um coeficiente de correlação

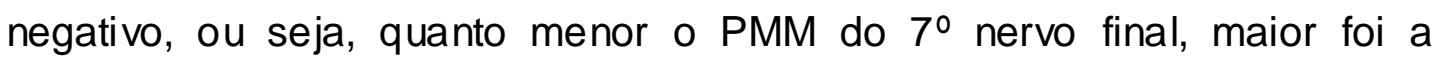
variação do HB (resultados, gráfico 3). Na apresentação de caso 1 , 0 paciente evoluiu com queda superior a $80 \%$ na amplitude registrada nos 2 ramos do nervo facial (resultados, gráfico 3) e piora de 3 graus no índice de HB. Interessante, neste caso, é que o paciente apresentou alterações neurofisiológicas importantes dos nervos $\mathbf{X}$ e $\mathrm{X}$ durante a cirurgia, com AI prolongada e perda do PMM do X, evoluindo com disfagia clínica importante 
até o sexto mês de evolução, quando ainda alimentava-se por sonda nasogástrica.

Acredita-se que a $\mathrm{EETCCN}^{57}$ e a estimulação magnética transcraniana do $\mathrm{TCoB}^{76}$ estimulem apenas parcialmente a via motora descendente, resultando na avaliação apenas parcial das fibras do TCoB. A queda na amplitude do PMM registra o que acontece apenas nessa parte da via que é aferida, não avaliando a via como um todo. Por causa disso, existem situações em que há queda da amplitude do PMM, mas não há déficit p.o.. Nossa opinião é que a queda da amplitude do PMM com EETcCN deve ser importante (superior a $60 \%$ ) para que, de fato, ocorra déficit p.o. dos nervos cranianos. Essa informação é importante na avaliação da margem de segurança do cirurgião, em face da informação de queda de amplitude do PMM, enquanto resseca o tumor.

A estratégia de monitoração e a escolha dos parâmetros de estimulação são determinados pelo tipo de cirurgia ${ }^{25,38}$. Tem importância crucial, nas cirurgias craniais, a profundidade da ativação do tracto corticoespinhal no seu trajeto descendente pela estimulação elétrica, pois estímulos muito fortes podem estimular estruturas abaixo da área de interesse ${ }^{38,71}$, como diretamente 0 tronco cerebral numa cirurgia acima desse nível (anexo, figura 6). Deletis et al. ${ }^{25}$ preconizam que o anodo deve estar situado sobre o córtex motor específico a ser estimulado. Nessa montagem, apenas o anodo é o estimulador. A EETc de moderada intensidade, no paciente anestesiado, ativaria o segmento inicial da porção proximal das células piramidais do tracto corticoespinha $\left.\right|^{56}$, gerando ondas $\mathrm{D}$ de trajeto descendente. Com o 
uso de carga elétrica alta (carga elétrica = intensidade $\mathrm{x}$ duração do pulso), tanto o cátodo como o anodo passam a ser estimuladores, e áreas mais profundas do TCoE são estimuladas ${ }^{35,75}$, ativando o axônio do motoneurônio primário, distalmente forâmen magno e até mesmo ativando diretamente os nervos cranianos no seu trajeto periférico.

A EETc, utilizando os pontos C3(+) e C4(-), leva à ativação sequencial do membro superior contralateral (direito), homolateral (esquerdo) e de membros inferiores ${ }^{38}$ à medida que há aumento na intensidade do estímulo. A ativação das quatro extremidades requer uma carga elétrica alta e resulta em contração da musculatura do pescoço, dos ombros e dorsal, o que pode atrapalhar a microdissecção ${ }^{25}$. É uma montagem eficiente para a obtenção dos PMM nas quatro extremidades simultanemante na maioria dos pacientes.

A escolha dos pontos de estimulação do TCoB para EETc foi original neste estudo. $\mathrm{O}$ anodo foi posicionado sobre a área motora correspondente à face, utilizando-se os pontos $\mathrm{C} 5(+)-\mathrm{C} z(-)$ ou $\mathrm{C} 6(+)-\mathrm{Cz}(-)$, visando a ativar o córtex contralateral ao dos nervos estudados (anexo, figura 7). A montagem do trem de estímulo objetivou a manutenção de uma baixa intensidade de estímulo, suficiente para provocar um PMM de amplitude máxima. O anodo foi mantido sobre a projeção somatotópica da face, mantendo a corrente elétrica de estímulo transitando no sentido lateral-medial do hemisfério contralateral (anexo, figura 7). A escolha desses pontos de estimulação resultou na obtenção de PMM em diversos nervos cranianos simultaneamente (anexo, tabela 4), desde o III até o XII nervo. Acreditamos 
que isso se deve à proximidade do anodo em relação à área do olho/testa e à área da mastigação/língua. Esses PMM, apesar de registrados, não são objetos de análise neste trabalho.

Pela baixa carga elétrica empregada acreditamos que não houve estimulação direta do nervo craniano, mas sim da sua via multissináptica acima de seu núcleo, justificando as latências de $7^{\circ}$ nervo variando de $10 \mathrm{~ms}$ a 16,3 ms (anexo, tabela 4 e figura 8). Outra vantagem foi a pouca movimentação cervical e dorsal provocada pelo estímulo, tornando a EETc aceitável pelo cirurgião durante a microdissecção.

Esse protocolo de estimulação foi montado baseando-se no conhecimento de que os pontos C5 ou C6 são localizados sobre a projeção da área da face na representação cortical somatotópica ${ }^{77}$. Todos os núcleos dos nervos cranianos recebem eferência cortical motora contralateral ${ }^{12,78,79,80}$. Portanto, a estimulação do hemisfério contralateral, nos pontos de projeção da face, língua, mandíbula, faringe e laringe - que são os pontos mais laterais na organi zação somatotópica do córtex motor, correspondendo aos pontos C5 e C6 no sistema 10-20 de EEG - resultaria na ativação do TCoB.

Foi empregado um conjunto de apenas 3 pulsos, cada qual com duração de $0,5 \mathrm{~ms}$, numa frequência de $1,1 \mathrm{~Hz}$, tendo sido eficiente para a captação do PMM do $7^{\circ}$ nervo em todos os casos estudados (resultados, gráfico 2). Os trabalhos publicados na literatura médica internacional informam montagens C3-C4 ou C4-C3 $3^{20,55,48,29 * 3,74}$ ou $\mathrm{C} 3 / \mathrm{C} 4-\mathrm{Cz}^{10,54,57}$, com trem de 3 a 5 pulsos,

\footnotetext{
3 * Neuloh et al. (2009) não citam a montagem para EETc no artigo, mas a autora da tese conhece seu trabalho por ter presenciado diversas MNIO na Uni-Klinik Bonn, Alemanha, em julho de 2009, sob orientação do Prof. Dr. Neuloh.
} 
para estudo do TCoB. A taxa de sucesso descrita para a montagem hemicraniana contralateral C3/C4-Cz é de $85 \%$ a $100 \%$, resultados similares aos da montagem trans-hemisférica C3-C4 com captação nas extremidades, que é de $90 \%$ a $98 \%$ (anexos, tabela 16 ).

Foram obtidos PMM polifásicos com latências variando de $10 \mathrm{~ms}$ a 16,3 ms (anexos, tabela 4) em 100\% dos pacientes. Em $78,2 \%$ deles $(n=18)$, o registro ocorreu em dois canais, em músculos de ramos zigomático e mandibular, simultaneamente. Em 14 deles, as alterações neurofisiológicas ocorreram em ambos os músculos, e em apenas 4 as alterações se limitaram a um dos ramos estudados. Consideramos que o registro em apenas um músculo foi eficiente na identificação de alterações intraoperatórias, mas que o emprego de dois músculos aumenta a sensibilidade do método devido à possibilidade de as alterações ficarem limitadas a parte dos fascículos do nervo facial.

Nos 5 pacientes em que o registro não pôde ser feito em dois canais, as causas foram variadas, como perda do eletrodo de um dos canais após a colocação dos campos cirúrgicos (2 pacientes); por paresia de nervo facial antes da cirurgia (2 pacientes) ou pelo grande número de eletrodos utilizados, optando-se por apenas um canal para o $7^{\circ}$ nervo.

Estudos mostram que PMM de nervo facial apresenta latência a partir de 10 ms a $12 \mathrm{~ms}^{54,57,74}$ e que, abaixo desse valor, o potencial é resultado da estimulação nervosa periférica. Para melhor elucidar essa questão, devemos entender a neurocondução periférica. Os índices que avaliam o coeficiente de amplitude do nervo facial perto do tronco cerebral e no MAI e a variação 
no seu limiar de estimulação o fazem por meio da estimulação periférica do nervo facial na sua porção intracraniana e fazem uma avaliação da alteração da condução num segmento intracraniano pequeno do nervo facial. Esse potencial motor obtido é chamado de potencial muscular de ação composta $(P M A C)^{81}$. A variação no seu limiar do estímulo e na amplitude do potencial traduz a ocorrência de um bloqueio de condução - que é uma alteração mielínica - e a alteração na amplitude dos potenciais pode ainda se correlacionar com perda axonal, ou seja, com a ocorrência de uma secção nervosa parcial. A secção completa do nervo facial leva à perda imediata do PMAC com a estimulação proximal. Entretanto não há alteração na amplitude do PMAC com a estimulação do coto nervoso distal, pois o processo de degeneração axonal descendente no caso do nervo facial leva de 7 a 10 dias para se completar.

O PMM é resultado da estimulação transcraniana multissináptica. No caso de a EETc provocar a resposta periférica do nervo facial, ou seja, resultar na obtenção do PMAC e não do PMM, não haverá variação transoperatória na amplitude do potencial obtido, pois a degeneração axonal descendente ainda não ocorreu no coto distal.

Neste estudo, os pacientes 2 (latência de 16,5 ms), 5 (latência de 10,6 ms) e 17 (latência de 10,4 ms) tiveram perda do PMM e evoluíram com piora duradoura (acima de quinze meses) e importante do índice HB. Isso embasa a nossa argumentação de que a estimulação foi efetivamente via cortical multissináptica, pois se tivesse havido estimulação do nervo na sua porção 
extracaraniana e não da via multissináptica, não teria havido perda intraoperatória do potencial.

A sensibilidade para queda da amplitude do PMM $7^{\circ}$ nervo foi de $14 \%$ a $89 \%$ e a especificidade foi de $78 \%$ a $89 \%$, de acordo com o critério de corte empregado, queda maior que $50 \%$ e $60 \%$, respectivamente. Analisando os mesmos grupos lla e Illa, o valor preditivo positivo variou de $50 \%$ a $92 \%$, respectivamente. Esses resultados estão em concordância com a literatura, pois ao aumentarmos o valor da queda da amplitude do PMM $7^{\circ}$ nervo, aumentamos a especificidade da avaliação - embora percamos em sensibilidade (anexo, tabela 16). Numa cirurgia em que os dados neurofisiológicos são constantemente repassados ao cirurgião em tempo real, as reações do cirurgião às informações prestadas - interrupção da ressecção, diminuição da tração, irrigação com soro morno podem ter um papel decisivo na instalação de um novo déficit p.o. ${ }^{70,73,74}$, e quanto maior for o valor preditivo positivo, melhor será a qualidade da informação. Por isso, ao aumentarmos o critério de avaliação para maior que $60 \%$, melhoramos a confiabilidade do parâmetro. Isso significa que o cirurgião tem uma margem de segurança de pelo menos $50 \%$ da amplitude basal do PMM 7ํㅡㄹ nervo com a qual trabalhar. A partir de 50\%, sua zona de conforto está no limite, e se a queda progredir para acima de $60 \%$, o paciente apresentará déficit imediato no p.o. em $92 \%$ dos casos.

O valor preditivo negativo foi de $100 \%$ para o emprego de neurofisiologia intraoperatória. Esse resultado tem um valor prático importante, visto que a 
ausência de alteração neurofisiológica correlacionou-se bem com a ausência de déficit p.o.. Isso traz segurança ao cirurgião, durante o procedimento. Não existem trabalhos com nível de evidência 1 sobre MNIO. Deve ser considerado, no entanto, que a quantidade de trabalhos publicados nas últimas duas décadas sobre o assunto, comprovando a eficácia do seu uso em prevenir e predizer déficit p.o. nas cirurgias de coluna e supratentoriais, torna temerária a realização de um estudo em que o grupo controle fique privado da $\mathrm{MNIO}^{24,25}$.

Tradicionalmente, a avaliação dos nervos III-XII era realizada com eletromiografia contínua e estimulação nervosa direta, que é útil na localização de fibras nervosas dissecadas, aderidas ou que transitam dentro do tumor. Potencial evocado auditivo é utilizado para a avaliação do $8^{\circ}$ nervo ${ }^{14}$. A utilização da EETc para monitoração do tracto corticobulbar abre caminho para a identificação mais precoce de alterações que possam ser revertidas e a determinação da sua relevância no status funcional p.o. deve ser estabelecida ${ }^{57,74}$.

O uso da MNIO multimodal, com a análise simultânea de múltiplas variáveis, melhora a qualidade da informação funcional fornecida e, neste estudo, a queda da amplitude do PMM do facial revelou-se a variável de maior importância na correlação com novo déficit p.o. imediato. $O$ emprego do EETCCN se justificaria por ser uma ferramenta de alta sensibilidade e boa especificidade, superior à identificação de Al isoladamente.

A monitoração neurofisiológica intraoperatória multimodal é um trabalho de equipe, envolvendo o cirurgião, o neurofisiologista e o anestesista, com o 
objetivo de aperfeiçoar o resultado da cirurgia, primeiramente por causa do paciente, mas também em nome do conhecimento médico e do desenvolvimento das técnicas cirúrgicas.

A cirurgia de ressecção de tumores no APC continua a ser uma cirurgia complexa que requer habilidade avançada do cirurgião, mas o objetivo atual a ser alcançado é o da preservação dos nervos cranianos. A utilidade da MNIO é muito mais alertar o cirurgião nas alterações de risco, possibilitando sua reação imediata, do que predizer com absoluta certeza danos p.o.. 


\section{CONSIDERAÇÕES FINAIS}

A estimulação dos pontos C5-Cz e C6-Cz mostrou um índice elevado de sucesso para a obtenção do PMM do $7^{\circ}$ nervo. Futuros trabalhos utilizando essa montagem deverão consolidar as vantagens do uso dessa metodologia, como a menor movimentação do paciente e menor risco de estimulação periférica do nervo facial. 


\section{CONCLUSÃo}

A queda da amplitude do PMM do $7^{\circ}$ nervo acima de $60 \%$, entre os parâmetros alterados, correspondeu ao mais sensível e específico na predição de piora funcional imediata do índice de HB.

A presença isolada de AI mostrou baixa sensibilidade e baixo valor preditivo positivo, exigindo cautela na sua interpretação durante a cirurgia.

A estimulação dos pontos $\mathrm{C} 5-\mathrm{Cz}$ ou $\mathrm{C} 6-\mathrm{C} z$ mostrou-se eficaz para a obtenção do PMM do $7^{\circ}$ nervo. 


\section{ANEXOS}

\subsection{FIGURAS}

Figura 1 - Anatomia de APC normal e modificada pelo tumor
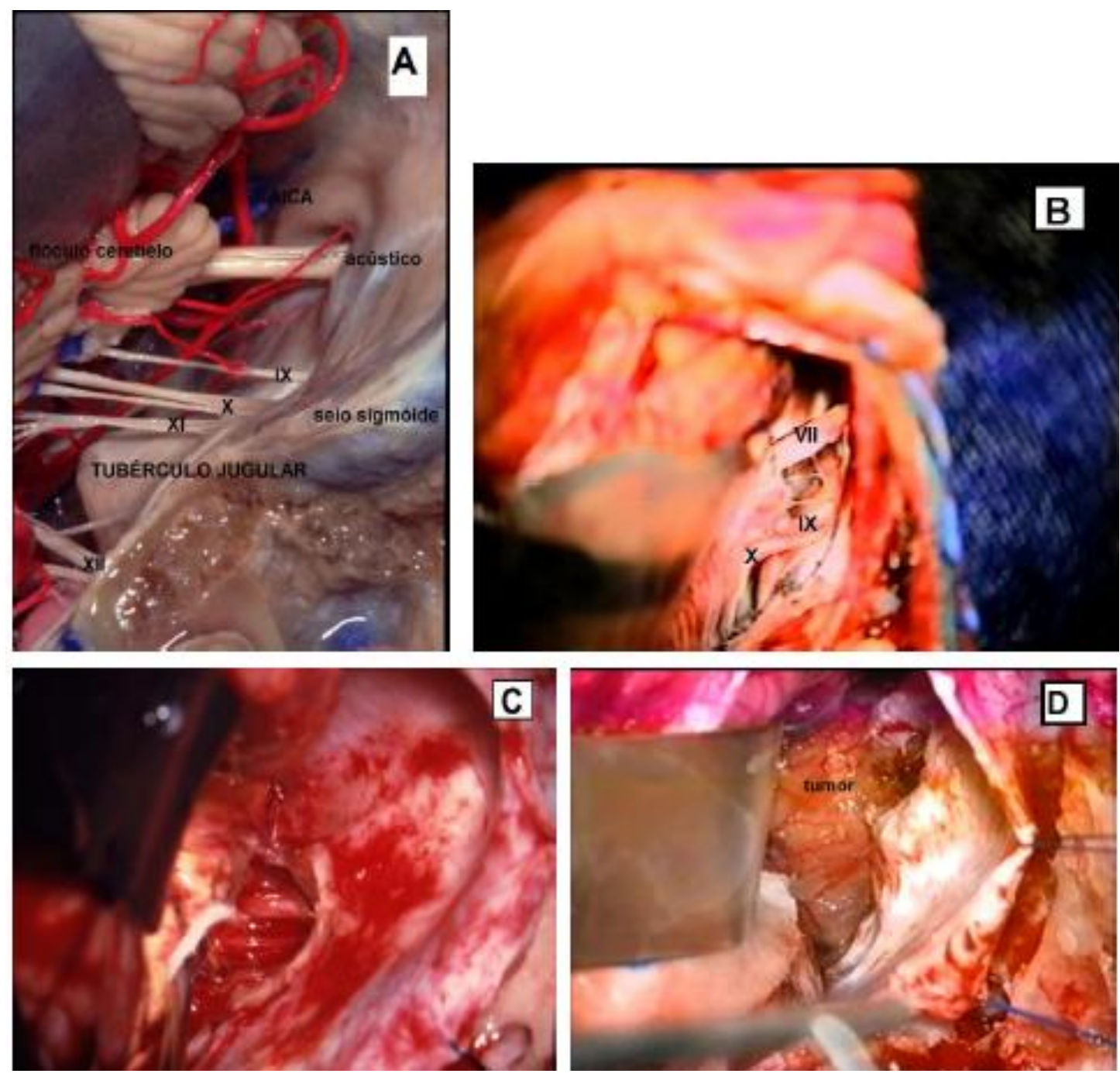

FONTE: A e C: acervo do Prof. Dr. Feres Eduardo Chaddad Neto; B e D: Acervo do Prof. Dr. Paulo Henrique Pires de Aguiar NOTA: Fotos $A$ e $B$ = APC com anatomia normal, visualização dos nervos cranianos VII ao XI e estruturas vasculares; fotos $C$ e $D=$ anatomia modificada por tumor, não sendo possível a visualização das estruturas nervosas e vasculares do APC (foto D: paciente 1). 
Figura 2 - Sistema 10-20 de EEG simplificado

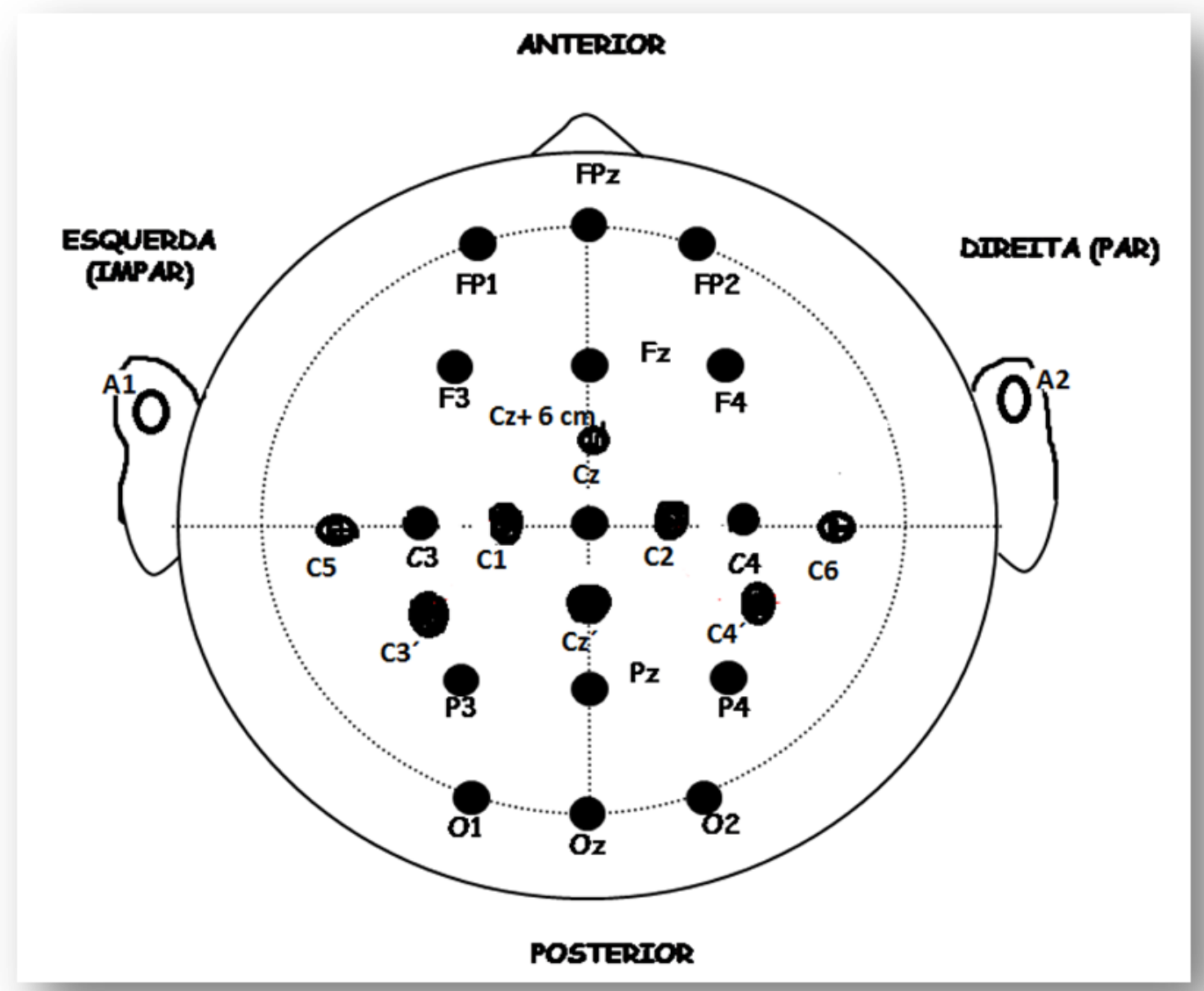

NOTA:

Pontos preconizados para EETc: C5+/Cz-, C6+/Cz-; C3+/C4- ou o contrário; $\mathrm{C} 1+/ \mathrm{C} 2$ - ou o contrário; $\mathrm{Cz}+/ 6 \mathrm{~cm}$ à frente de $\mathrm{Cz}$-. Pontos utilizados para PESS: Cz'-Fz; C3'-Fz; C4'-Fz. Pontos utilizados para BERA: A1-Cz'; A2$\mathrm{Cz}^{\prime}$. 
Figura 3 - Sistema Internacional de EEG 10-10

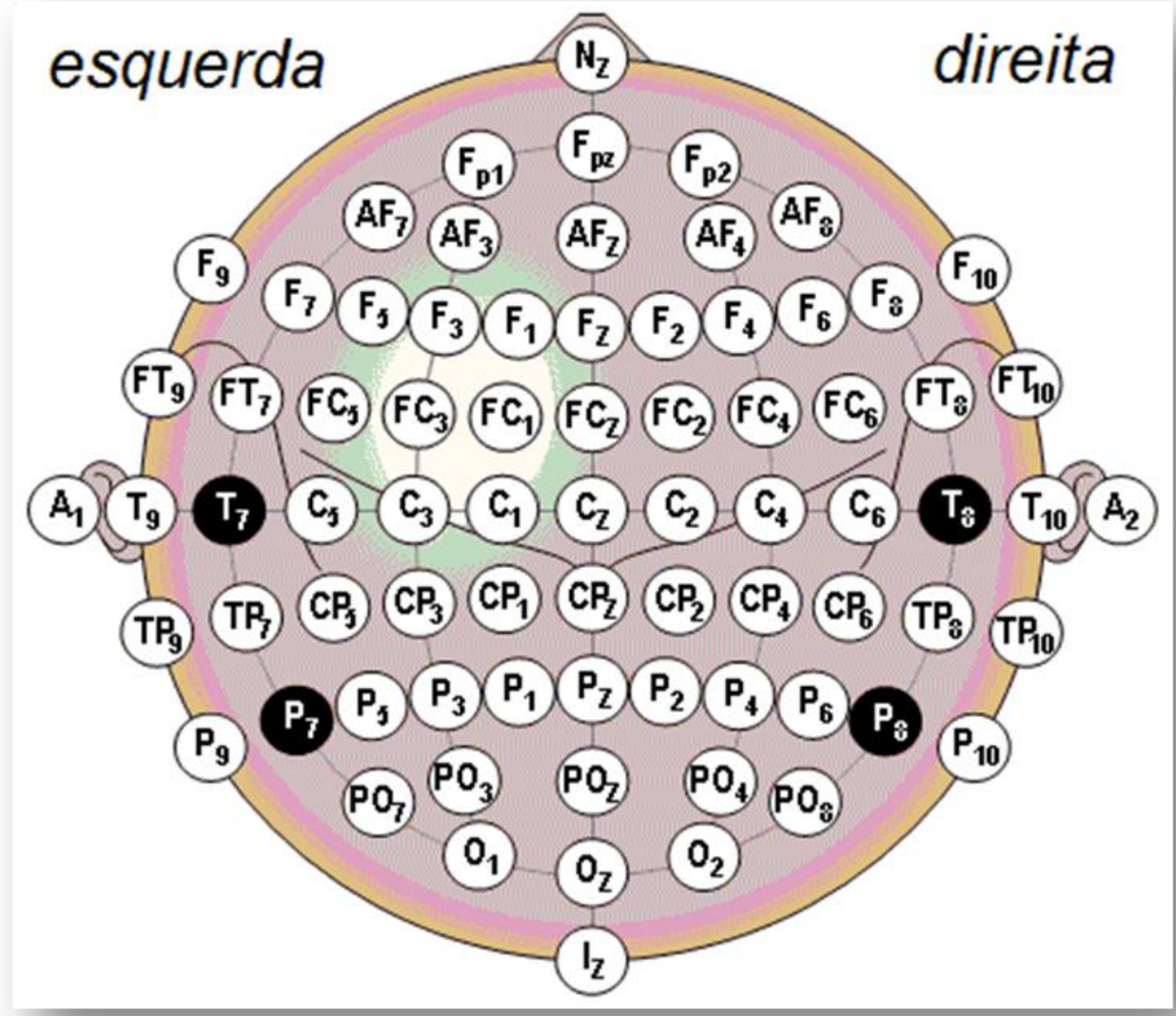

FONTE: KLEM et al. ${ }^{34}$

NOTA: Desenho mostrando os pontos com distância de $10 \%$ entre si - a distância total considerada é a do comprimento do eixo avaliado. Então, se o eixo coronal entre os pontos pré-auriculares medir $36 \mathrm{~cm}$, o ponto central $\mathrm{Cz}$ estará a $18 \mathrm{~cm}$ do ponto pré-auricular. A partir de $\mathrm{Cz}$ teremos: o ponto $\mathrm{C} 1 \mathrm{a}$ $1,8 \mathrm{~cm}, \mathrm{C} 3$ a $3,6 \mathrm{~cm}$ e $\mathrm{C} 5$ a $5,4 \mathrm{~cm}$. 
Figura 4 - Pontos motores clássicos para EETc: geração de estímulo único e do conjunto de pulsos e suas respectivas respostas

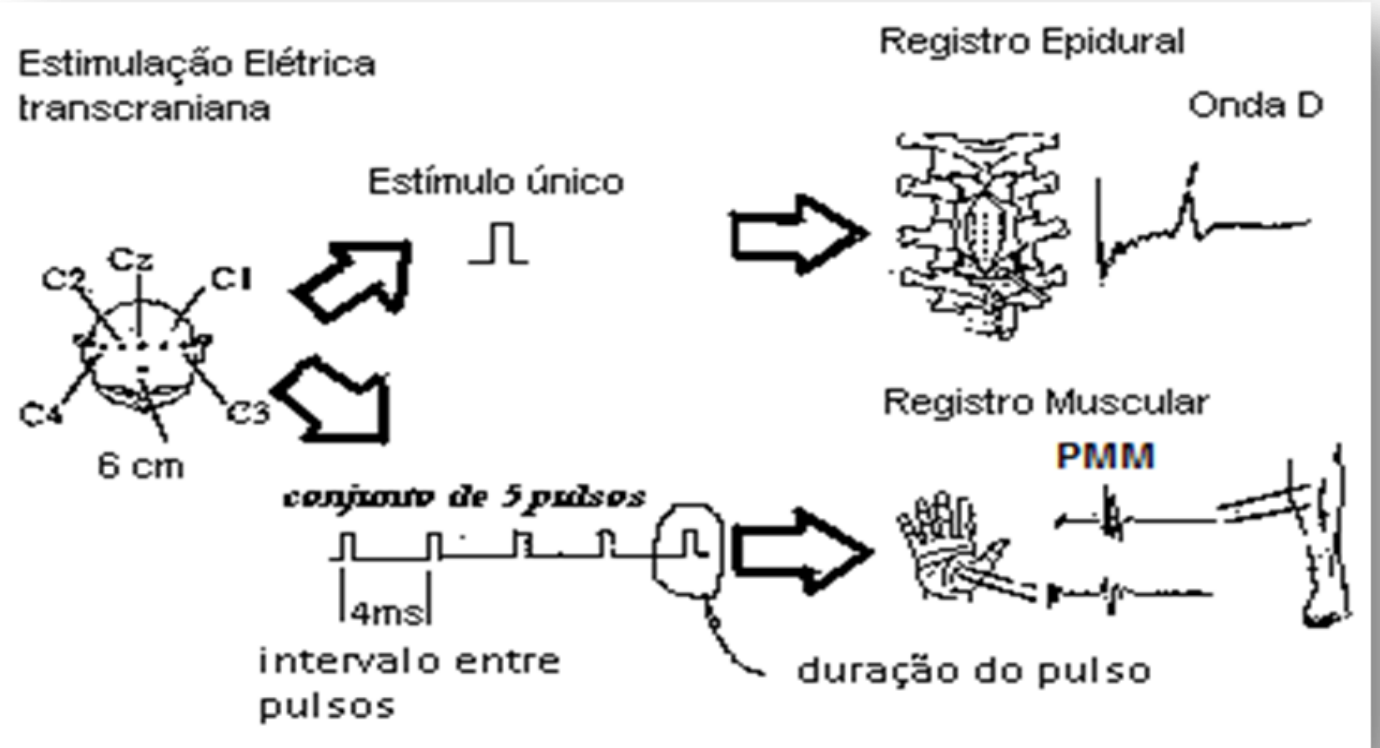

FONTE: Deletis et al. ${ }^{13}$. Desenho original do Dr. Vedran Deletis, reproduzido, traduzido e modificado com sua autorização.

NOTA: Estímulo único por EETc produz uma resposta única captada sobre o TCoE e denominada onda direta (onda $\mathrm{D}$ ).

Conjunto de 5 pulsos leva à despolarização do $2^{\circ}$ neurônio motor e contração de um conjunto de fibras musculares, originando um PMM. Os parâmetros do conjunto de pulsos: duração do pulso, número de pulsos, intervalo entre os pulsos, intensidade do estímulo e frequência de repetição do conjunto de pulsos são ajustados no estimulador do equipamento de monitoração de acordo até a obtenção de um PMM de amplitude máxima. 
Figura 5 - Representação da via de estimulação motora descendente com a EETc

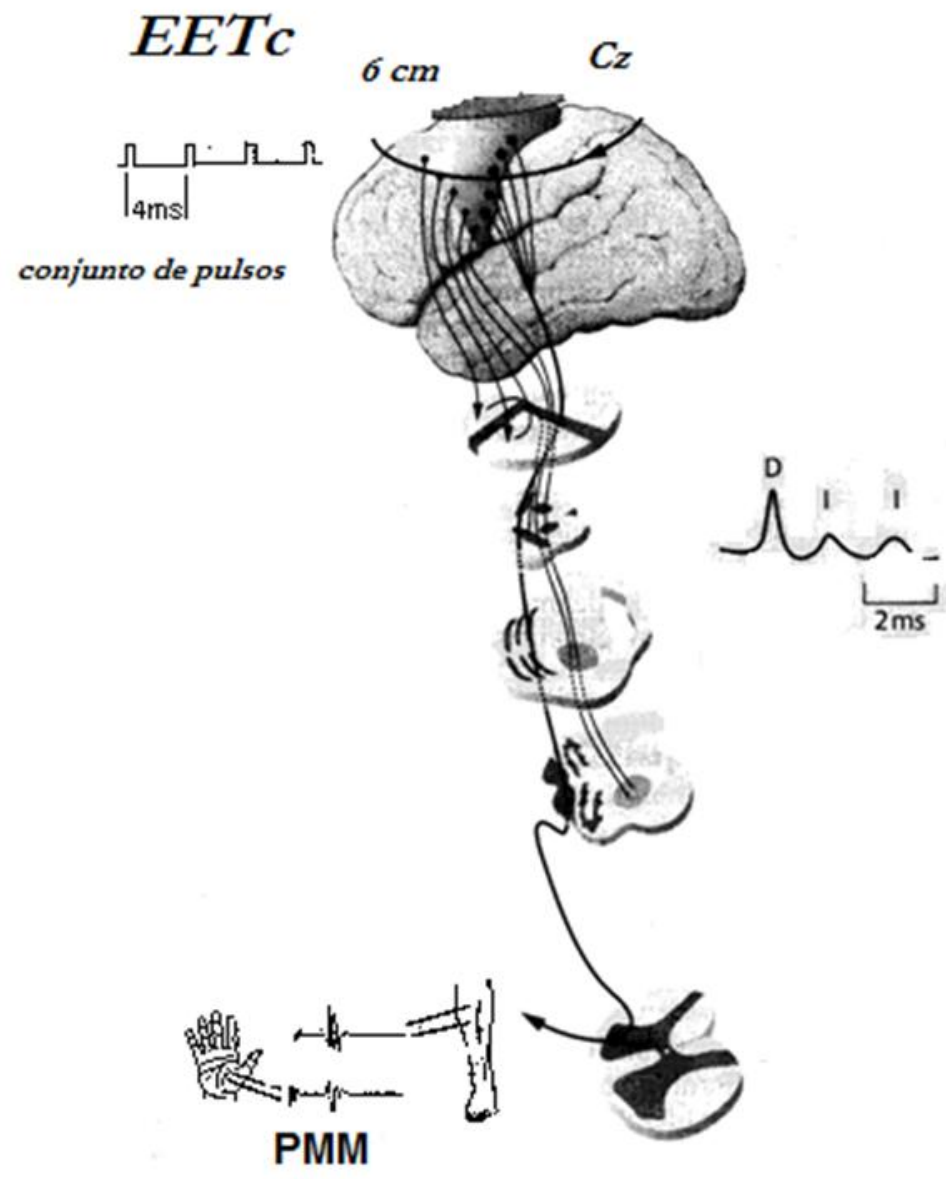

FONTE: Deletis et al. ${ }^{13}$. Desenho original do Dr. Vedran Deletis, reproduzido, traduzido e modificado com sua autorização.

NOTA: EETc com conjunto de 4 pulsos e trajeto descendente das ondas $D$ geradas ( 1 pulso $=1$ onda $\mathrm{D}$ ), resultando na despolarização sincronizadas dos $2^{\circ}$ motoneurônios e geração de PMM. 
Figura 6 - Intensidade do estímulo da EETc e via motora ativada

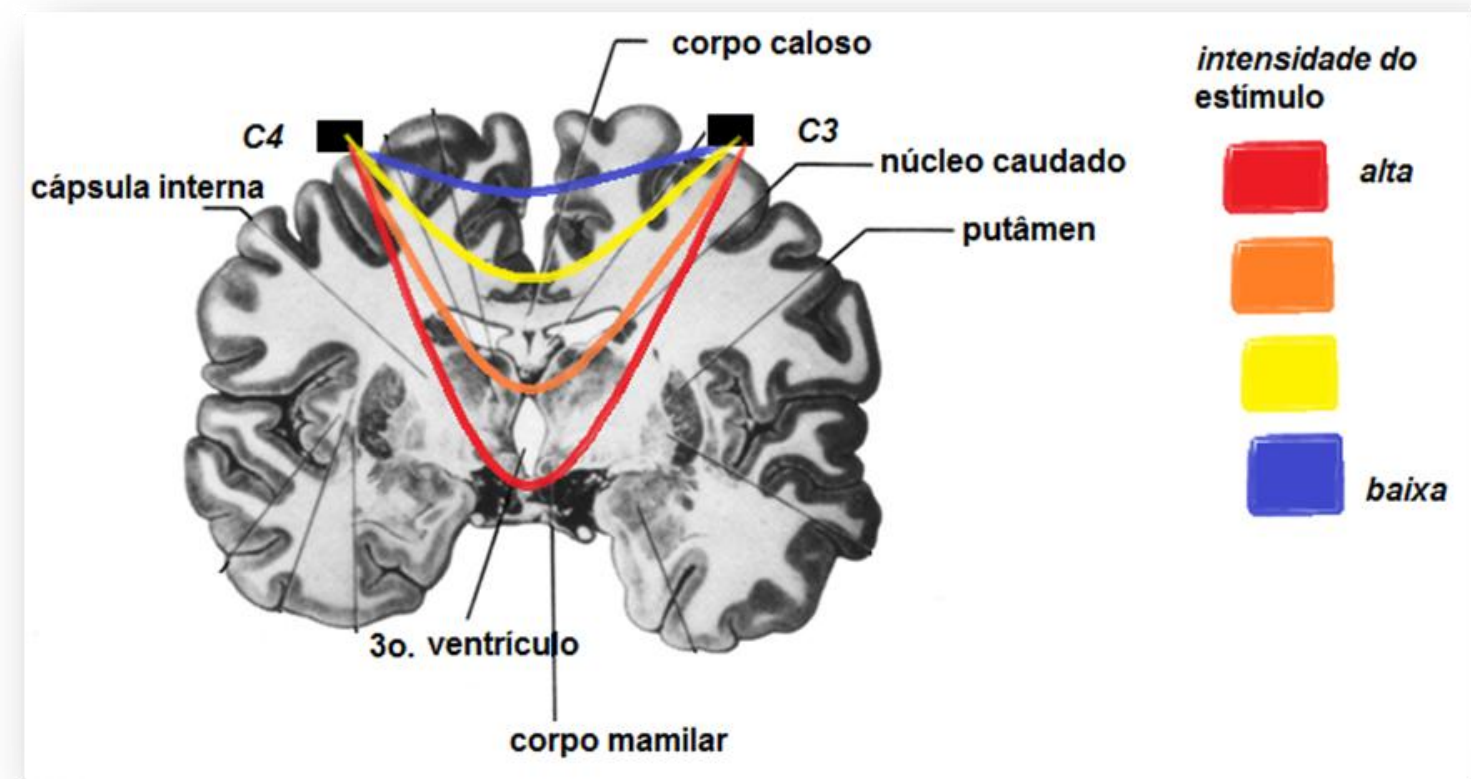

NOTA: Variação do local de ativação da via motora descendente de acordo com a intensidade do estímulo aplicado - quanto maior o estímulo, mais caudal será a ativação. 
Figura 7 - Indicação dos pontos utilizados para EETcCN sobre o homúnculo de Penfield

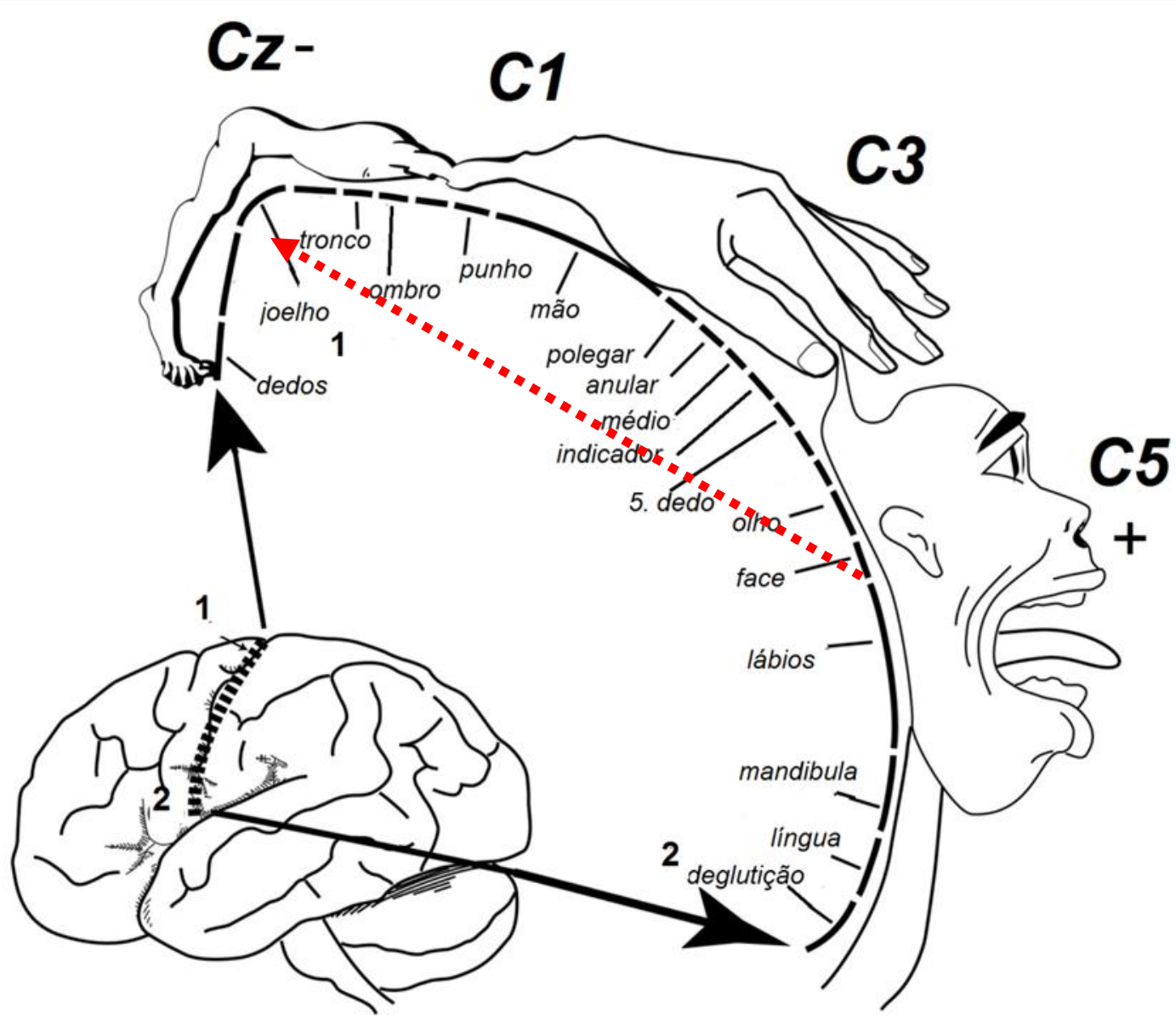

FONTE: http://www.psywww.com/intropsych/ch02_human_nervous_system/ homunculus.html. Acesso em: 20/01/2011.

NOTA: Modificada a partir do desenho original. Sentido da transmissão da corrente elétrica indicado pela seta tracejada vermelha. Com baixa intensidade de estímulo, apenas o anodo (C5+) é o estimulador, o que diminui a possibilidade de estímulo da porção extracraniana do nervo contralateral (que estará sob risco durante a cirurgia). 
Figura 8 - Marcação das latências do PMM dos nervos cranianos
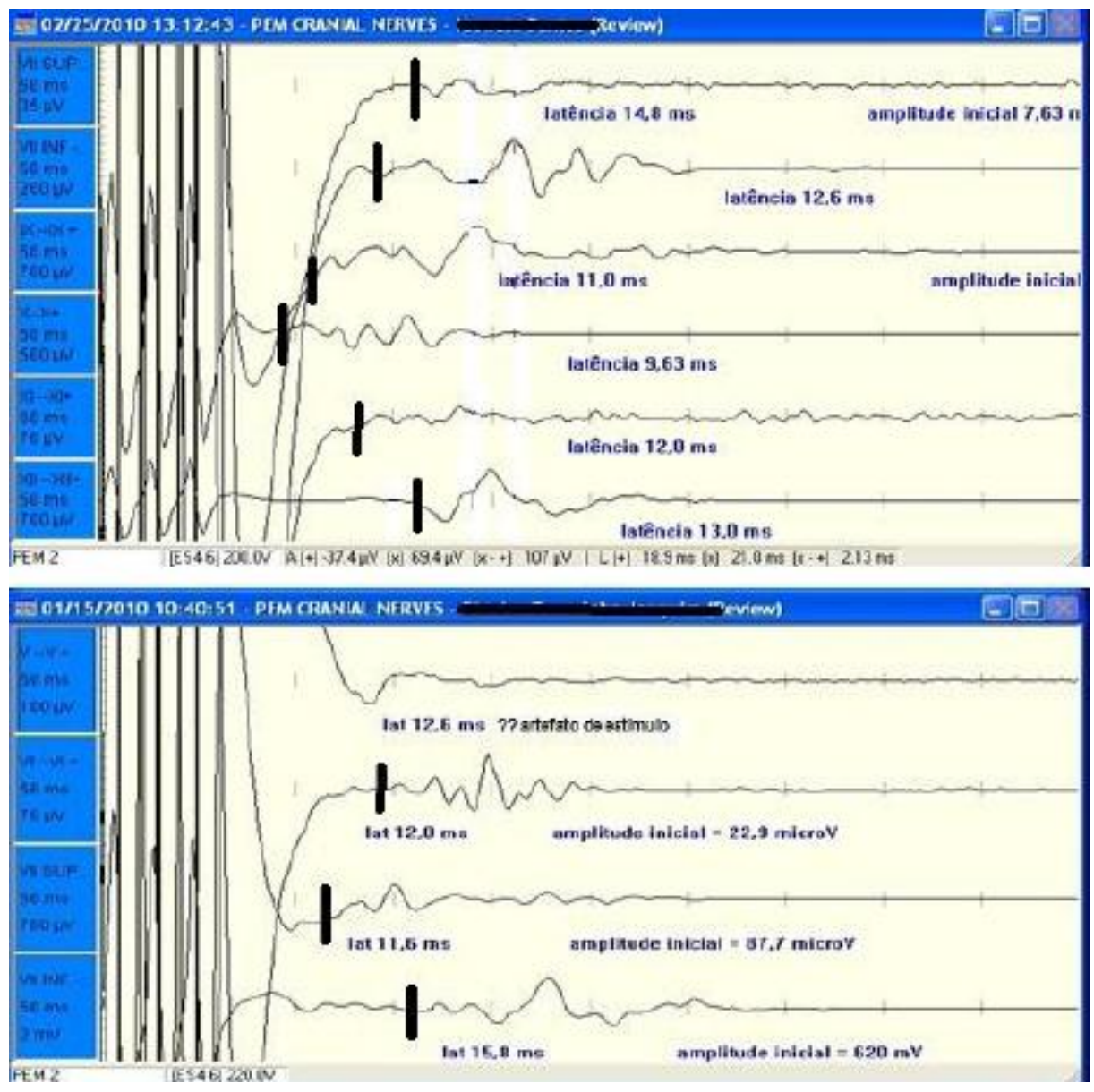

NOTA: Pacientes 15 e 16: apresentação dos PMM de nervos cranianos com as respectivas latências. 


\subsection{GRÁFICOS}

Gráfico 6 - Comparação do resultado estatístico entre Prell et al. e este estudo

\section{Comparação Grupo I com dados da literatura}

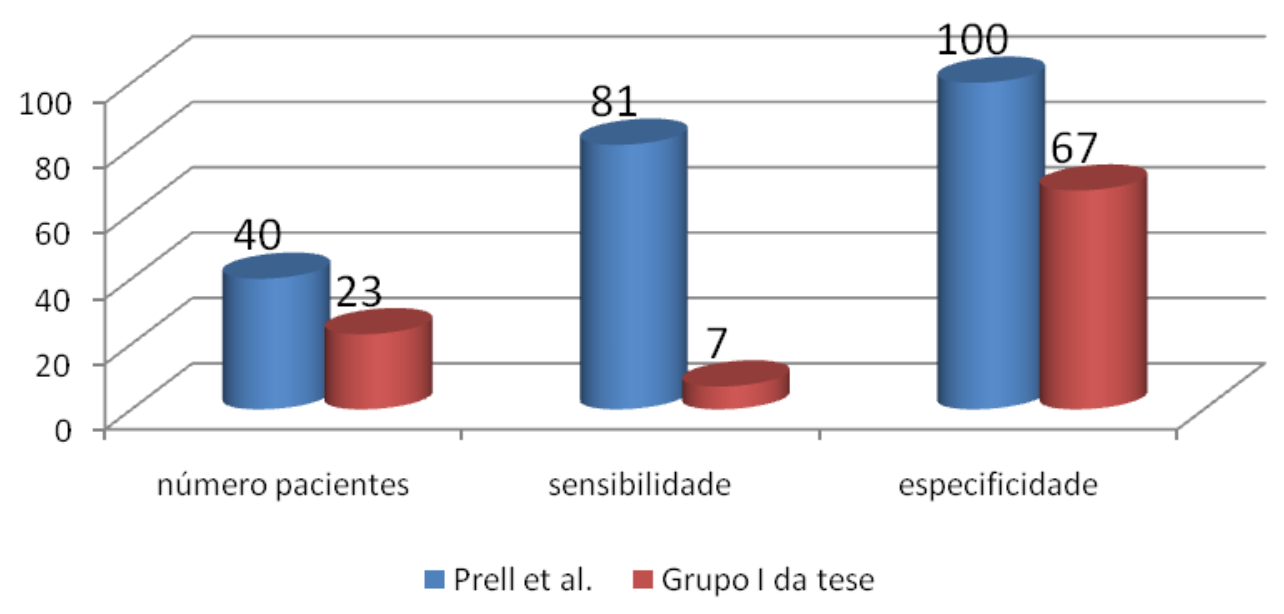

NOTA: Há uma grande diferença nos resultados de sensibilidade e especificidade. 


\subsection{APRESENTAÇÃO DE CASOS ILUSTRATIVOS}

\section{Apresentação de caso 1: Al e queda de amplitude PMM $7^{\circ}$ nervo}

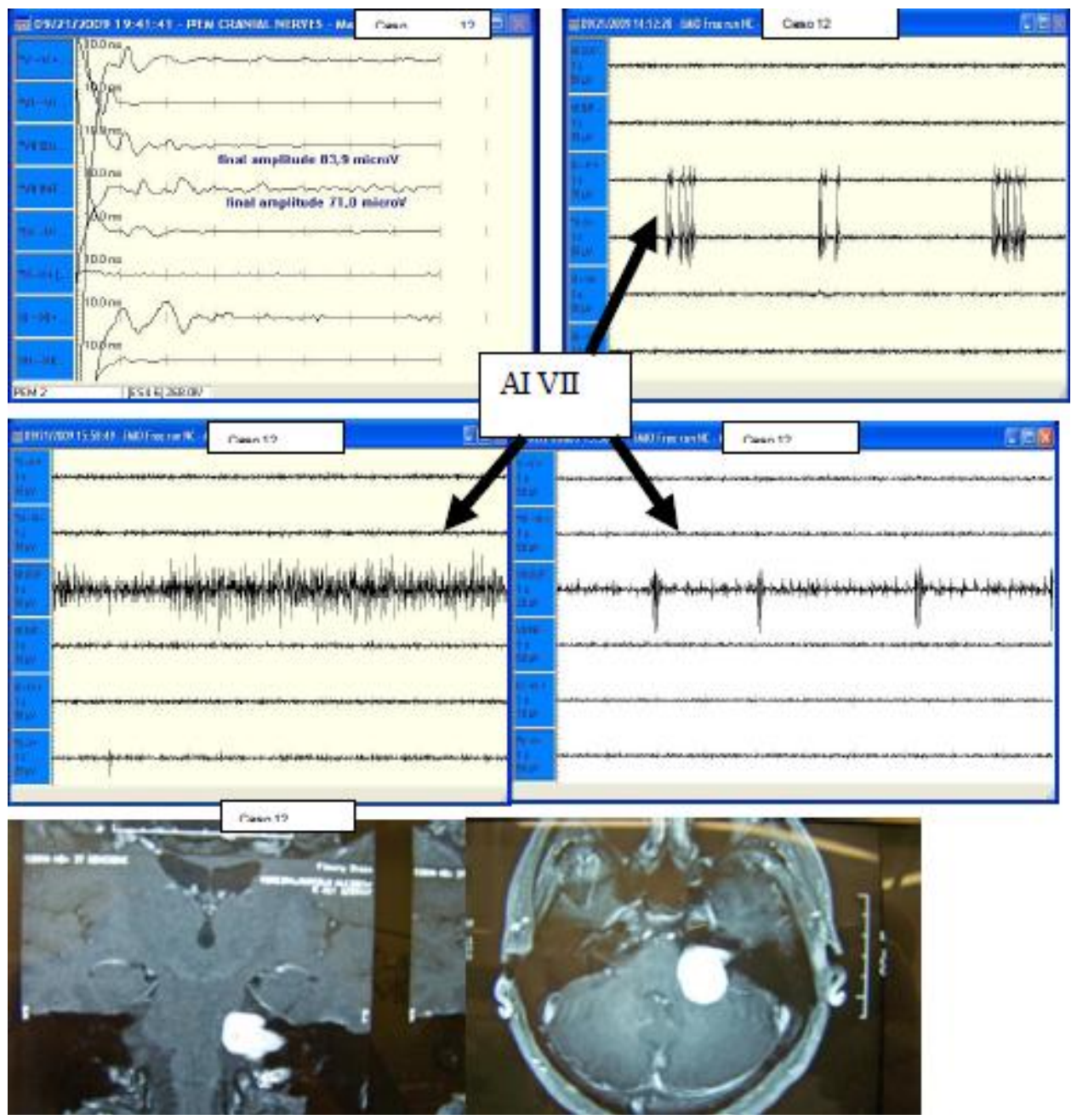

NOTA: Paciente 12: queda da amplitude do PMM $7^{\circ}$ nervo + AI de $7^{\circ}$, IX e X nervos. HB p.o. imediato 4. Notar a perda do PMM de $X$ nervo e a queda da amplitude PMM IX e XII. Paciente evoluiu com disfagia e disfonia, inalteradas após seis meses. 
Apresentação de caso 2: Posicionamento de eletrodos do paciente 15
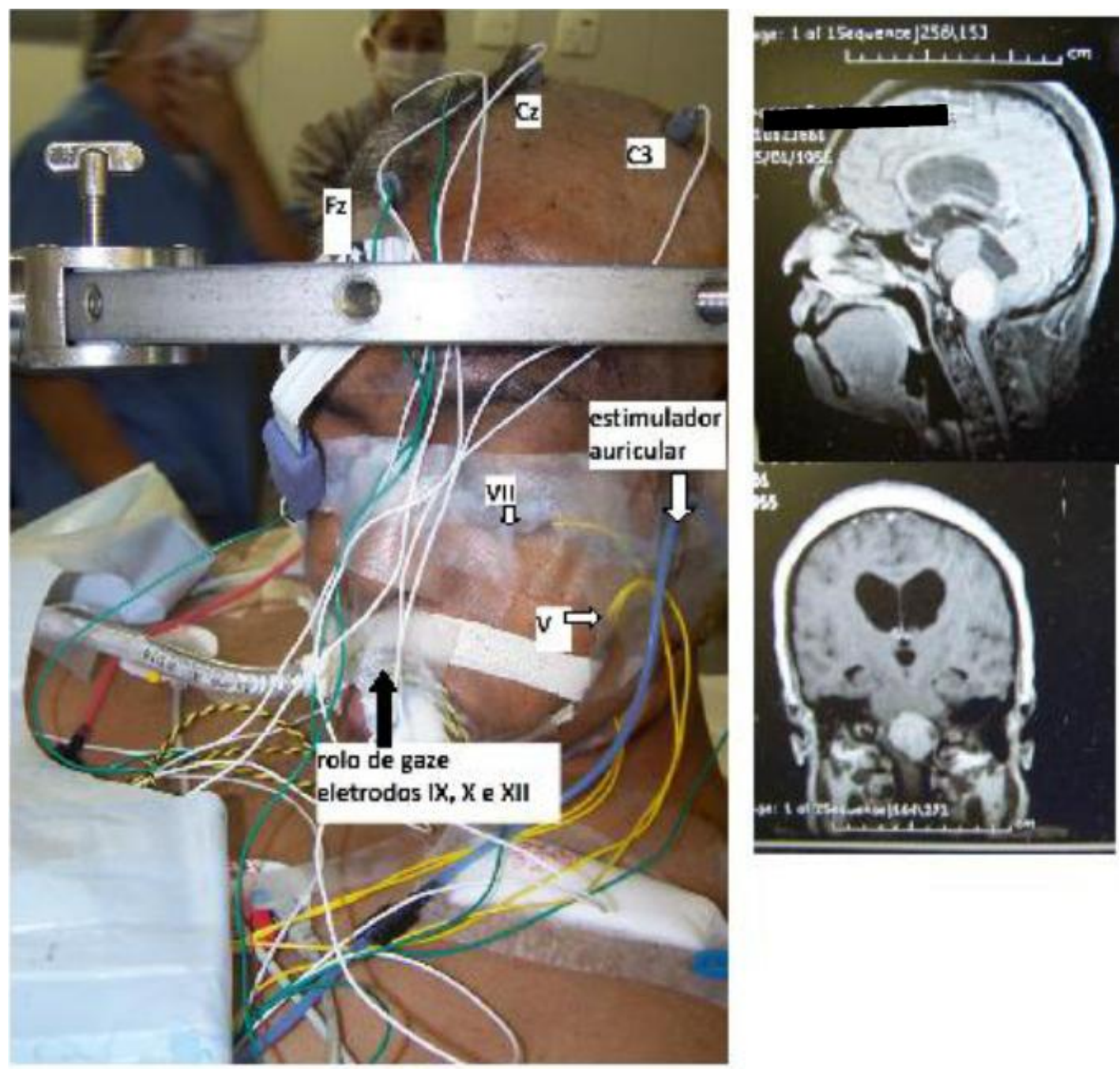

NOTA: Submetido a craniectomia retrossigmoidea em posição semissentada. Eletrodos tipo saca-rolhas para captação do PESS e referência no BERA e para estimulação EETC. Estimuladores intraauriculares para BERA e agulhamento pareado para músculos de inervação craniana dos nervos V-XII. Rolo de gaze na boca para impedir a mastigação da língua durante a EETc. 
Apresentação de Caso 3: Colocação de eletrodos - nervos cranianos III-VII
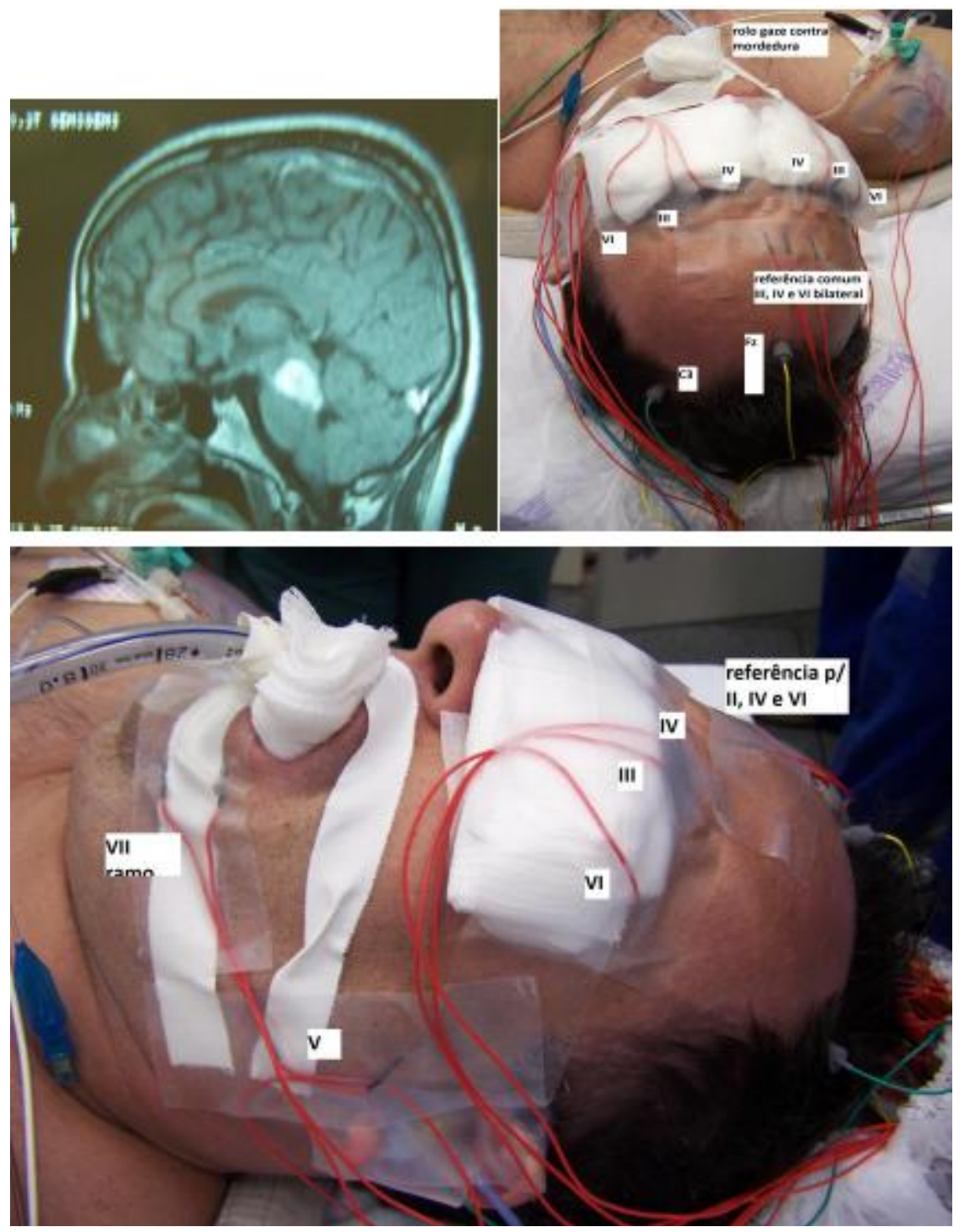

NOTA: paciente excluído da análise estatística por apresentar tumor intraaxial. Exemplificação de colocação de eletrodos em músculos de inervação pelos nervos cranianos III, IV e VI. 


\section{Apresentação de caso 4: Al e queda da amplitude PMM 7º nervo}

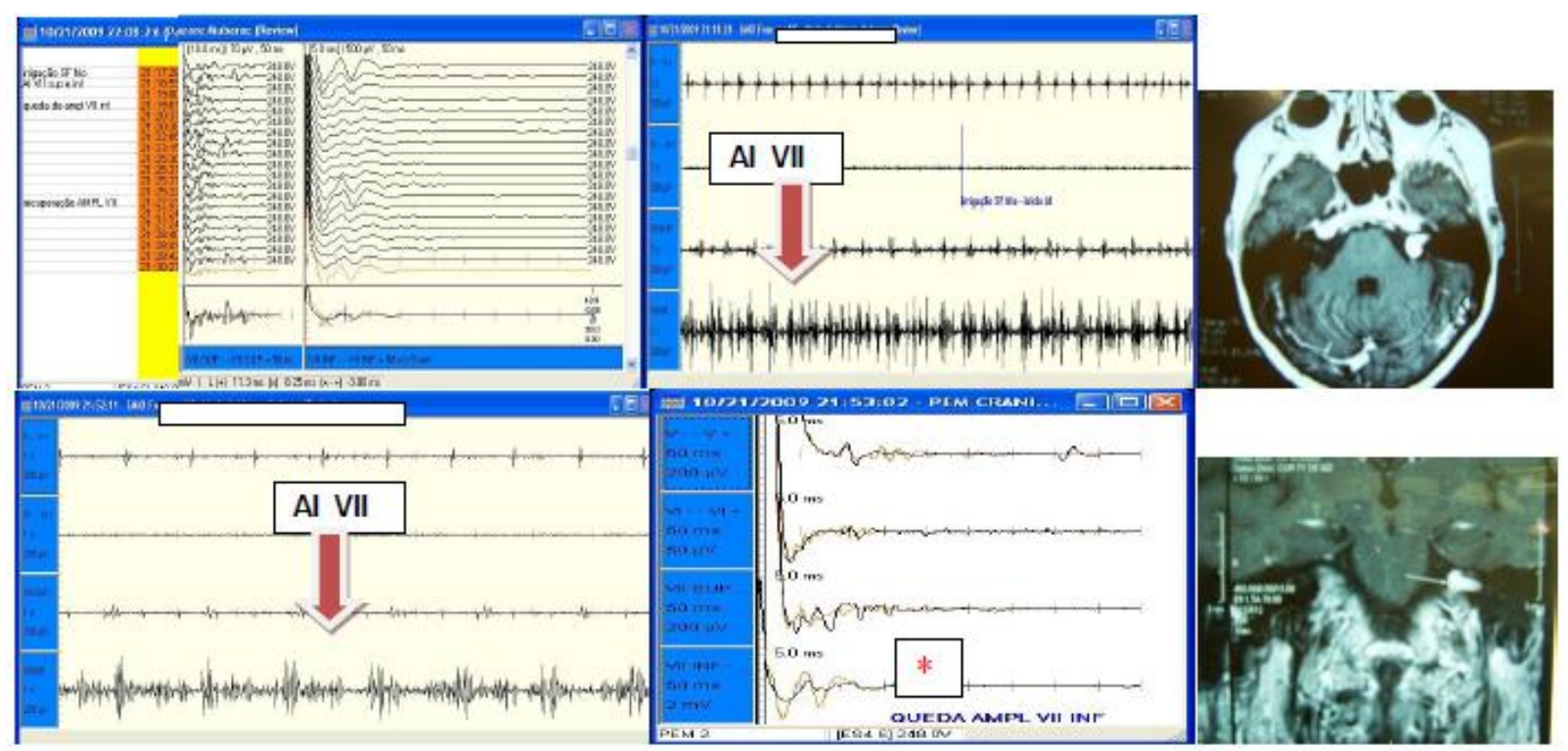

NOTA: Paciente 18: apesar da frequente e prolongada Al (51 minutos ininterruptos de orbicular dos lábios) e da queda da amplitude PMM $7^{\circ}$ nervo (54\% para ramo inferior), o paciente evoluiu sem déficit no p.o..

*Linha vermelha $=$ PMM basal/linha preta PMM às 21h53. Notar a diferença na amplitude do PMM, inicialmente do tamanho do tracejado vermelho e no final do tamanho da linha azul contínua. 


\subsection{TABELAS}

Tabela 1 - Índice de House-Brackmann de gradação funcional do nervo facial

\begin{tabular}{ll}
\hline Grau 1 & Normal \\
Grau2 & Paresia leve \\
Grau3 & Paresia moderada, com fechamento ocular total ao esforço \\
Grau 4 & Paresia moderada a severa, com fechamento ocular incompleto \\
Grau5 & Paresia acentuada, com movimentação facial discreta e assimetria \\
& facial em repouso \\
Grau6 & Paralisia completa \\
\hline
\end{tabular}

Tabela 2 - Agulhamento muscular para estudo via EETc

\begin{tabular}{ll}
\hline NERVO CRANIANO & MUSCULO \\
\hline III & reto superior \\
IV & oblíquo superior \\
V & masseter \\
VI & reto lateral \\
VII ramo zigomático ou superior & orbicular do olho \\
VII ramo mandibular ou inferior & orbicular dos lábios \\
IX & retrofaringe - atrás do palato mole \\
X & laringe acima das cordas vocais \\
XI & trapézio \\
XII & hemilíngua \\
\hline
\end{tabular}




\section{Tabela 3 - Dados clínicos, informações sobre o tumor e resultado funcional}

\begin{tabular}{|c|c|c|c|c|c|c|c|c|c|}
\hline PAC & $\begin{array}{l}\text { SEXO, } \\
\text { IDADE }\end{array}$ & $\begin{array}{l}\text { QUEXAS } \\
\text { CÍINICAS }\end{array}$ & DIAGNOSTICO & $\begin{array}{c}\text { DIAMETRO } \\
\text { MÁXIMO } \\
\text { TUMOR }\end{array}$ & $\begin{array}{l}\text { RESSEC- } \\
\text { ÇÃO }\end{array}$ & & $\begin{array}{l}\text { INDICE } \\
\text { DEHB }\end{array}$ & & $\begin{array}{l}\text { TEMPO } \\
\text { DE } \\
\text { SEGUI } \\
\text { MENTO }\end{array}$ \\
\hline & & & & $(\mathrm{cm})$ & & Inicial & Imediato & Final & \\
\hline 1 & $\mathrm{~m}, 41$ & $\begin{array}{c}\text { acusia, } \\
\text { hipoestesia face } \\
\text { e língua }\end{array}$ & Neurinoma D & 3,5 & total & 1 & 3 & 1 & $\begin{array}{c}\text { (Mleses) } \\
6\end{array}$ \\
\hline 2 & $\mathrm{f}, 32$ & $\begin{array}{l}\text { reoperação; } \\
\text { déficit V, VII , IX } \\
\text { e X, IXe X }\end{array}$ & Neurinoma $E$ & 5,5 & total & 2 & 5 & 5 & 16 \\
\hline 3 & f, 38 & $\begin{array}{l}\text { reoperação; } \\
\text { acusia }\end{array}$ & Neurinoma $E$ & 4,5 & total & 1 & 3 & 3 & 6 \\
\hline 4 & $\mathrm{f}, 43$ & $\begin{array}{l}\text { déficit de VII dir } \\
\text { e hipoestesia V }\end{array}$ & $\begin{array}{l}\text { Meningeoma } \\
\text { petroclival D }\end{array}$ & 5,5 & subtotal & 2 & 2 & 1 & 12 \\
\hline 5 & f, 53 & acusia & Neurinoma $\mathrm{E}$ & 4,5 & subtotal & 1 & 5 & 5 & 15 \\
\hline 6 & f, 26 & $\begin{array}{l}\text { hipoacusia, } \\
\text { zumbido }\end{array}$ & Neurinoma E & 6 & total & 1 & 3 & 1 & 6 \\
\hline 7 & f, 39 & hipoacusia & $\begin{array}{l}\text { Meningeoma } \\
\text { petrocival D }\end{array}$ & 5,5 & subtotal & 1 & 1 & 1 & 12 \\
\hline 8 & $\mathrm{~m}, 68$ & $\begin{array}{l}\text { vertigens, } \\
\text { acusia }\end{array}$ & Meningeoma & 3,5 & subtotal & 1 & 3 & 2 & 7 dias* \\
\hline 9 & $\mathrm{f}, 81$ & $\begin{array}{l}\text { hipoacusia, } \\
\text { ataxia }\end{array}$ & $\begin{array}{c}\text { Meningeoma } \\
\text { D }\end{array}$ & 3 & subtotal & 1 & 1 & 1 & 12 \\
\hline 10 & $\mathrm{f}, 3$ & zumbido & $\begin{array}{l}\text { Meningeoma } \\
\text { petroclival E }\end{array}$ & 3 & total & 1 & 1 & 1 & 12 \\
\hline 11 & f, 54 & zumbido & $\begin{array}{c}\text { Meningeoma } \\
\text { D }\end{array}$ & 3 & total & 1 & 1 & 1 & 12 \\
\hline 12 & $\mathrm{~m}, 42$ & hipoacusia & Neurinoma $E$ & 5 & subtotal & 1 & 3 & 3 & 6 \\
\hline 13 & $\mathrm{~m}, 49$ & $\begin{array}{c}\text { déficit deglutição } \\
\text { e fonação }\end{array}$ & Neurinoma D & 5 & total & 1 & 1 & 1 & 3 \\
\hline 14 & $\mathrm{~m}, 36$ & hipoacusia & Neurinoma $E$ & 3,5 & total & 1 & 4 & 2 & 2 \\
\hline 15 & $f, 55$ & $\begin{array}{c}\text { vômitos } \\
\text { vertigens, ataxia } \\
\text { há } 3 \text { anos }\end{array}$ & $\begin{array}{l}\text { Meningeoma } \\
\text { forâmen } \\
\text { magno E }\end{array}$ & 3 & total & 1 & 2 & 3 & $6^{* *}$ \\
\hline 16 & $\mathrm{f}, 45$ & acusia, vertigem & Neurinoma D & 4,5 & total & 1 & 2 & 4 & $7^{* * *}$ \\
\hline 17 & $f, 49$ & $\begin{array}{l}\text { zumbido, } \\
\text { vertigem, déficit } \\
\text { facial }\end{array}$ & Neurinoma $\mathrm{E}$ & 3 & total & 2 & 3 & 3 & 15 \\
\hline 18 & $\mathrm{f}, 72$ & hipoacusia & Meningeoma & 4 & total & 1 & 1 & 1 & 10 \\
\hline 19 & $\mathrm{~m}, 43$ & $\begin{array}{l}\text { hipoacusia, } \\
\text { vertigem }\end{array}$ & $\begin{array}{c}\text { Meningeoma } \\
\text { E }\end{array}$ & 3,5 & subtotal & 1 & 1 & 1 & 10 \\
\hline 20 & f, 32 & acusia & Neurinoma $\mathrm{E}$ & 4 & total & 1 & 1 & 1 & 2 \\
\hline 21 & $\mathrm{~m}, 57$ & déficit VII & Neurinoma E & 5 & subtotal & 1 & 2 & 1 & 6 \\
\hline 22 & $f, 39$ & vertigem & Meningeoma & 3 & total & 1 & 2 & 1 & 2 \\
\hline 23 & f, 39 & acusia & Neurinoma D & 4 & total & 1 & 3 & 2 & 4 \\
\hline
\end{tabular}


NOTA: * óbito no 7o. p.o. por AVCH ponte; ${ }^{* *} \mathrm{HB} 3$ pós-isquemia fosseta lateral de ponte no 3o. p.o. na UTI; ${ }^{* * *}$ HB 4 pós-sangramento no leito cirúrgico 3. p.o.. 
Tabela 4 - Integra dos dados neurofisiológicos relativos à EETcCN

\begin{tabular}{|c|c|c|c|c|c|c|c|c|}
\hline \multirow[t]{2}{*}{ PAC } & \multirow[t]{2}{*}{$\begin{array}{c}\text { NERVO } \\
\text { CRANIANO }\end{array}$} & \multicolumn{2}{|c|}{$\begin{array}{c}\text { AMPLITUDE } \\
(\mu \mathrm{V})\end{array}$} & \multirow{2}{*}{$\begin{array}{c}\text { LATENCIA } \\
\text { (m s) }\end{array}$} & \multicolumn{2}{|c|}{$\begin{array}{c}\text { INTENSIDADE } \\
(\text { Volts })\end{array}$} & $\mathrm{Al}$ & \multirow{2}{*}{$\begin{array}{c}\text { DURAÇAO DE } \\
\text { CADA EPISÓDIO } \\
\text { Em minutos } \\
\text { separada por "/" }\end{array}$} \\
\hline & & Inicial & Final & & Inicial & Final & $\begin{array}{l}\text { Episó- } \\
\text { dio }\end{array}$ & \\
\hline \multirow[t]{5}{*}{1} & V & 134 & 80,4 & $X$ & 228 & 252 & - & - \\
\hline & VI & 9,16 & 5,7 & $X$ & & & 1 & 3 \\
\hline & VIIs & 40,4 & 34,6 & 15,8 & & & - & - \\
\hline & VIII & 81,6 & 16,3 & 13 & & & - & - \\
\hline & VIII & 0 & 0 & - & & & - & - \\
\hline \multirow[t]{8}{*}{2} & V & 0 & 0 & - & 64 & 232 & - & - \\
\hline & VIII & 100 & 0 & 16,5 & & & - & - \\
\hline & VIIs & 0 & 0 & - & & & - & - \\
\hline & AUD & 0 & 0 & - & & & - & - \\
\hline & IX & 50,4 & 35,1 & $X$ & & & - & - \\
\hline & $X$ & 13,7 & 31,3 & $X$ & & & - & - \\
\hline & $X I$ & 20,6 & 23 & $x$ & & & - & - \\
\hline & XII & 38,1 & 40,4 & $X$ & & & - & - \\
\hline \multirow[t]{8}{*}{3} & VI & & & $X$ & 232 & 200 & 2 & $4 / 15$ \\
\hline & VII i & 440 & 160 & 10,2 & & & 3 & $6 / 5 / 9$ \\
\hline & VIIs & 730 & 190 & 10,7 & & & - & - \\
\hline & AUD & 0 & 0 & - & & & - & - \\
\hline & IX & 19 & 3 & $x$ & & & 2 & $1 / 4$ \\
\hline & $X$ & $\mathrm{~S} / \mathrm{ALT}$ & & $X$ & & & 2 & $1 / 15$ \\
\hline & $X I$ & $\mathrm{~S} / \mathrm{ALT}$ & & $X$ & & & 1 & 58 \\
\hline & XII & $S / A L T$ & & $x$ & & & - & - \\
\hline \multirow[t]{10}{*}{4} & III & 120 & 115 & $X$ & 248 & 400 & 1 & 68 \\
\hline & IV & 51 & 9,9 & $X$ & & & 1 & 30 \\
\hline & V & 51,9 & 15,3 & $x$ & & & 1 & 78 \\
\hline & VI & 73,2 & 21,4 & $X$ & & & 1 & 78 \\
\hline & VIIs & 86 & 228 & 10,9 & & & 1 & 78 \\
\hline & VIII & 50 & 47 & 12,3 & & & 1 & 96 \\
\hline & IX & 10,7 & 25,9 & $X$ & & & - & - \\
\hline & $x$ & 16 & 29,8 & $x$ & & & - & - \\
\hline & XI & 22,1 & 19,8 & $X$ & & & - & - \\
\hline & XII & 74 & 21 & $X$ & & & - & - \\
\hline \multirow[t]{2}{*}{5} & V & 320 & 0 & $x$ & 232 & 220 & - & - \\
\hline & VI & 320 & 0 & $X$ & & & - & - \\
\hline
\end{tabular}




\begin{tabular}{|c|c|c|c|c|c|c|c|c|}
\hline \multirow{17}{*}{6} & VIlls & 320 & 0 & 10,9 & & & - & - \\
\hline & VIII & 410 & 7,5 & 10,6 & & & - & - \\
\hline & IX & 230 & 110 & $x$ & & & - & - \\
\hline & $x$ & 170 & 210 & $x$ & & & & - \\
\hline & $X I$ & 160 & 48,8 & $x$ & & & 1 & 60 \\
\hline & XII & 110 & 51,1 & $x$ & & & 1 & 38 \\
\hline & III & 3,81 & 32,8 & $x$ & 268 & 268 & - & - \\
\hline & IV & 27,5 & 2,29 & $x$ & & & - & - \\
\hline & $\mathrm{V}$ & 109 & 59,5 & $x$ & & & 1 & 12 \\
\hline & VI & 95,4 & 9,9 & $x$ & & & - & - \\
\hline & VIIs & 500 & 291 & 11,9 & & & - & - \\
\hline & VIIi & 540 & 500 & 16,3 & & & - & - \\
\hline & VIII & 0 & 0 & - & & & - & - \\
\hline & IX & 32,8 & 16,8 & $x$ & & & - & - \\
\hline & $x$ & 0 & 3,8 & $x$ & & & - & - \\
\hline & $X I$ & 620 & 7,6 & $x$ & & & 1 & 48 \\
\hline & XII & 38,9 & 9,16 & $x$ & & & - & - \\
\hline \multirow[t]{5}{*}{7} & III & 2,75 & 7 & $x$ & 292 & 292 & - & - \\
\hline & IV & 4,5 & 10,1 & $x$ & & & - & - \\
\hline & V & 12,8 & 1,5 & $x$ & & & - & - \\
\hline & VI & 10,4 & 31,5 & $x$ & & & - & - \\
\hline & VIIs & 191 & 154,6 & 12,1 & & & - & - \\
\hline \multirow[t]{7}{*}{8} & VI & 27,5 & 0,76 & $x$ & 392 & 400 & - & - \\
\hline & VIIs & 137 & 13,7 & 13,3 & & & 1 & 2 \\
\hline & VIII & 126 & 93,8 & 12,1 & & & 1 & 2 \\
\hline & IX & 55,7 & 16 & $X$ & & & - & - \\
\hline & $x$ & 50,4 & 52,6 & $x$ & & & - & - \\
\hline & $X I$ & 34,3 & 0 & $x$ & & & - & - \\
\hline & XII & 14,7 & 36,3 & $x$ & & & - & - \\
\hline \multirow[t]{3}{*}{9} & V & 42 & 34,3 & $x$ & 88 & 148 & - & - \\
\hline & VIIs & 4,5 & 3,8 & 15,4 & & & - & - \\
\hline & VIIi & 71 & 149 & 12,5 & & & 2 & $3 / 8$ \\
\hline \multirow[t]{6}{*}{10} & III & 22,3 & 12,8 & $x$ & 400 & 400 & - & - \\
\hline & IV & 14 & 14,6 & $x$ & & & - & - \\
\hline & V & 3 & 0 & $x$ & & & - & - \\
\hline & VI & 7,3 & 19,8 & $x$ & & & - & - \\
\hline & VIIs & $\begin{array}{l}\text { perda } \\
\text { eletrodo }\end{array}$ & - & - & & & - & - \\
\hline & VIIi & 15 & 6,1 & 10 & & & - & - \\
\hline
\end{tabular}




\begin{tabular}{|c|c|c|c|c|c|c|c|c|}
\hline \multirow[t]{3}{*}{11} & $\mathrm{~V}$ & 135 & 71,7 & $\bar{X}$ & 296 & 296 & - & - \\
\hline & VIIs & 170 & 260 & 11 & & & 2 & $5 / 3$ \\
\hline & VIIi & 1260 & 850 & 10,6 & & & 2 & $2 / 5$ \\
\hline \multirow[t]{8}{*}{12} & V & 45,8 & 3 & $x$ & 220 & 264 & - & - \\
\hline & VI & 7 & 3 & $x$ & & & - & - \\
\hline & VIIs & 97,7 & 83,9 & 12,3 & & & 1 & 7 \\
\hline & VIli & 470 & 71,0 & 11,4 & & & - & - \\
\hline & IX & 58 & 2,2 & $x$ & & & 2 & $11 / 5$ \\
\hline & $x$ & 41,2 & 0 & $x$ & & & 5 & $45 / 5$ \\
\hline & $X I$ & & 6,8 & $x$ & & & - & - \\
\hline & XII & 908 & 6,1 & $x$ & & & - & - \\
\hline \multirow[t]{8}{*}{13} & V & 42,4 & 5,4 & $x$ & 242 & 242 & - & - \\
\hline & VI & 27,5 & 35,1 & $x$ & & & - & - \\
\hline & VIIi & 155 & 20,6 & 11,9 & & & 2 & $2 / 2$ \\
\hline & VIIs & $\begin{array}{l}\text { perda } \\
\text { eletrodo }\end{array}$ & - & - & & & - & - \\
\hline & IX & 0,76 & 3,81 & $x$ & & & 4 & $3 / 3 / 3 / 3$ \\
\hline & $x$ & 30,5 & 35,9 & $x$ & & & 2 & $5 / 5$ \\
\hline & $X I$ & 45,8 & 0 & $x$ & & & 1 & mais de 60 \\
\hline & XII & 43,5 & 42 & $x$ & & & 2 & $5 / 10$ \\
\hline \multirow[t]{4}{*}{14} & V & 176 & 152 & $x$ & 200 & 236 & - & - \\
\hline & VIIs & 510 & 350 & 10,3 & & & - & - \\
\hline & VIIi & 50 & 32 & 10,1 & & & 2 & $2 / 2$ \\
\hline & $x$ & 35,1 & 5,3 & $x$ & & & - & - \\
\hline \multirow[t]{6}{*}{15} & VIIs & 7,63 & 12,2 & 14,8 & 220 & 240 & - & - \\
\hline & VIIi & 64,9 & 13 & 12,6 & & & - & - \\
\hline & IX & 193 & 15,3 & $x$ & & & 1 & 2 \\
\hline & $x$ & 108 & 7,6 & $x$ & & & - & - \\
\hline & $X I$ & 6,87 & 48,1 & $x$ & & & - & - \\
\hline & XII & 279 & 143 & $x$ & & & - & - \\
\hline \multirow[t]{4}{*}{16} & V & 14,5 & 70 & $X$ & 220 & 340 & - & - \\
\hline & VI & 22,9 & 39,7 & $x$ & & & - & - \\
\hline & VIIs & 87,7 & 146 & 12 & & & 2 & $7 / 23$ \\
\hline & VIIi & 620 & 230 & 11,6 & & & 2 & $7 / 23$ \\
\hline \multirow[t]{5}{*}{17} & V & 1,5 & 25,3 & $x$ & 400 & 340 & - & - \\
\hline & VIIs & 4,5 & 3,8 & 10,4 & & & - & - \\
\hline & VIII & 7,6 & 0 & 10,9 & & & 2 & $32 / 1$ \\
\hline & IX & 8,4 & 24,4 & $x$ & & & - & - \\
\hline & $x$ & 16 & 45 & $x$ & & & 1 & 42 \\
\hline
\end{tabular}




\begin{tabular}{|c|c|c|c|c|c|c|c|c|}
\hline \multirow[b]{2}{*}{18} & XI & 3,8 & 0 & $\bar{X}$ & & & - & - \\
\hline & V & 21,4 & 36,6 & $x$ & 248 & 248 & - & - \\
\hline \multirow{7}{*}{19} & VI & 16,8 & 26,7 & $x$ & & & - & - \\
\hline & VIIs & 70,2 & 53,4 & 11,1 & & & - & - \\
\hline & VIIi & 100 & 46 & 12,3 & & & 1 & 51 \\
\hline & V & 107 & 16,8 & $X$ & 268 & 292 & - & - \\
\hline & VI & 32,8 & 13 & $x$ & & & - & - \\
\hline & VIIs & 16,8 & 43,5 & 13,8 & & & - & - \\
\hline & VIII & 18,3 & 35,9 & 129 & & & - & - \\
\hline \multirow{10}{*}{20} & IX & 6,1 & 13,7 & $X$ & & & - & - \\
\hline & $X$ & 0 & 6,8 & $X$ & & & - & - \\
\hline & XI & 2,29 & 7,6 & $x$ & & & - & - \\
\hline & XII & 113 & 43,5 & $x$ & & & - & - \\
\hline & V & 45,8 & 47,3 & $X$ & 232 & 232 & - & - \\
\hline & VI & 10,7 & 43.5 & $x$ & & & - & - \\
\hline & VIIs & 21,4 & 16,8 & 12,1 & & & - & - \\
\hline & VIII & 390 & 470 & 10,6 & & & - & - \\
\hline & IX & 8,3 & 13,7 & $X$ & & & - & - \\
\hline & $X$ & 3 & 4,6 & $x$ & & & - & - \\
\hline \multirow[t]{4}{*}{21} & V & 6,1 & 0 & $x$ & 200 & 200 & - & - \\
\hline & VI & 0 & 0 & $X$ & & & 1 & 33 \\
\hline & VIIs & 25,9 & 6,8 & 13,9 & & & 2 & 10 \\
\hline & VIII & 338,9 & 83,2 & 11 & & & 3 & 10 \\
\hline \multirow[t]{2}{*}{22} & VIIs & 37,4 & 15,3 & 10,4 & 216 & 272 & - & - \\
\hline & VIII & 17,5 & 50,4 & 11,1 & & & 1 & 14 \\
\hline \multirow[t]{9}{*}{23} & V & 47,3 & 21,4 & $X$ & 272 & 272 & - & - \\
\hline & VI & 2,3 & 0 & $x$ & & & - & - \\
\hline & VIIs & 3 & 0 & 11,1 & & & - & - \\
\hline & VIII & 144 & 72,5 & 11,8 & & & 4 & $3 / 31 / 17 / 4$ \\
\hline & VIII & 0 & 0 & - & & & - & - \\
\hline & IX & 61 & 58,7 & $x$ & & & - & - \\
\hline & $x$ & 61,8 & 22,9 & $x$ & & & - & - \\
\hline & $X I$ & 19 & 10,7 & $x$ & & & 2 & $110 / 20$ \\
\hline & XII & 390 & 4,5 & $x$ & & & - & - \\
\hline
\end{tabular}

NOTA: Dados exibidos por paciente, mostrando amplitude dos PMM dos nervos cranianos estudados, número de episódios de Al e duração de cada um deles e intensidade de estímulo da EETCCN. Em vermelho, destacados os dados relativos ao $7^{\circ}$ nervo - sendo VIls = seu ramo superior e VIli = seu ramo inferior. 
Tabela 8 - Classificação dos pacientes de acordo com a apresentação neurofisiológica do $7^{\circ}$ nervo

\begin{tabular}{|c|c|}
\hline GRUPO & CARACTERISTICA NEUROFISIOLOGICA \\
\hline$T$ & somente Al \\
\hline II a & queda da amplitude PMM do $7^{\circ}$ nervo entre $50-60 \%$ \\
\hline II b & $\begin{array}{l}\text { queda da amplitude PMM do } 7^{\circ} \text { nervo entre } 50-60 \% \text { associada } \\
\text { a Al }\end{array}$ \\
\hline III a & queda da amplitude PMM do $7^{\circ}$ nervo acima de $60 \%$ \\
\hline III b & $\begin{array}{l}\text { queda da amplitude PMM do } 7^{\circ} \text { nervo acima de } 60 \% \text { associada } \\
\text { a Al }\end{array}$ \\
\hline IV & sem alteração \\
\hline
\end{tabular}


Tabela 9 - Apresentação neurofisiológica por paciente e correlação com o índice de HB

\begin{tabular}{|c|c|c|c|}
\hline PAC & $\begin{array}{c}\text { APRESENTAÇÃO } \\
\text { NEUROFISIOLÓGICA }\end{array}$ & $\begin{array}{l}\text { ÍNDICE DE HB EM } \\
\text { QUANTOS GRAUS }\end{array}$ & \\
\hline 1 & Queda amplitude acima 60\% & piora em 3 & \\
\hline 2 & Queda amplitude acima $60 \%$ & piora em 2 & \\
\hline 3 & Queda amplitude acima $60 \%+\mathrm{Al}$ & piora em 2 & \\
\hline 4 & $\mathrm{Al}$ & sem piora & \\
\hline 5 & Queda amplitude acima $60 \%$ & piora em 4 & Grupo I \\
\hline 6 & Queda $50-60 \%$ & piora em 2 & Grupo Ila \\
\hline 7 & Inalterado & sem piora & Grupo Illb \\
\hline 8 & Queda amplitude acima $60 \%+\mathrm{Al}$ & piora em 2 & Grupo IIla \\
\hline 9 & $\mathrm{Al}$ & sem piora & Grupo IIIb \\
\hline 10 & Queda $50-60 \%$ & sem piora & Grupo IV \\
\hline 11 & $\mathrm{Al}$ & sem piora & \\
\hline 12 & Al + Queda amplitude acima $60 \%$ & piora em 2 & \\
\hline 13 & $\mathrm{Al}+$ Queda amplitude acima $60 \%$ & sem piora & \\
\hline 14 & $\mathrm{Al}$ & piora em 3 & \\
\hline 15 & Queda amplitude acima 60\% & piora em 1 & \\
\hline 16 & Queda amplitude acima $60 \%+\mathrm{Al}$ & piora em 1 & \\
\hline 17 & Queda amplitude acima $60 \%+\mathrm{Al}$ & piora em 2 & \\
\hline 18 & queda amplitude $50-60 \%+\mathrm{Al}$ & sem piora & \\
\hline 19 & Inalterado & sem piora & \\
\hline 20 & Inalterado & sem piora & \\
\hline 21 & Queda amplitude acima 60\%+ Al & piora em 2 & \\
\hline 22 & Queda amplitude 50- 60\% + Al & piora em 1 & \\
\hline 23 & Queda amplitude acima $60 \%+\mathrm{Al}$ & piora em 2 & \\
\hline
\end{tabular}




\section{Tabela 16 - Revisão da literatura em relação à montagem da EETc e sua eficácia e apresentação dos resultados de sensibilidade e especificidade para diferentes critérios de avaliação do PMM.}

\begin{tabular}{|c|c|c|c|c|c|}
\hline & Akagami et al. ${ }^{10}$ & Dong et al. ${ }^{57}$ & Acioly et al. ${ }^{54}$ & Zhou et al. ${ }^{75}$ & Krammer et al. ${ }^{71}$ \\
\hline ano publicação & 2005 & 2005 & 2010 & 2001 & 2009 \\
\hline numero pacientes & 71 & 76 & 60 & 50 & 94 \\
\hline população & Tu APC intra/extra-axial & Tu APC intra/extra-axial & Tu APC intra/extra-axial & $\begin{array}{c}\text { Tu supra e } \\
\text { infratentoriais }\end{array}$ & $\begin{array}{c}\text { Tu medulares e supra e } \\
\text { infratent oriais }\end{array}$ \\
\hline montagem EETc & $\mathrm{C} 3(+)-\mathrm{Cz}(-) / \mathrm{C} 4(+)-\mathrm{Cz}(-)$ & $\mathrm{C} 3(+)-\mathrm{Cz}(-) / \mathrm{C} 4(+)-\mathrm{Cz}(-)$ & $\mathrm{C} 3(+)-\mathrm{Cz}(-) / \mathrm{C} 4(+)-\mathrm{Cz}(-)$ & $\begin{array}{c}\mathrm{C} 3(+)-\mathrm{C} 4(-) / \mathrm{C} 4(+)- \\
\text { C3(-) } \\
\text { músculos inerv } 7^{\circ}\end{array}$ & $\begin{array}{c}{[\mathrm{C} 3(+)-\mathrm{C} 4(-) / \mathrm{C} 4(+)-\mathrm{C} 3(-)] \mathrm{e}} \\
\mathrm{Cz}-\mathrm{Fz}\end{array}$ \\
\hline captação & músculos inerv $7^{\circ}$ nervo & músculos inerv $7^{\circ}$ nervo & músculos inerv $7^{\circ}$ nervo & nervo & Extremidades \\
\hline \% eficácia montagem & $100 \%$ & $92,10 \%$ & $85-86,7 \%$ & $96 \%$ & 90-98\% (medular-craniana) \\
\hline critério de alarme 1 & queda $\geq 50 \%$ ampl PMM & queda $\geq 50 \%$ ampl PMM & queda $\geq 20 \%$ ampl PMM & $\begin{aligned} & \text { queda } \geq 50 \% \text { ampl } \\
& \text { PMM }\end{aligned}$ & queda $\geq 50 \%$ ampl PMM \\
\hline sensibilidade & $90 \%$ & $100 \%$ & $66,7(\mathrm{OO})-53,5 \%(\mathrm{OL})$ & $100 \%$ & $83-100 \%$ (medular-craniana) \\
\hline especificidade & $89 \%$ & $88 \%$ & $71,8(\mathrm{OO})-69,2 \%(\mathrm{OL})$ & Não informada & $68-42 \%$ (medular-craniana) \\
\hline critério de alarme 2 & $x$ & queda $\geq 65 \%$ ampl PMM & queda $\geq 50 \%$ ampl PMM & $X$ & $\begin{array}{c}\text { queda } \geq 50 \% \text { ampl PMM e } \uparrow \\
\text { intens EETc }>20 \%\end{array}$ \\
\hline sensibilidade & $X$ & $91 \%$ & $41,7(\mathrm{OO})-53,8 \%(\mathrm{OL})$ & $x$ & $83-100 \%$ (medular-craniana) \\
\hline especificidade & $X$ & $97 \%$ & $92,3(\mathrm{OO})-89,7 \%(\mathrm{OL})$ & $\mathrm{X}$ & $86-62 \%$ (medular-craniana) \\
\hline critério de alarme 3 & $x$ & queda $\geq 100 \%$ ampl PMM & queda $\geq 65 \%$ ampl PMM & $x$ & queda $\geq 100 \%$ ampl PMM \\
\hline sensibilidade & $x$ & $64 \%$ & $25(\mathrm{OO})-53,8 \%(\mathrm{OL})$ & $x$ & $67-89 \%$ (medular-craniana) \\
\hline especificidade & $x$ & $100 \%$ & $92,3(\mathrm{OO})-100 \%(\mathrm{OL})$ & $\mathrm{X}$ & $95-87 \%$ (medular-craniana) \\
\hline
\end{tabular}

NOTA: Acioly et al. encontraram estatísticas diferentes de acordo com o músculo em que houve a captação do PMM: OO = orbicular do olho/ OL = orbicular dos lábios. Para Krammer et al., mostramos as estatísticas referentes às cirurgias medulares e cranianas, respectivamente. Em todos os trabalhos acima citados, o regime anestésico compreendia a aplicação endovenosa contínua de propofol e remyfentanyl - não houve uso de bloqueadores da junção mioneural após entubação ou de agentes inalatórios. Intens = intensidade. 


\section{REFERÊNCIAS}

1 Nadeau DP, Sataloff RT. Fascicle Preservation Surgery for Facial Nerve Neuromas Involving the Posterior Cranial Fossa. Otol Neurotol 2003;24: 317-25.

2 Barbosa-Coutinho LM, Hilbig A. Patologia dos Meningiomas. In.: Meningiomas - Diagnóstico e Tratamento Clínico e Cirúrgico - Aspectos Atuais. São Paulo: Revinter, 2006. Cap 3, p.17-25.

3 Bento RF. Neurinoma do Acústico. [Citado em 12 mar 2011]. Disponível em: http://www.neurinoma.com.br/neurinoma.html\#1.

4 Mauldaun MVC, Aguiar PHP. Patologia dos Meningiomas. In: Meningiomas - Diagnóstico e Tratamento Clínico e Cirúrgico - Aspectos Atuais. São Paulo: Revinter, 2006. Cap 14, p. 88-90.

5 Duffau H, Lopes M, Arthuis F, Bitar A, Sichez J, Van Effenterre R, Cappele L. Contribution of intraoperative electrical stimulation in surgery of low grade gliomas: a comparative study between two series without (1985-96) and with (1996-2003) functional mapping in the same institution. $J$ Neurol Neurosurg Psychiatry 2005;76:845-851.

6 Kanno T. Kiya N, Karagiozov K, Agrawal A, Kumar S, Kato Y, Sano H. Meningiomas In.: Surgical Techniques in Brian Tumor Surgery. $2^{\text {nd }}$ Ed., Tokyo: Neuron Publishing Co., 2007. Cap 1, p 3-20.

7 Samii M, Matthies C. Management of 1000 Vestibular Schwannomas (Acoustic Neuromas): Surgical Management and Results with an Emphasis on Complications and How to Avoid Them. Neurosurgery 40 (1): 1997. Interactive Article: [citado em 02 fev 2011]. Disponível em: http://www.c3.hu/ mavideg/ns/samii1-97.html.

8 Ramina R, Neto MC, Fernandes YB, Bordignon KC. Meningiomas petroclivais - Diagnóstico, Tratamento e Resultados. In.: Meningiomas Diagnóstico e Tratamento Clínico e Cirúrgico - Aspectos Atuais. São Paulo: Revinter, 2006. Cap 25, p.174-184.

9 Gerganov VM, Klinge GPM, Nouri M, Stieglitz L, Samii M, Samii A, Prognostic clinical and radiological parameters for immediate facial nerve function following vestibular schwannoma surgery. Acta Neurochir 2009; 151:581-87. 
10 Akagami R, Dong CCJ, Westerberg BD. Localized Transcranial Electrical Motor Evoked Potentials for Monitoring Cranial Nerves in Cranial Base Surgery. Neurosurgery [ONS Suppl 1]2005;57:78-85.

11 Camargo AB, Deletis V. Monitoração Neurofisiológica Intraoperatória. In: Neurologia Oncológica Pediátrica: Manejo Multidisciplinar das Neoplasias do Sistema Nervoso Central da Infância. São Paulo: Lemar, 2003. Cap 12, p.129-50.

12 Deletis, V. Intraoperative Neurophysiology And Methodologies Used To Monitor The Functional Integrity Of The Motor System. In: Neurophysiology in Neurosurgery. San Diego: Elsevier, 2002. Cap. 2, p. 25-49.

13 MacDonald DB. Intraoperative Motor Evoked Potentials Monitoring: Overview and Update. J Clin Monit Computing 2006; 20(5):347-77.

14 Sherman JD, Dagnew E, Pensak ML, Van Loverren HR, Tew JM. Facial nerve neuromas: report of 10 cases and Review of the Literature. Neurosurg 2002;50(3):450-55.

15 Brackmann DE, Kwartler JA. A review of acoustic tumors: 1983-1988. Am J Otol 1990;11(3):216-32.

16 Gjuric, M, Rudic M. What is the Best Tumor Size to Achieve Optimal Functional Results in Vestibular Schwannoma Surgery? Skull Base 2008; 18(5):317-25.

17 Brackmann DE. A review of acoustic tumors: 1979-1982. Am J Otol 1984;5 (3):233-44.

18 Deletis V. What does intraoperative monitoring of motor evoked potentials bring to the neurosurgeon? Acta Neurochir (Wien) 2005;147:1015-7

19 Deletis V, Sala F. Neurophysiologic evaluation. Phys Med Rehab 1990; 4(3):421-32.

20 Morota N, Ihara S, Deletis V. Intraoperative neurophysiology for surgery in and around the brainstem: role of brainstem mapping and corticobulbar tract motor-evoked potential monitoring. Childs Nerv Syst 2010;26:51321.

21 Duffau H, Capelle L, Sichez J, Faillot T, Abdennour L, Law Koune JD, Dadoun S, Bitar A, Arthuis F, Van Effenterre R, Fohanno D. Intraoperative 
direct electrical stimulations of the central nervous system: the Salpêtrière experience with 60 patients. Acta Neurochir (Wien) 1999;141:1157-67.

22 Dickins JRE Graham SS. A Comparison of Facial nerve Monitoring Systems in Cerebellopontine Angle Surgery. Am J Otol 1991;12(1):1-6.

23 Grill J, Pascal C, Chantal K. Childhood Ependimoma. A Systematic Review of treatment Options and Strategies. Pediatr Drugs 2003;5(8): 533-43.

24 Sala F, Manganotti P, Tramontano V, ABricolo A, Gerosa M. Monitoring of motor pathways during brain stem surgery: What we have achieved and what we still miss? Clin Neurophysiol 2007 37:399-406.

25 Deletis V., Sala F. Intraoperative neurophysiological monitoring of the spinal cord during spinal cord and spine surgery: A review focus on the corticospinal tracts. Clin Neurophysiol 2008;119:248-64.

26 Guerit J. Neuromonitoring in the operating room: why, when, and how to monitor? Electroencephalography and Clinical Neurophysiology 1998; 106:1-21.

27 Morota N, Deletis V, Constantini S, Kofler M, Cohen H, Epstein FJ. The Role of motor evoked potentials during surgery for intramedullary spinal cord tumors. Neurosurg 1997;41(6):1327-36.

28 Fujiki M, Furukawa $\mathrm{Y}$, Kamida T, Anan M, Inoue R, Abe T, Kobayashi H. Intraoperative corticomuscular motor evoked potentials for evaluation of motor function: a comparison with corticospinal D and I waves. J Neurosurg 2006;104(1):85-92.

29 Neuloh G, Bogucki J, Schramm J. Intraoperative preservation of corticospinal function in the brainstem. J Neurol Neurosurg Psychiatry 2009;80:417-22.

30 Neuloh G, Pechstein U, Cedzich C, Schramm J. Motor Evoked Potential monitoring with supratentorial surgery. Neurosurg 2004;54:1061-72.

31 Penfield, W, Boldrey, E. Somatic motor and sensory representation in the cerebral cortex of man as studied by electrical stimulation. Brain 1937;60: 389-443.

32 James ML, Husain AM. Brainstem auditory evoked potential monitoring. When is change in wave V significant? Neurology 2005;65:1551-5. 
33 Legatt $A D$. Mechanisms of intraoperative brainstem auditory evoked potential changes. J Clin Neurophysiol 2002;19(5):396-408.

34 Loiselle DL, Nuwer MR. When should we warn the surgeon? Diagnosisbased warning criteria for BAEP monitoring . Neurology 2005;65:1522-3.

35 Moller AR. Neurophysiology Monitoring. In: Cranial Base Surgery. $2^{\text {nd }}$ Ed., London: Churchill Livingstone, 2000. Cap 5, p.79-99.

36 Prell J, Stefan R, Romstöck J, Fahlbusch R, Strauss C. Train time as a quantitative electromyographic parameter for facial nerve function in patients undergoing surgery for vestibular schwannoma. J Neurosurg 2007;106:826-32.

37 Lin VYW, Houlden D, Bethune A, Nolan M, Pirouzmand F, Rowed D, Nedzelski JM, Chen JM. A Novel Method in Predicting Immediate Postoperative Facial Nerve Function Post Acoustic Neuroma Excision. Otol Neurotol 2006;27:1017-22.

38 Matthies C, Samii M. Management of Vestibular Schwannomas (Acoustic Neuromas): The Value of Neurophysiology for Evaluation and Prediction of Auditory Function in 420 Cases [Clinical Studies]. Neurosurgery 1997; 40(5):919-30.

39 Romstöck J, Strauss C, Fahlbusch R. Continuous electromyography monitoring of motor cranial nerves during cerebellopontine angle surgery. J Neurosurg 2000;93:586-93.

40 Sven G, Pechstein U, Vougioukas VI, Velthoven VV. Monitoring motor function during resection of tumours in the lower brain stem and fourth ventricle. Childs Nerv Syst 2006;22:1288-95.

41 Ciric I, Zhao J, Rosenblatt S, Wiet R, O'Saughnessy B. Suboccipital retrosigmoid approach for removal of vestibular schwannomas: facial nerve function and hearing preservation. Neurosurgery 2005;56:560-70.

42 Strauss C, Prell J, Rampp S, Romstöck J. Split facial nerve course in vestibular schwannoma. J Neurosurg 2006;105(5):698-705.

43 Sala F. Intraoperative neurophysiology is here to stay. Childs Nerv Syst 2010;26:413-7.

44 Axon PR, Ramsden RT. Facial nerve injury caused by vestibular schwannoma compression: severity and adaptation to maintain normal clinical facial function. Am J Otol 1999;20(6):763-9. 
45 Isaacson B, Kileny PR, El-Kashlan HK. Prediction of Long-Term Facial Nerve Outcomes with Intraoperative Nerve Monitoring. Otol Neurotol 2005;26:270-3.

46 Cueva RA, Morris GF, Prioleau GR. Direct Cochlear Nerve Monitoring: First Report on a new atraumatic, self-retaining electrode. Am J Otol 1998;19:202-7.

47 Chiappa KH. Short Latency Somatossensory Evoked Potentials: Interpretation. In: Evoked Potentials in Clinical Medicine. $3^{\text {rd }}$ Ed., Philadelphia: Lippincott-Raven Publishers, 1997. Cap. 9, p. 341-401.

48 Merton PA, Hill DK, Marsden CD, Morton HB. Scope of a technique for electrical stimulation of human brain, spinal cord and muscle. Lancet 1982;ii: 597-8.

49 Sutter M, Eggspuehler A, Grob D, Jeszenszky D, Benini A, Porchet F, Mueller A, Dvorak J. The diagnostic value of multimodal intraoperative monitoring (MNIO) during spine surgery: a prospective study of 1,017 patients. J Eur Spine 2007;16(Suppl 2):S162-70.

50 MacDonald DB. Safety of Intraoperative Transcranial Electrical Stimulation Motor Evoked Potential Monitoring. J Clin Neurophysiol 2002;19(5):41629.

51 Shirazi MA, Leonetti JP, Marzo SJ, Anderson DE. Surgical management of facial neuromas: lessons learned. Otol Neurotol 2007;28: 958-63.

52 Youssef SA, Downes AE. Intraoperative neurophysiological monitoring in vestibular schwannoma surgery: advances and clinical implications. Neurosurg Focus 2009;27(4):E9.

53 Klem GH, Lüders HO, Jasper HH, Elger C. The ten-twenty electrode system of the international federation. In: Deuschl G, Eisen A (eds.). Recommendations for the Practice of Clinical Neurophysiology: Guidelines of the International Federation of Clinical Physiology (EEG Suppl. 52). Philadelphia: Elsevier, 1999:3-6.

54 Acioly MA, Liebsch M, Carvalho $\mathrm{CH}$, Gharabaghi A, Tatagiba M. Transcranial electrocortical stimulation to monitor the facial nerve motor function during cerebellopontine angle surgery. Neurosurgery [ONS Suppl 2]: 2010;66:354-62. 
55 Deletis V, Fernandez-Conejero I, Ulkatan S, Costantino P. Methodology for intraoperatively eliciting motor evoked potentials in the vocal muscles by electrical stimulation of the corticobulbar tract. Clin Neurophysiol 2009;120:336-41.

56 Szelenyi A, Kothbauer KF, Deletis V. Transcranial electric stimulation for intraoperative motor evoked potential monitoring: Stimulation parameters and electrode montages. Clin Neurophysiol 2007;118:1586-95.

57 Dong CC, MacDonald DB, Akagami R, Westerberg B, AlKhani A, Kanaan I, Hassounah M. Intraoperative facial motor evoked potential monitoring with transcranial electrical stimulation during skull base surgery. Clin Neurophysiol 2005;116:588-96.

58 MacDonald DB. Intraoperative Facial Motor Evoked Potentials? J. Neurosurg 2007;106:517-20.

59 Deletis V, Sala F. The Role of Intraoperative Neurophysiology in the Protection or Documentation of Surgically Induced Injury to the Spinal Cord [Neuroprotective Agents: Fifth International Conferencea: Part IV. Neuroprotection in Neurosurgery]. Annals of the New York Academy of Sciences 2001,939:137-44.

60 Henry H., Zhou HH., Kelly PJ. Transcranial Electrical Motor Evoked Potential Monitoring for Brain Tumor Resection. Neurosurgery 2001;48 (5):1075-81.

61 Calancie B, Molano MR. Alarm Criteria for Motor-Evoked Potentials: What's Wrong With the "Presence-or-Absence" Approach. Spine 2008;33 (4):406-14.

62 House WF, Brackmann DE. Facial Nerve Grading System. Neck Surg 1985;93(2):184-93.

63 Ling C, Li-hua C, Feng L, Yun-sheng L, Samii M, Samii A. Removal of vestibular schwannoma and facial nerve preservation usinf small subocciptal retrogmoid craniotomy. Chin Med J 2010;123(3):274-80.

64 Hamm CW. Neuroanesthesia considerations in skull base surgery. In: Cranial Base Surgery. London: Churchill Livingstone, 2000. Cap 6, p.99128. 
65 Scheufler KM, Zentner J. Total intravenous anesthesia for intraoperative monitoring of the motor pathways: an integral view combining clinical and experimental data. J Neurosurg 2002;96(3) 571-9.

66 Wang AC, Than KD, Etame AB, La Marca F, Park P. Impact of anesthesia on transcranial electric motor evoked potential monitoring during spine surgery: a review of the literature. Neurosurg Focus 2009;27(4):E7.

67 Sloan, TB, Heyer EJ. Anesthesia for Intraoperative Neurophysiology Monitoring of the Spinal Cord. J Clin Neurophysiol 2002;19(5):430-43.

68 Lotto ML, Banoub M, Schubert A. Effects of Anesthetic Agents and Physiologic Changes on Intraoperative Motor Evoked Potentials. Neurosurg Anesthesiol 2004;16(1):32-42.

69 Čabraja M, Stockhammer F, Mularski S, Suess O, Kombos T, Vajkoczy P. Neurophysiological intraoperative monitoring in neurosurgery: aid or handicap? An international survey. Neurosurg Focus 2009;27(4):E2.

70 Krammer MJ, Wolf S, Schul DB, Gerstner W, Lumenta CB. Significance of intraoperative motor function monitoring using transcranial electrical motor evoked potentials (PMM) in patients with spinal and cranial lesions near the motor pathways. Br J Neurosurg 2009;23(1):48-55.

71 Triggs WJ, Ghacibeh G, Springer U, Bowers D. Lateralized asymmetry of facial motor evoked potentials. Neurology 2005;65(2):541-4.

71 Grant GA, Rostomily RR, Kim K, Mayberg MR, Farrel D, Avellino A, Duckert LG, Gates GA, Winn R. Delayed facial palsy after resection of vestibular schwannoma. J Neurosurg 2002;97:93-6.

73 Neuloh G, Pechstein U, Schramm J. Motor tract monitoring during insular glioma surgery. J Neurosurg 2007;106:582-92.

74 Fukuda M, Oishi M, Takao T, Saito A, Fugii Y. Facial nerve motor-evoked potential monitoring during skull base surgery predicts facial nerve outcome. J Neurol Neurosurg Psychiatry 2008;79:1066-70.

75 Morota N. Nobu MD, Deletis V, Lee M, Epstein F. Functional Anatomic Relationship between brain stem tumors and cranial motor nuclei. Neurosurgery 1996;39(4):787-94.

76 Zhou HH, Kelly PJ. Transcranial Electrical Motor Evoked Potentials Monitoring for Brain Tumor resection. Neurosurgery 2001;48(5):1075-81. 
77 Guggisberg AG, Dubach P, Hess CW, Wüthrich C, Mathis J. Motor evoked potentials from masseter muscle induced by transcranial magnetic stimulation of the pyramidal tract: the importance of coil orientation. Clin Neurophysiol 2001;112(12):231216-9.

78 Terao S, Miura N, Takeda A, Takahashi A, Mitsuma T, Sobue G. Course and distribution of facial corticobulbar tract fibres in the lower brain stem. $J$ Neurol Neurosurg Psychiatry 2000;69:262-5.

79 Cruccu G, Inghilleri M, Berardelli A, Romaniello A, Manfredi M. Cortical mechanisms mediating the inhibitory period after magnetic stimulation of the facial motor area. Muscle Nerve. 1997;20(4):418-24.

80 Urban PP, Wicht S, Vucorevic G, Fitzek S, Marx J, Thömke F, MikaGrüttner A, Fitzek C, Stoeter P, Hoft HC. The course of corticofacial projections in the human brainstem. Brain. 2001;124:1866-76.

81 Preston DC, Shapiro BE. Basic nerve conduction studies. In: Electromyography and Neuromuscular Disorders. Newton: ButterworthHeinemann; 1998. Cap.3, p.25-44. 


\section{APÊNDICES}

\subsection{Aprovação do projeto pela Comissão de Ética para Análise de Projetos de Pesquisa da USP}

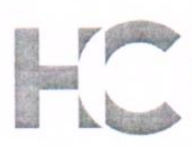

APROVAÇĀO

A Comissão de Ética para Análise de Projetos de Pesquisa CAPPesq da Diretoria Clínica do Hospital das Clínicas e da Faculdade de Medicina da Universidade de São Paulo, em sessão de 27/01/2010, APROVOU O Protocolo de Pesquisa $n^{\circ}$ 0800/07, intitulado: "O USO DA MONITORAÇÃO NEUROFISIOLÓGICA INTRA-OPERATÓRIA COMO FATOR COADJUVANTE NA PREDIÇÃO DE BONS RESULTADOS FUNCIONAIS EM CIRURGIAS DE TUMORES DE ÂNGULO PONTO-CEREBELAR DE GRANDE VOLUME' apresentado pelo Departamento de NEUROLOGIA, inclusive o Termo de Consentimento Livre e Esclarecido.

Cabe ao pesquisador elaborar e apresentar à CAPPesq, os relatórios parciais e final sobre a pesquisa (Resolução do Conselho Nacional de Saúde n 196, de 10/10/1996, inciso IX.2, letra "c"I.

Pesquisador (a) Responsável: Prof.Dr. Paulo Henrique Pires de Aguiar Pesquisador (a) Executante: Silvia Mazzali-Verst

CAPPesq, 28 de Janeiro de 2010

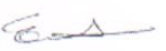

Prof. Dr. Eduardo Massad Presidente da Comissão de Ética para Análise de Projetos de Pesquisa 


\title{
10.2. Aprovação do projeto pela Comissão de Ética em Pesquisa do Hospital Israelita Albert Einstein
}

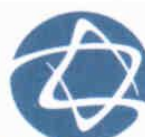 \\ ALBERT EINSTEIN \\ EINSTITUTO ISRAELITA DE \\ São Paulo, 10 de novembro de 2010. \\ Processo CEP/Einstein $n^{\circ}$. 10/1459 \\ Projeto de Grupo III \\ Título: "O uso da monitorização neurofisiológica intra-operatória como fator coadjuvante na predição de \\ bons resultados funcionais em cirurgias de tumores de ângulo ponto-cerebelar de grande volume." Protocolo \\ apresentado sem número de versão e data, com solicitação de isenção de Termo de Consentimento Livre e \\ Esclarecido. \\ Pesquisadora Responsável: Silvia Mazzali Verst \\ Instituição: Hospital Israelita Albert Einstein \\ Instituição vinculada: Departamento de Neurologia do Hospital das Clinicas da Faculdade de Medicina da \\ USP. \\ Responsável institucional: Umbertina Conti Reed - Chefe do Departamento de Neurologia \\ Entrada no CEP/Einstein: 9 de novembro de 2010 \\ Patrocinador: pesquisadora
}

PARECER

O Comitê de Ética em Pesquisa do Hospital Israelita Albert Einstein no cumprimento de suas atribuições, analisou e aprovou o projeto de pesquisa supracitado, bem como a isenção do Termo de Consentimento Livre e Esclarecido.

Aproveitamos a oportunidade para orientar a pesquisadora sobre os seguintes itens:

- O pesquisador deve desenvolver a pesquisa conforme delineada no protocolo aprovado e descontinuar o estudo somente após análise das razōes da descontinuidade pelo CEP que o

Aprovou (Res. CNS 196 Item III. 3.z)

- O CEP deve ser informado de todos os fatos relevantes que alterem o curso normal do estudo (Res. CNS Item V.4).

- Eventuais modificações ou emendas ao protocolo devem ser apresentadas ao CEP de forma clara e sucinta, identificando a parte do protocolo a ser modificada e suas justificativas.

- Ao pesquisador cabe elaborar e apresentar ao CEP/Einstein os relatórios semestrais e o relatório final (Res. CNS 196, IX.2.c), inicialmente em 10 de maio de 2011, conforme o modelo padronizado disponivel em http://apps.einstein. br/forms/pesquisa/form-padr.htm

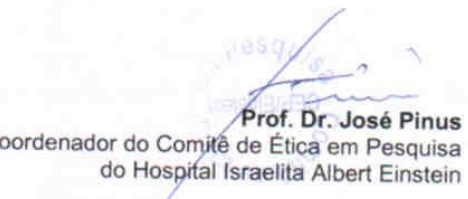

Instituto Israelita de Ensino e Pesquisa Albert Einstein

Av. Albert Einstein, 627 - Morumbi - Säo Paulo - SP - 05652-000 - Brasil

Tel: $(55-11) 21513729$ Fax: $(55-11) 21510273$ 
10.3 Termo de Responsabilidade e Consentimento Cirúrgico

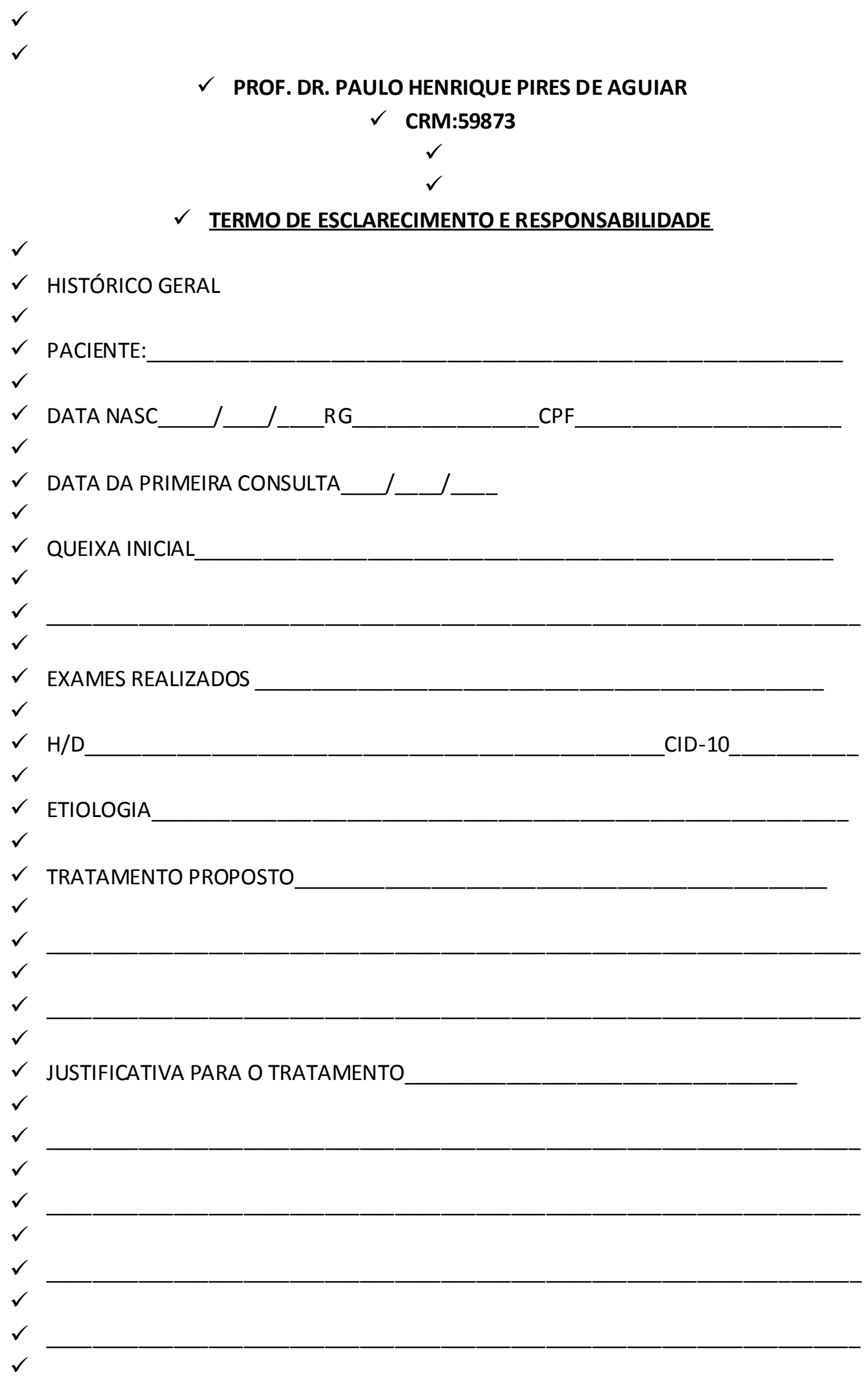


PROF. DR. PAULO HENRIQUE PIRES DE AGUIAR

$\checkmark$ CRM:59873

TERMO DE ESCLARECIMENTO E RESPONSABILIDADE

$\checkmark$ EU

$\checkmark$ PORTADOR(

a) DO RG № E CPF DE №

$\checkmark$ RESIDENTE A RUA: BAIRRO

$\checkmark$ CIDADE CEP ESTADO TEL

$\checkmark$ ESTADO CIVIL: CONJUGE

$\checkmark$

$\checkmark$ Declaro que fui informado (a) sobre todos os riscos referentes ao tratamento cirúrgico proposto pelo meu médico, o qual me explicou claramente e minuciosamente todo o processo do procedimento o qual irei submeter-me de livre e espontânea vontade, tendo em vista que os tratamentos alternativos como: remédios antiinflamatórios, fisioterapia e procedimentos não evasivos, já não fazem efeito de melhora. Fui informado sobre a realização da monitoração neurofisiológica intra-operatória e esclarecido que é um teste de baixo risco, que será utilizado com o objetivo de reduzir ao mínimo a possibilidade de algum dano motor decorrente do procedimento. Estou ciente, que sua realização não me garante com absoluta certeza complicação decorrente da cirurgia a qual me submeterei. Assim sendo, estou de acordo a realizar a cirurgia, mesmo ciente de todos os riscos e isento tanto o Prof. Dr. Paulo Henrique Pires de Aguiar, quanto todos os membros de sua equipe, como também o anestesista, de qualquer responsabilidade caso ocorra alguma complicação durante cirurgia e póscirúrgica.

$\checkmark$ Estou de acordo ainda que o Prof. Dr. Paulo Henrique Pires de Aguiar e sua equipe utilizem os meus dados de exames, dados clínicos e da cirurgia para pesquisa científica, publicação de artigos médicos e ministrar aulas, desde que preservada minha identidade.

$\checkmark$ Fui informado que posso revogar esta autorização a qualquer momento, por escrito.

$\checkmark$

$\checkmark$ São Paulo de de

$\checkmark$ Testemunhas:

$\checkmark$

$\checkmark$

$\checkmark \overline{\text { Assinatura paciente/responsável }}$ Nome:

$\checkmark$

$\checkmark$

$\checkmark$

$\checkmark$ Prof.Dr. Paulo Henrique Pires de Aguiar $\checkmark$ 


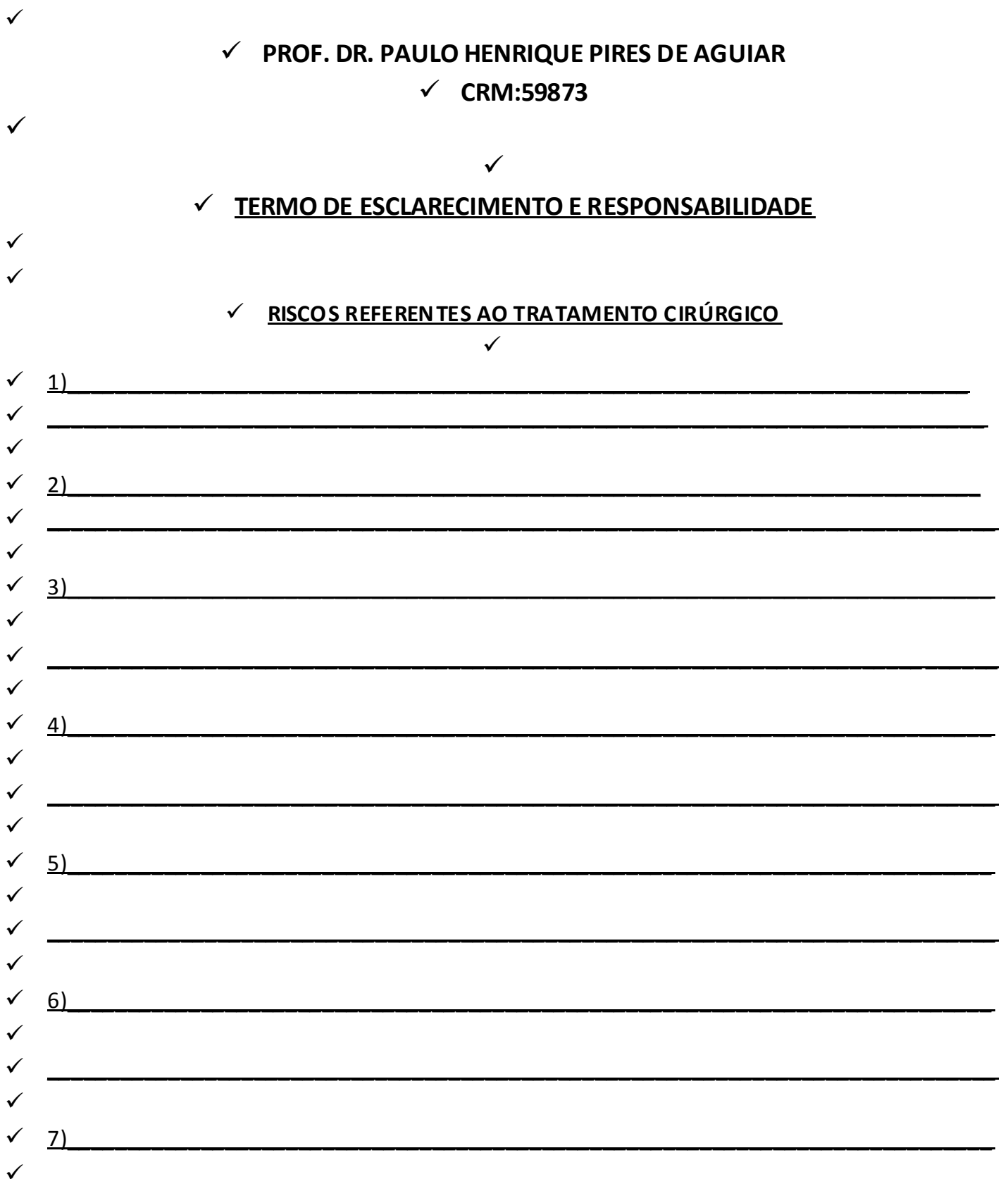

